\title{
THE REACTION OF OXYGEN ATOMS \\ WITH CARBON TETRACHLORIDE
}

\author{
by
}

ALBAN YOU-MING UNG, M.Sc.

A thesis submitted to the Faculty of Graduate Studies and Research of McGill University in partial fulfilment of the requirements for the degree of Doctor of Philosophy

MCGill University,

Montreal, Canada.

April 1961 


\section{ACKNOWLEDGEMENTS}

The author wishes to express his most sincere gratitude

to

Dr. H.I. Schiff

under whose direction and guidance

this work was carried out,

and to

Dr. L. Elias

for his valuable suggestions and

generous assistance in this work. 
PRODUCTION OF OXYGEN ATOMS $\ldots$..

(1) Mercury Photosensitized Decomposition of Nitrous Oxide .. ... ...

(2) Photolysis of Nitrogen Dioxide $\ldots 4 \quad 4$

(3) Electrode Discharge of Water Vapour .. 5

(4) Microwave Discharge of Oxygen .. .. 5

(5) Titration of Nitrogen Atoms with

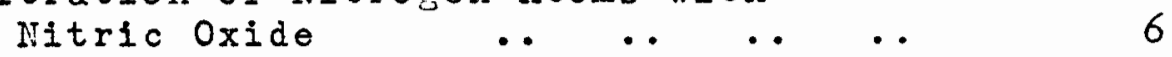

NATURE OF DISCHARGED OXYGEN $\quad \ldots \quad \ldots \quad \ldots .6$

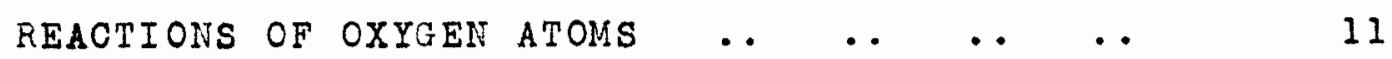

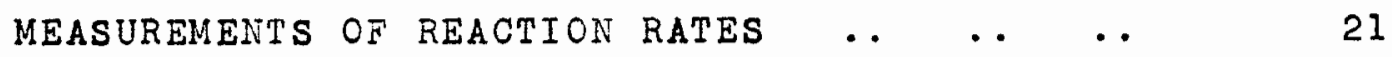

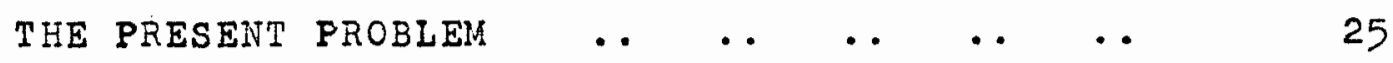

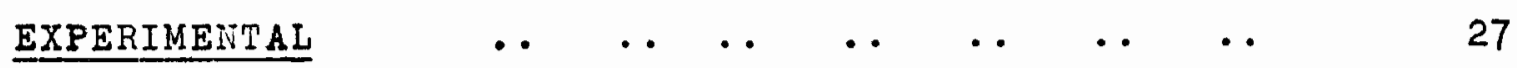

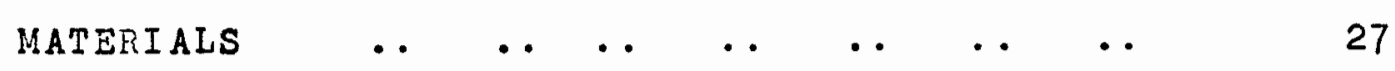

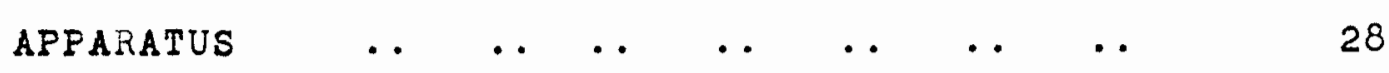

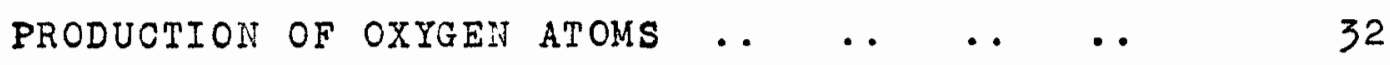

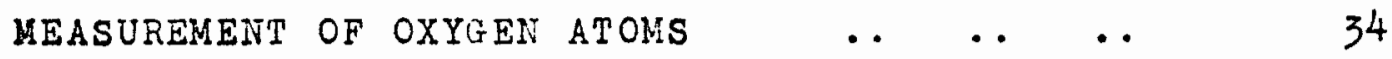

THE DECAY OF OXYGEN ATOMS THROUGH RECOMBINATION 39

THE REACTION OF OXYGEN ATOMS WITH CARBON

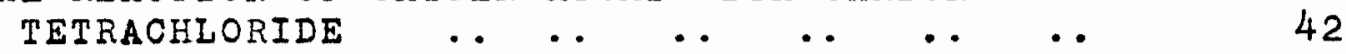

IDENTIFICATION AND ANALYSIS OF REACTION PRODUCTS 45

THE REACTION OF OXYGEN ATOMS WITH PHOSGENE .. 47

THE REACTION OF OXYGEN ATOMS WITH CARBON TETRACHLORIDE IN AN OXYGEN-FREE SYSTEM

MEASUREMENT OF THE RATE CONSTANTS OF THE PRIMARY REACTION OF O-ATOMS WITH CARBON TETRACHLORIDE

MEASUREMENT OF THE RATES OF THE OVERALL

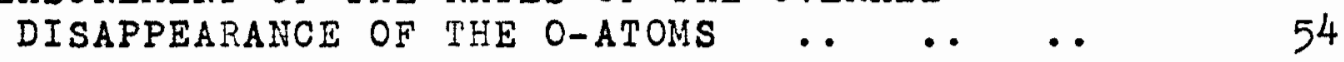

MEASUREMENT OF THE HEAT OF REACTION $\ldots$. . 


\section{TABLE OF CONTENTS (CONTD.)}

$\underline{\text { Page }}$

RESULTS AND DISCUSSION ․ $\quad \ldots \quad \ldots \quad \ldots \quad \ldots$

THE RECOMBINATION OF OXYGEN ATOMS N ...

THE REACTION OF OXYGEN ATOWS WITH CARBON TETRACHLORIDE

Variation of Products with the Reactant Concentration

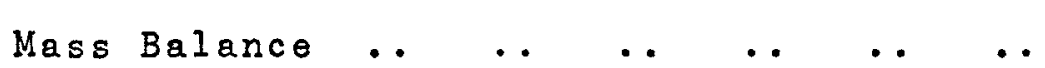

Effect of Reaction Temperature

Eefect of Reaction Temperature $\quad \cdots$

Effect of Total Pressure $\ldots \ldots$...

Reaction of Oxygen Atoms with Carbon Tetrachloride in the Absence of Molecular oxygen

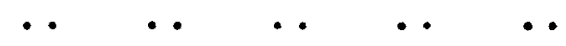

The Mechanism of the Reaction of O-Atoms with Carbon Tetrachloride .. .. ..

MEASUREMENT OF THE RATE CONSTANTS OF THE PRIMARY REACTION OF OXYGEN ATOMS WITH CARBON

TETRACHLORIDE $\quad \ldots \quad \ldots \quad \ldots \quad \ldots \quad \ldots \quad \ldots$

APPENDIX A $\quad \ldots \quad \ldots \quad \ldots \quad \ldots \quad \ldots \quad \ldots \quad \ldots$

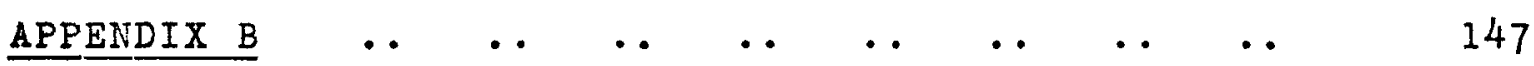

SUMHARY_AND CONTRIBUTIONS TO KNOWLEDGE $\quad \ldots \quad \ldots$.

BIBLIOGRAPHY 


\section{INT RODUCTION}

The subject of oxygen atoms has a long history dating back to Becquerel (1). In 1859, he described a 'longlived luminous species' produced when an electric current was passed through oxygen. In 1891, during an investigation of electrical discharges through various gases at low pressures, Thomson (2) observed a luminous glow in oxygen which persisted 'some considerable time' after the electrical discharge had been interrupted. This glow was subsequently called the 'oxygen afterglow', but is now generally referred to as 'air afterglow'. In the years between 1859 and 1900 , a large number of investigators found a variety of afterglows from discharged air of unknown purity. The first serious investigation of the 'oxygen afterglow' was made by strutt in $1910^{(3)}$. He showed that a trace of nitric oxide in the discharged oxygen was essential for the appearance of the afterglow, and that the spectrum of the afterglow was composed of a continuum ranging from 4200 to $6700 \AA$. Reactions of the discharged oxygen with various gases were also studied spectroscopically in his laboratory ${ }^{(4)}$. He concluded from his experiments that the afterglow was the result of a chemiluminescent reaction, and that the active species produced by discharging oxygen reacted with the nitric oxide formed in the discharge to produce the afterglow. He believed that these active species were ozone. Although there was much interest in the subject in the following years, attention was mainly directed to the influence of the condition of the walls of the discharge tube on the occurrence of the glow, and on the 
use of the water vapour to strengthen it. In a more careful study of the afterglow, stoddart (5) observed, besides the continuum, 28 to 30 diffuse bands throughout the visible region with a maximum intensity in the green. This region was found to correspond to the absorption spectrum of thermally excited nitrogen dioxide. But the interpretation of the nature of discharged oxygen remained that of strutt, namely that ozone was the active species which was responsible for all the chemical reactivities of the discharged oxygen. It seems now to be well established that oxygen atoms are the primary species in the discharged oxygen. The nature of the discharge products will be discussed in the later section. Kinetic studies of oxygen atom reactions were first carried out by Harteck and Kopsch(6) in 1931. Oxygen atoms were produced by dissociating molecular oxygen in a WoodBonhoeffer's discharge tube (7). This apparatus was found to be satisfactory for producing such atoms as chlorine, hydrogen, nitrogen, etc. for kinetic studies. Unfortunately, this method was not as satisfactory for the production of oxygen atom because of the corrosive nature of oxygen at high temperatures, which resulted in the attack of the electrodes. The walls of the reaction vessel soon became contaminated with particles of metal and metallic oxide. The oxygen atoms recombine on these particles giving poor reproducibility in the experimental results. Obviously, this makes the kinetic study of the oxygen atom reactions extremely difficult. Results obtained in the early studies wore essentially qualitative in nature. 
In recent years, when it was discovered that oxygen atoms play an important role in many combustion processes and in reactions occurring in the upper atmosphere, oxygen atom reactions have received much attention, and the investigations of this subject have been greatly intensified. However, only a relatively few oxygen atom reactions have boen reported in the literature, and considerable controversy and uncertainty with respect to the identity of the elementary processes involved and the type of reaction product formed still exist between various workers. In order to obtain better understanding of the oxygen atom reactions, the need for more direct methods for studying the elementary processes became apparent.

PRODUCTION OF OXYGEN ATOMS

As mentioned above, the success of the study of an oxygen atom reaction will depend largely on the reliability of the atom source. A variety of methods for the production of oxygen atoms are theoretically possible, but many of them are impractical. Five methods are currently in use for the study of oxygen atom reactions.

(1) Mercury Photosensitized Decomposition of Nitrous Oxide This method was first described as a source of oxygen atoms by Cretanovic(8). He reported that normal oxygen atoms were formed by the reaction:

$$
\mathrm{N}_{2} \mathrm{O}+\mathrm{Hg} \stackrel{\mathrm{hv}(2537 \AA)}{-} \mathrm{N}_{2}\left({ }^{1} \Sigma\right)+\mathrm{O}\left(3_{\mathrm{p}}\right)+\mathrm{Hg}
$$

and that side reactions resulting in the formation of nitric oxide occurred to less than $3 \%$. Since nitrous oxide and 
nitrogen are largely inert to oxygen atoms and most radicals, this technique was claimed to be a highly satisfactory source of oxygen atoms for studies of hydrocarbon reactions. However, the presence of small and somewhat variable amounts of mercury and mercury oxide in the system might affect the quantitative kinetic studies of the oxygen atom reactions. This is particularly true in systems containing halogen compound s.

\section{(2) Photolysis of Nitrogen Dioxide}

Ford and Endow (9) have prepared oxygen atoms by photolysis of nitrogen dioxide at $3660 \AA$. They assumed the following mechanism to explain the reactions involved in the system

$$
\begin{aligned}
& \mathrm{NO}_{2}+\mathrm{hv} \rightarrow \mathrm{NO}+\mathrm{O} \\
& 0+o_{2}+M \rightarrow O_{3}+M \ldots \ldots \ldots . \\
& 0+\mathrm{NO}_{2}+\mathrm{M} \rightarrow \mathrm{NO}_{3}+\mathrm{M} \ldots \ldots \ldots \ldots \\
& \mathrm{O}+\mathrm{NO}_{2} \rightarrow \mathrm{NO}+\mathrm{O}_{2} \\
& \mathrm{O}+\mathrm{NO}+\mathrm{M} \rightarrow \mathrm{NO}_{2}+\mathrm{M} \\
& \mathrm{NO}_{3}+\mathrm{NO} \rightarrow 2 \mathrm{NO}_{2} \\
& \mathrm{O}_{3}+\mathrm{NO} \rightarrow \mathrm{NO}_{2}+\mathrm{O}_{2}
\end{aligned}
$$

By assuming Benson and Axworthy's value(10) for reaction (2), the authors were able to evaluate a number of rate constants for oxygen atom reactions. It is obvious that the success of this source of atoms depends on the validity of the mechanism assumed. Furthermore, the presence of the reactive products of the photolysis makes an interpretation of the 
effect of an added reactant highly uncertain.

\section{(3) Electrode Discharge of Water Vapour}

Avramenko (11) has generated oxygen atoms in an electrical discharge in water vapour. He showed that oxygen atoms at their ground state were the main product of the discharge. This source of atoms, free from excess molecular oxygen, has been used by Avramenko and his co-workers for a series of reactions with various hydrocarbons. Undoubtedly, hydrogen atoms and hydroxyl radicals are also formed in this discharge. The complex nature of these active particles in the syatem could complicate the reaction and make the interpretation of experimental results rather uncertain.

(4) Microwave Discharge of Oxygen

This method resulted from the development of very intense microwave sources for radar during the second World War. The magnetron oscillator tube, capable of providing a very large power output at frequencies above 600 megacycles per second, is notable in this respect. When the microwave output from such a generator is directed at a stream of oxygen, a discharge can be initiated with a Tesla-coil spark (under the proper conditions of pressure and flow). This 'electrodeless dischargo' has been used as a source of oxygen atoms by several investigators $(12,13,14,15)$. Linnett and Marsden (12) have concluded that a higher steady proportion of oxygen atoms could be produced by this method than by other methods. This procedure seems most sultable for the present work and, therefore, was chosen as the source o: oxygen atoms. 
(5) Titration of Iitrogen Atoms with Nitric Oxide

Very recently, Morgan, Elias and Schiff(16)

described a method to produce oxygen atoms by titrating nitrogen atoms with nitric oxide. The reaction of nitrogen ators with nitric oxile has been investigated by geveral norkers $(17,18,19)$, and the following mechanism seems fairly well established

$$
\begin{aligned}
& N+\mathrm{NO}-\mathrm{N}_{2}+\mathrm{O} \\
& \mathrm{N}+\mathrm{O}+\mathrm{M} \rightarrow \mathrm{NO}+\mathrm{M}+\mathrm{hv} \\
& \mathrm{O}+\mathrm{NO} \rightarrow \mathrm{NO}_{2}+\mathrm{hv}
\end{aligned}
$$

Thus, when nitric oxide is added to the nitrogen atom stream, excess of either reactent results in chemiluminescence greenish-yellow glow with excess nitric oxide, blue glow with excess nitrogen atoms. Only when the correct stoichiometric proportions of both reactants are present, an intermediate 'dark' condition can then be obtained. Under these conditions the gas stream contains only oxygen atoms and nitrogen. This source of oxygen atoms was used by the above authors to study the direct atom recombination

$$
\mathrm{O}+\mathrm{O}+\mathrm{M} \rightarrow \mathrm{O}_{2}+\mathrm{M}
$$

The success of this method depends largely on the steadiness of the gas phase titration.

NATURE OF DISCHARGED OXYGEN

When molecular oxygen is subjected to electrical discharge, a variety of species conceivably could be produced. The literature on the products of the discharged oxygen has been reviewed recently by Linnett and Marsden(12). They 
concluded that most of the oxygen was present as normal molecules and atoms.

Harteck and Kopsch $(6)$ tried to detect ions a few centimeters down stream from the discharge by using an ion gauge without success. McCarthy $(20)$ observed no evidence for the existence of ions in the activated oxygen glow under magnetic or electrical fields. It seems quite certain that ions are not present in discharged oxygen in significant concentrations.

Ozone was believed to be the primary active species in the discharged oxygen (3). Tanaka and shimazu (21) showed that ozone and nitric oxide react to produce a red glow, and not the greenish-yellow glow produced from the reaction of nitric oxide with discharged oxygen. It was therefore concluded that ozone is not the major active species in discharged oxygen. In 1933, Harteck (22) measured the amount of ozone present in discharged oxygen by its absorption at $2537 \AA$. He reported that under normal conditions about $0.1 \%$ ozone was present at room temperature, and about $2 \%$ at dry-ice temperature. From a recent study of the thermal decomposition of ozone, Benson and Axworthy (10) have determined the rate constants for the following reactions:

$$
\begin{aligned}
0+0_{2} & +M \stackrel{k_{1}}{\longrightarrow} o_{3}+M \\
k_{1} & =6 \times 10^{7} e^{600 / R T} c^{2} \mathrm{~mole}^{-2} \mathrm{sec}^{-1} \\
0+0_{3} \stackrel{\mathrm{k}_{2}}{\longrightarrow} 20_{2} & \\
k_{2} & =2.96 \times 10^{10} \mathrm{e}^{-6000 / R T} \mathrm{ccmole} \mathrm{sec}^{-1}
\end{aligned}
$$


Using these two rate constants, the steady-state concentration of ozone is estimated to be $0.29 \%$ of the oxygen molecules in the flow system at room temperature and at pressure of $1 \mathrm{~mm}$ Hg. More recently, in a mas spectrometric study of discharged oxygen, Herron and schiff( 14$)$ found that ozone is not present in activated oxygen in concentration greater than $0.02 \%$ up to pressures of $2 \mathrm{~mm} \mathrm{Hg}$. The authors suggested that the discrepancy between their work and Benson and Axworthy's result might be mainly due to the fact that ozone formed has been rapialy destroyed by the excited oxygen molecules present in discharged oxygen.

Schumacher (23) has shown, from the photolysis of nitrogen dioxide, that molecular hydrogen reacts with ${ }^{1} D$ oxygen atoms, but does not react with ${ }^{3} \mathbf{P}$ (ground state) atoms. Harteck and Kopsch $(6)$ found that discharged oxygen does not react with hydrogen. This indicated that the concentration of excited atoms is very low in the discharge products of oxygen.

Kurt and Phipps (24) measured the magnetic moment of the discharged oxygen and found that their results were consistent with the assumption that the atoms are in ground state.

Rawson and Beringer ${ }^{(25)}$ studied discharged oxygen by the paramagnetic resonance method. They found transition corresponding to ${ }^{3} \mathrm{P}$ but not to ${ }^{1} \mathrm{D}$ atoms.

Herron and schiff(14) have reported an appearance potential of 13.9 ev for oxygen atoms from the discharged 
oxygen. Since no appearance potentials below the ionization potential of ${ }^{3} \mathrm{P}$ atoms were ever observed, they concluded that metastable atoms are not present in appreciable quantities.

Several investigators have presented spectroscopic evidence for the existence of the ${ }^{1} \Sigma_{g}^{+}$and ${ }^{3} \Sigma_{u}$ states of oxygen in 'active oxygen'. Kaplan $(26)$ observed the ${ }^{1} \Sigma_{g}^{+}$$3 \Sigma_{g}^{-}$transition while both Branscomb (27) and Broida and Gaydon (28) observed the ${ }^{3} \Sigma_{u}-{ }^{3} \Sigma_{g}$ transition. No concentration estimates were reported. Each author assumed that the species concerned were formed from the reaction:

$$
\mathrm{O}+\mathrm{O}+\mathrm{M} \rightarrow \mathrm{O}_{2}^{*}+\mathrm{M}
$$

Because the rate of this reaction is probably extremely small(10), the concentration of these species would be necessary low.

In two mass spectrometric studies, Foner and Hudson(29) and Herron and Schiff(14) reported a species with an appearance potential about 1 ev below normal oxygen in activated oxygen. since Herzberg $(30)$ has reported the excitation energy of the ${ }^{1} \Delta_{g}$ state oxygen to be $0.98 \mathrm{ev}$, It was suggested that the presence of this electronically excited molecule would account for the results. The concentration of ${ }^{1} \Delta_{g}$ state oxygen was estimated at about $10 \%$ of the total oxygen when the pressure was $1 \mathrm{~mm} \mathrm{Hg}$ with an electrodeless discharge. Since the concentration of this species exceeds the initial oxygen atom concentration, Herron and schiff (14) auggested that it was probably not a product of the oxygen atom decay, but rather a primary species produced in the discharge. Very recently, in the study of discharged 
oxygen by means of an isothermal calorimetric detector, Elias, Ogryzlo and schiff(15) have presented evidence for the existence of the excited molecules. They found that these species did not appear to be vibrationally excited molecules. Based on the energy liberated from these species, it was suggested that the excited molecules are in the ${ }^{1} \Delta_{g}$ state.

No direct evidence exists for the presence of vibrationally excited molecules in discharged oxygen. However, in the flash photolysis study of nitrogen dioxide, ozone and $\mathrm{ClO}_{2}$, Norrish et $\mathrm{a} 1 .(31,32)$ have recently observed fairly large amounts of vibrationally excited oxygen molecules. They assumed the excited molecules were formed from the reactions:

$$
\begin{aligned}
& 0+\mathrm{NO}_{2} \rightarrow \mathrm{NO}+\mathrm{O}_{2}^{*} \\
& 0+\mathrm{O}_{3} \rightarrow \mathrm{O}_{2}+\mathrm{O}_{2}^{*} \\
& 0+\mathrm{OlO}_{2} \rightarrow \mathrm{OlO}+\mathrm{O}_{2}^{*}
\end{aligned}
$$

It was also reported that the excited molecules produced by either reaction have sufficient energy to dissociate ozone in the following manner:

$$
\mathrm{O}_{2}^{*}+\mathrm{O}_{3} \rightarrow \mathrm{O}_{2}+\mathrm{O}_{2}+\mathrm{O}
$$

The authors also reported that the deactivation of the species requires more than $10^{7}$ collisions with nitrogen and argon, 7000 collisions with carbon dioxide, and less than 500 collisions with nitrogen dioxide.

In the study of recombination of oxygen atoms, Linnett and Greaves $(33)$ have recently reported that the measurement of relative concentrations, using a catalytic 
probe, showed a direct proportionality over a wide range of atom percentages to absolute atom concentrations as measured by a Wrede-Harteck gauge. They concluded that the oxygen in the region where the meagurements were made does not contain appreciable quantities of excited atoms or molecules or ozone. However, Kaufman $(34)$ has recently obtained additional evidence for the existence of the ${ }^{1} \Delta_{g}$ oxygen. The energy of a ${ }^{I \Delta}$ gxygen is about $23 \mathrm{Kcal}$ per mole which is too small to initiate most chemical reactions. It can therefore be safoly assumed that the ground state oxygen atoms are the primary active species which account for most of the chemical activity in the discharged oxygen. REACTIONS OF OXYGEN ATOMS

Most of the early studies of oxygen atom reactions were carried out by Harteck and Kopach $(6)$, Geib and Harteck $(35,36)$ Geib and Voidya $(37)$ and Geib $(38)$. The oxygen atoms were produced by means of a hood-Bonhoeffer type of discharge, and were reacted with a variety of organic compounds. Results obtained from these experiments were mainly qualitative in nature and the mechanism of any of the reactions could not be satisfactorily determined.

For reactions with formaldehyde, formic acid, mothanol and ethanol, products found were frequently carbon monoxide, cerbon dioxide, water and hydrogen*, but no decisive

\footnotetext{
*Reaction of oxygen atoms with formic acid was the only one containing no hydrogen in its reaction products.
} 
mechanism could be formulated. Spectroscopic evidence for the presence of hydroxyl radicals was also obtained for these reactions, but it was not known whether they were formed in a primary or a secondary reaction. In a discussion of the mechanism of the reaction with formaldehyde, Geib(39) favoured the process

$$
\mathrm{O}+{ }_{\mathrm{H}}^{\mathrm{H}} \mathrm{C}=\mathrm{O} \rightarrow \mathrm{OH}+\mathrm{CHO}
$$

as a primary step in the reaction, on the basis of Rice and Teller's principle of least motion(40). It was generally considered that the abstraction of a hydrogen atom was a possible primary step in the reactions with all $\mathrm{C}_{\mathrm{x}} \mathrm{H}_{\mathrm{y}} \mathrm{O}_{z}$ type compounds.

For reactions with unsaturated hydrocarbons, cC, $\mathrm{CH}, \mathrm{OH}$ and $\mathrm{CHO}$ bands were observed spectroscopically in the resctions with acetylene and ethylene(37), although the products for the acetylene reaction were reported to be water, carbon dioxide, carbon monoxide and hydrogen $(6)$. No explanation for the occurence of those bands could be found. It was considered that the addition of an oxygen atom to a double bond of an unsaturated compound might be the possible primary step, and the consequent decomposition of the primary product at low pressures, as operated in the flow systems, would be responsible for the appearance of the emission bands and the formation of the final stable products. Accordingly, it was believed that, by decreasing the temperature of the reaction vessel to suppress the decomposition reaction, aditional products could be obtained. Hence Geib and 
Harteck $(35,36)$ performed experiments with acetylene, ethylene, benzene, trimethylamine and methylamine at liquid air temperature and reported that additional products were found for all these reactions. The following reactions were therefore considered primary steps of these reactions:

$$
\begin{aligned}
& \mathrm{O}+\mathrm{C}_{2} \mathrm{H}_{2} \rightarrow \mathrm{C}_{2} \mathrm{H}_{2} \mathrm{O} \\
& \mathrm{O}+\mathrm{C}_{2} \mathrm{H}_{4} \rightarrow \mathrm{C}_{2} \mathrm{H}_{4} \mathrm{O} \\
& 0+\mathrm{C}_{6} \mathrm{H}_{6} \rightarrow \mathrm{C}_{6} \mathrm{H}_{6} \mathrm{O} \\
& \mathrm{O}+\left(\mathrm{CH}_{3}\right)_{3} \mathrm{~N} \rightarrow\left(\mathrm{CH}_{3}\right)_{3} \mathrm{NO} \\
& 0+\mathrm{CH}_{3} \mathrm{NH}_{2} \rightarrow \mathrm{CH}_{3} \mathrm{NH}_{2} \mathrm{O}
\end{aligned}
$$

Howerer, according to steacie(4l), these reactions were probably surface-catalized on the walls of the reactor vessel. Furthermore, ozone might have been the reacting species at this temperature. Therefore it is doubtful whether this is evidence for the addition reaction at room temperature.

For reactions with saturated hydrocarbons, considerable controversy exists between different workers regarding the nature and the amounts of the products. This is true even for the simplest compound, methane. Harteck and Kopsch $(42,6)$ found that the products were water and carbon dioxide and that they were in a ratio of 2 to 1 . In addition to water and carbon dioxide, steacie and Parlee (43) found carbon monoxide was among the products. They suggested the following equation to represent tine primary step:

$$
\mathrm{O}+\mathrm{CH}_{4} \rightarrow \mathrm{CH}_{2}+\mathrm{H}_{2} \mathrm{O}
$$

However, Kuschnerev and Schechter (44) have investigated this 
reaction with similar experimental techniques and found that formaldehyde was about $50 \%$ of the gas products. They believed that it was formed directly from the reaction

$$
\mathrm{O}+\mathrm{CH}_{4} \rightarrow \mathrm{CH}_{2} \mathrm{O}+\mathrm{H}_{2}
$$

and that this was followed by further oxidation of $\mathrm{CH}_{2} \mathrm{O}$ to give carbon dioxide and water. In the study of the oxidation of methane, Norrish(45) suggested

$$
\mathrm{O}+\mathrm{CH}_{4}-\mathrm{CH}_{3}+\mathrm{OH}
$$

as a possible step, but this mechanism is not generally accepted.

The reactions with ethane, pentane and hexane were investigated by Harteck and Kopsch $(6)$. They reported that carbon dioxide and water wore the major products and that $O H$ bands were observed spectroscopically for every reaction. Hence, the abstraction of a hydrogen atom was assumed to be a primary step for all these reactions.

The reactions of oxygen atoms with chloromethane wore only briefly investigated by Harteck and Kopsch. Equal amounts of phosgene and chlorine were found to be the only products in the $\mathrm{COl}_{4}$ reaction. $25 \%$ reaction was first reported(42), but in a later and more detailed paper(6) only 2 to $5 \%$ reaction was reported under the same experimental conditions. The reaction could be simply represented as

$$
\mathrm{O}+\mathrm{CCl}_{4}-\mathrm{COOl}_{2}+\mathrm{Cl}_{2}
$$

However, steacie(43) did not consider this mechaniam to be particularly plausible. Reactions with chloroform, methylene chloride and methyl chloride were also studied. Reaction 
products reported were phosgene, hydrogen chloride and small amounts of chlorine for the chloroform reactions; phosgene, hydrogen and some chlorine for the methylene chloride reaction; and hydrogen chloride, chlorine, water, carbon dioxide and carbon monoxide for the methyl chloride reaction. At room temperature, $100 \%$ reaction was reported in the first paper(42) and only 10 to $25 \%$ reaction in the final

publication $(6)$ for these three reactions. Chemiluminescence was observed for reactions with chloroform, methylene chloride and methyl chloride, but no information regarding the mechanism of these reactions was given.

Since 1952 Avramenko and his co-workers have reported a series of qualitative experiments on the reaction of oxygen atoms with formaldehyde, acetaldehyde, ethane, methane, ethylene, propylene and butadiene. Oxygen atoms were obtained from two sources. Atoms from the electrical discharge in water vapour were used to provide syotems containing no molecular oxygen, and atoms from the electrical discharge in oxygen were used to provide systems containing excess of oxygen molecules. Most of the experiments were carried out at temperatures botween $100^{\circ} \mathrm{C}$. and $250^{\circ} \mathrm{C}$. Results obtained from their investigations are quite different from those obtained from the previous workers. In the reaction of oxygen atoms with formaldehyde, Avramenko and Lorentso $(46,47)$ found carbon monoxide and carbon dioxide to be the main products but observed no hydroxyl radicals spectroacopically. Therefore they 
concluded that the primary step in this reaction is not the abstraction of a hydrogen atom, but rather the reaction

$$
\mathrm{O}+\mathrm{HCHO}-\mathrm{CO}+\mathrm{H}_{2} \mathrm{O}
$$

is the primary step. However, steacie(41) pointed out that the $O H$ radical would not have been observed if it were removed very rapidly by another reactive species.

In the reactions with saturated hydrocarbons, Avramenko and Kolesnikova have found that formaldehyde, methanol, carbon monoxide and carbon dioxide were the products for the reaction with methane $(48)$ and that formaldehyde, ethanol, methane, carbon monoxide, carbon dioxide and ethylene were the major products for the reaction with othane(49), while acetaldehyde and an organic peroxide were found in small quantities. Based on the products obtained, a variety of primary steps were suggested to account for their formations. Consequently, the following generalizations were formulated by the authors for the reactions of oxygen atoms with the saturated hydrocarbons and aldehydes:

(1) Abstraction of one hydrogen atom with the formation of OH radical.

(2) Rupture of the $\mathrm{C}-\mathrm{C}$ bond.

(3) Insertion of an oxygen atom into the C-H bond with the formation of alcohol.

(4) Abstraction of two hydrogen atoms in a single process with the formation of water.

In the reactions of oxygen atoms with ethylene $(50,51)$ propylene $(51)$ and butadiene $(51)$, the reaction products were 
also complex. With the assistance of a theoretical method $(52,53)$ to determine the sequences of elementary reactions the authors were able to explain their results on the basis of the nature and the rate of formation of the products. The conclusions for reactions with unsaturated hydrocarbons may be summarized as follows:

(1) Oxygen atom is capable of disrupting the double bond with the formation of aldehyde.

(2) Oxygen atom may insert into the $\mathrm{C}-\mathrm{H}$ bond not only at the saturated but also at the unsaturated carbon atoms.

(3) Bond rupture occurs just as frequently at the single bond as it does at the double bond.

From all their evidence Avramenko et al. characterized oxygen atoms as having a very great capacity for entering into various reactions because of their free valencies. However, the more recent work of Cretanovic has cast doubt on some of the above conclusions.

\section{Since 1955 Cretanovic started a systematic}

investigation on the oxygen atom reactions $(54,55,56,57,58)$.

The atoms were prepared by the mercury photosensitized decomposition of nitrous oxide for most of their experiments, although photolysis of nitrogen dioxide $(59,60)$ and electrical discharge methods (6I) were also used occasionally for comparison. Most of the experiments were carried out at room temperature and at relatively high pressures.

The results obtained for reaction with acetaldehyde(56) 
were strikingly different from thosereported by Avramenko and Lorentso $(46,47)$. Whereas cretanovic found the main products to be diacetyl and water, with a smaller amount of acetone, Avramenko and Lorentso reported formaldehyde, carbon dioxide, acetic acid and formic acid. These two results cannot be compared because of the temperature difference, and the presence of molecular oxygen in the experiments of Avramenko and Lorentso. Cretanovic has stressed that the presence of molecular oxygen has a marked effect on the formation of the reaction products.

In the reaction with ethylene, Cvetanovic $(54)$ has shown that aldehydes $\left(\mathrm{CH}_{3} \mathrm{CHO}, \mathrm{C}_{2} \mathrm{H}_{5} \mathrm{CHO}\right.$ and $\left.\mathrm{C}_{3} \mathrm{H}_{7} \mathrm{CHO}\right)$, carbon monoxide, mothane, ethane, propane, butane, traces of formaldehyde and some other substances were the products. Avramenko and Kolesnikova $(50)$ reported for the same reaction that formaldehyde and carbon monoxide were the basic products, while carbon dioxide, acetaldehyde and acetylene were found in small quantities. Avramenko and Kolesnikova also reported that the presence of molecular oxygen in this reaction does not change the character of the reaction products, but merely increases the yield of formaldehyde. Very recently, Cvetanovic and Doyle ${ }^{(62)}$ obtained results for the resction of oxygen atoms with butadiene. It was found that the reaction with this conjugated diolefin conforms to the general mechanism for the analogous reactions of the monoolifins. Only 1,2-addition occurs, and the reaction products were butadiene monoxide and 3-butenal, the latter readily isomerizing to the more stable crotonaldehyde. 
This is entirely different from the conclusion of Avramenko and Kolesnikova(51) for the same reaction, in which the following elementary process was considered a primary step: $\mathrm{O}+\mathrm{CH}_{2}=\mathrm{CH}-\mathrm{CH}=\mathrm{CH}_{2} \rightarrow \mathrm{CH}=\mathrm{OH}-\mathrm{CHO}+\mathrm{OH}_{2}$

This reaction results in the formation of the primary acrolein and the primary radical $\mathrm{CH}_{2}$, the latter reacting with oxygen to give the secondary formaldehyde. However, Cretanovic and Doyle $(62)$ have observed a very pronounced pressure effect on the formation of the products in this reaction. They concluded that the addition products, possessing excess energy when formed as a result of high heat of reaction, might be decomposed at pressures of a few millimeters of mercury, and are tren not observable experimentally. This feature and some other factors wore considered sufficient to account for the discrepancies between the two different results.

In a series of experiments with olefins, Cvetanovic found that the formation of the addition products was favoured by increasing the complexity of the olefins. This is supported by the evidence that, in the reactions of butene and pentene, approximately half of the product was the corresponding epoxy compound, and the other half was a mixture of two carbonyl compounds. Fragmentation occurred only to a very small extent. In the reaction with ethylene $(54)$, fragmentation was great and very little epoxy compound was detected among the products. Furthermore, Cvetanovic reported that in all cases no evidence for hydrogen abatraction 
was observed with olefins. Cvetanovic generalized the following rules for the reaction of an oxygen atom with an olefin:

(1) An oxygen atom adds to one carbon atom of a double bond to form a biradical, and the addition occurs in the case of unsymmetrical alkenes predominently at the less substituted carbon atom.

(2) Degradation of this triplet state can occur in two ways:

(a) by forming the corresponding epoxide, and (b) by forming a carbonyl compound through the migration of a hydrogen atom or radical from the carbon atom which is carrying the oxygen atom to the other carbon atom of the original double bond.

The above generalization can be represented schematicaliy as follows:

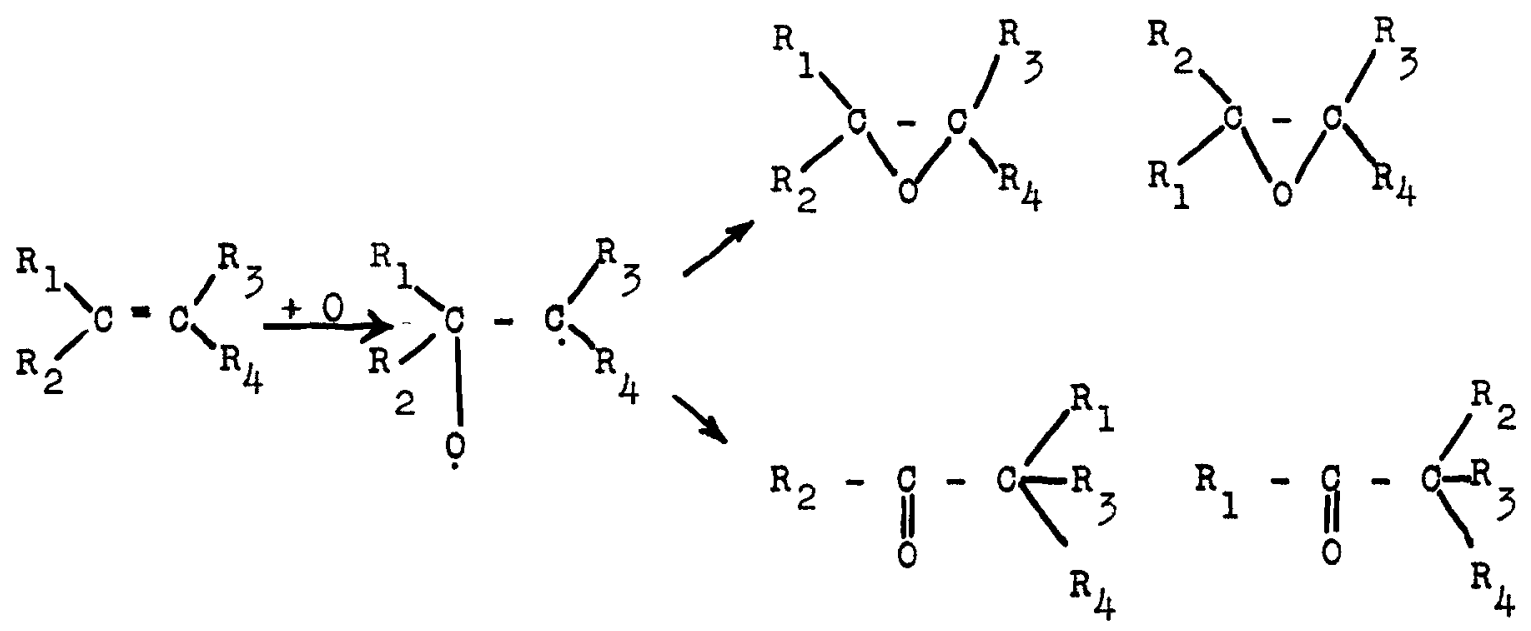

It is assumed in this scheme that the first carbon of the double bond is 'less substituted', and $R_{1}, R_{2}, R_{3}$ and $R_{4}$ can 
be alkyl radicals or hydrogen atoms.

\section{MEASUREMENTS OF REACTION RATES}

Because of lack of the quantitative kinetic data, accurate information on the rate of oxygen atom reactions was essentially non-existent in the early literature. In most cases only rough estimates of the collision efficiencies of the reaction could be made from a knowledge of the extent to which the reaction proceeded. This was done by assuming that each primary product formed represented a fruitful collision, and the collision yield was then calculated from the relationship

$S=\frac{\text { number of fruitful collisions per second }}{\text { total number of collisions between reactants per second }}$. Since most of the experiments were carried out at only one temperature, the activation energy of the reaction was usually obtained by assuming a value near unity for the steric factor. In 1957 measurements of rate constants for reactions of oxygen atoms with hydrocarbons were reported by Ford and Endow (9). They prepared oxygen atoms by the photolysis of nitrogen dioxide at $3660 \AA$ and reacted them with three hydrocarbons. On the assumption of the validity of the mechanism given on Page 4, the rate of reaction of oxygen atoms with hydrocarbon was obtained relative to the rate of reaction of oxygen atoms with molecular oxygen. Using the rate constant for the reaction $\mathrm{O}+\mathrm{O}_{2}+\mathrm{M} \rightarrow \mathrm{O}_{3}+\mathrm{M}$, obtained by Benson and Axworthy $(10)$ from their mechanism for the thermal decomposition of ozone, it was possible to calculate indirectly the following absolute rate constants: 


$$
\begin{array}{ll}
\text { Cis 2-pentene } & k=1.1 \times 10^{13} \mathrm{ccmole}-1 \mathrm{sec}^{-1} \\
\mathrm{~N}-1 \text { pentene } & k=3.0 \times 10^{12} \mathrm{ccmole} \mathrm{sec}^{-1} \\
3 \text {-methyl heptane } k=6.5 \times 10^{10} \mathrm{ccmole}-1 \mathrm{sec}^{-1}
\end{array}
$$

It is obvious that the success of this method depends on the validity of the mechanism proposed and the correctness of the value for reaction (2).

In the study of oxygen atom reactions, cretanovic (63) has presented a list of relative rate constants for reactions of oxygen atoms with olefins. The principle of the technique involves the measurements of the relative rates of two different olefins competing for the oxygen atoms. The reaction scheme can be represented as follows:

$$
\begin{aligned}
& 0+A_{1} \rightarrow \alpha_{1} P_{1} \quad \ldots \ldots \ldots \ldots \\
& 0+A_{2} \rightarrow \alpha_{2} P_{2} \quad \ldots \ldots \ldots \ldots
\end{aligned}
$$

Where $A_{1}$ and $A_{2}$ are two olefins competing for oxygen atoms; $P_{1}$ and $P_{2}$ are one of the products of reactions (1) and (2) respectively; $\alpha_{1}$ and $\alpha_{2}$ are the amounts of $P_{1}$ and $P_{2}$ produced per oxygen atom reacting with $A_{1}$ and $A_{2}$, respectively. Assuming the rate of formation of the product $P_{1}$ or $P_{2}$ per oxygen atom reacting, with either $A_{1}$ or $A_{2}$, was independent of the presence of the other reactant, the ratio of the rate constants of reaction (1) and (2) could be determined. This condition was reported to be satisfied at sufficiently high total pressure by most of the products of these reactions, since they are mostly formed by direct addition of an oxygen atom to the olefinic double bond. The absolute rate constants could then be evaluated from the relative rate 
constants if the rate of one reaction could be determined absolutely. It was found that the ratio of the rate constants obtained by Ford and Endow $(9)$ with cis 2-pentene and 3-methyl heptane compared favourably with that obtained by Cvetanovic. The observed difference of a factor of four in the ratios was considered reasonable in view of the use of two completely different techniques. From his relative rate measurements, Cretanovic was able to demonstrate the electrophilic character of the oxygen atoms in their reactions with olefing $(64)$. In the study of the nature of the air afterglow, Kaufman (13) has found that the intensity of the afterglow is proportional to the concentrations of oxygen atoms and nitric oxide, and that the overall process is independent of the amount and nature of any third body. Since the reaction

$$
\mathrm{O}+\mathrm{NO}_{2} \rightarrow \mathrm{NO}+\mathrm{O}_{2}
$$

is very fast, NO is quickly regenerated and thus remains essentially constant within each experiment. If the concentration of NO is kept small, its contribution to the removal of oxygen atoms is also small and the intensity of the glow becomes a measure of the concentration of the oxygen atoms. Therefore, it was concluded that this technique is well suited for the quantitative study of the oxygen atom reactions. Kaufman produced oxygen atoms in an electrodeless discharge, and followed their decay in the presence of a reactant by adding a small amount of nitric oxide to the mixture. The light emission used to monitor the concentration of the oxygen atoms was measured photometrically. Using this 
method, he was able to measure the rate constants for a number of compounds. A rate constant for the reaction of oxygen atoms with ethylene has been reported to be $5 \times 10^{10} \mathrm{ccmoles}^{-1} \mathrm{sec}^{-1}$. This value can be compared to that obtained by combining Ford and Cvetanovic's results (9) which is $4.6 \times 10^{11} \mathrm{cc}$ moles $\mathrm{sec}^{-1}$.

Recentiy, Elias and schiff ${ }^{(65)}$ have reported the absolute rate constants for the reactions of oxygen atoms with ethylene and with butane. The measurements were carried out in a fast flow-system in which oxygen atoms were produced by an electrodeless discharge in molecular oxygen. Since the presence of molecular oxygen does not affect the rate of consumption of the hydrocarbon (54), the initial oxygen attack was considered to be rate-determining. The rate of disappearance of hydrocarbon can then be represented by a simple bimolecular equation:

$$
\frac{-\mathrm{d}[\mathrm{RH}]}{\mathrm{dt}}=\mathrm{k}[\mathrm{O}][\mathrm{RH}]
$$

Here [RH] represents the concentration of the reactant. On the assumption that $\mathrm{RH}$ is neither reformed nor consumed in the subsequent reactions, the integration of the above equation between time limits $t_{1}$ and $t_{2}$ are

$$
\ln \frac{[\mathrm{RH}]_{1}}{[\mathrm{RH}]_{2}}=\int_{\mathrm{t}_{1}}^{\mathrm{t}_{2}}[0] \mathrm{dt}
$$

[0] can be measured along the length of the reaction vessel, which corresponds to the reactiontime, and the integrel evaluated graphically. The rate constant is then obtained from the measurements of $[R H]$ at times $t_{1}$ and $t_{2}$ and the 
value of the integral in that time interval. It was reported that the ratio of the rate constants for reactions with ethylene and with butane was $28 \pm 3$ at $25^{\circ} \mathrm{c}$;

Cvetanovic $(54)$ found this ratio to be $22 \pm 5$ from the relative rate measurements. This agreement was considered to be quite satisfactory. Elias and schiff also reported the activation energy and the pre-exponential factor for these two reactions, which appears to be the first directly measured values for these parameters reported for reactions of oxygen atoms with organic compounds.

\section{THE PRESENT PROBLEM}

Inspection of the literature reviowed in the foregoing section indicates clearly that the existing information on oxygen atom reactions is still insufficient to draw a decisive conclusion regarding the kinetic character of the oxygen atoms. Although extensive experimental data have been accumulated for reactions with olefins, controversies and uncertainties still exist. On the other hand, no satisfactory mechanism has yet been proposed for the reactions of oxygen atoms with other type molecules. This is particularly true for the reactions with the chlorinated alkanes. It is the purpose of the present research to investigate the reaction of oxygen atoms with carbon tetrachloride. This molecule was chosen since it possesses no double bonds and hydrogen atoms. It was hoped that the reaction products would then be sufficiently simple to permit a satisfactory mechanism to be formulated. An attempt was also made to measure the absolute rate constant, the 
activation energy and the steric factor of this reaction.

It is known that oxygen and nitrogen in their

atomic form are important constituents of the upper atmosphere. In order to study the composition of the upper atmosphere, the measurements of the concentrations of these atoms become important. Sobering and Winkler ${ }^{(66)}$ have observed that nitrogen atoms and carbon tetrachloride react with a bright orange flame, while Harteck and Kopach (6) observed no flame in the reaction of oxygen atoms with carbon tetrachloride. There exists therefore the possibility of using carbon totrachloride as a titrant for determining upper atmospheric composition. This is an additional reason for a quantitative kinetic study of the reaction of oxygen atoms with carbon tetrachloride.

Since there still were some discrepancies between various methods for measuring the concentration of the oxygen atoms, it was decided to test various methods in order to select the best technique for the present study. In conjunction with this study, recombination of oxygen atoms was also investigated, since this recombination will occur regardless of the presence of another reaction. 


\section{EXPERIMENTAL}

MATERIALS

Tank oxygen was obtained from Dinsmore, Canadian Liquid Air, Linde Air, Mathoson Company and Imperial Oxygen, most of which claimed a purity of $99.9 \%$ for their product. The main impurity is nitrogen. Since the discharge produces nitric oxide from the nitrogen impurity, the intensity of the air afterglow gives a very good indication of the purity of oxygen used. It was found that the Dinsmore oxygen contained the largest nitrogen concentration while Imperial Oxygen had the lowest nitrogen content among all the cylinders tested.

It is well known that small amounts of certain added species increase the extent of the dissociation of oxygen molecules $(67,68)$. Very recently, Kaufman and Kelso(68) have studied the catalytic effects in the dissociation of oxygen in microwave discharges and found that only small disoociation could be obtained from the very pure oxygen, but small amounts of added nitrogen $(0.01$ to $0.05 \%)$ increased the oxygen atom yield at a rate equivalent to the formation of 80 to 90 oxygen atoms for one nitrogen molecule. Although it seems desirable to have a small amount of nitrogen impurity in order to obtain reasonable amounts of oxygen atoms for the kinetic studies, it was desirable to keep the nitrogen content to a minimum. Imperial oxygen was therefore used without further purification for the present work, and oxygen from the same cylinder was used for the complete series of experiments.

Certified reagent grade carbon tetrachloride was obtained from the Fisher Scientific Company. This reagent was further purified by trap-to-trap distillation under vacuum, and only the middle fraction was used.

Nitric oxide was obtained from the Matheson Company. 
Acidic impurities (mainly $\mathrm{NO}_{2}$ ) were removed by pasing the gas through a column of ascarite (NaOH - asbestos). No further purification was found necessary in this work.

Nitrogen dioxide was prepared by mixing the purified nitric oxide with oxygen, and stored with a small excess of oxygen. It was used only if the solid was pure white in colour, when it was condensed at low temperature.

Chlorine, phosgene, carbon dioxide and carbon monoxide were obtained from the Matheson Company and purified by simple distillation.

\section{AFPARATUS}

A conventional flow system, constructed of Pyrex glass, was used in the present work, the principal components of which are shown in Fig. 1. The reaction vessel had an internal diameter of 26 millimeters and a length of 40 centimeters. It was surrounded by a jacket through which tap water could be flowed and an outer vacuum jacket to keep the temperature steady in the reaction vessel and to prevent frosting which would interfere with the optical observations and measurements when the vessel was operated at low temperatures.

The reaction vessel was thermostatted at higher temperatures by the vapours of appropriate liquids boiling in a flask, F, atteched to the apparatus and refluxing in a condenser, W.C. The temperatures of the reaction vessel were measured by a thermometer located at Tm. The oxygen was discharged in a quartz tube which had an outer diameter of about 13 millimeters, and was located about 20 centimeters 


\section{FIGURE 1}

\section{Flow System}

$$
\begin{aligned}
& \text { B - bubbler } \\
& \text { C - capillary } \\
& N \text { - needle valve } \\
& \text { M - manometer } \\
& T \text { - trap } \\
& R \quad \text { - reservoir } \\
& \text { Q - quartz } \\
& F \text { - distilling flask } \\
& J \text { - inlet jets } \\
& \text { RT - reaction tube } \\
& \text { W.G. - wave guide } \\
& \text { W.C. - water condenser } \\
& \text { T.M. - tilting McLeod gauge } \\
& \text { Tm - thermometer } \\
& \text { S.W. - silver wire } \\
& \text { A.C. - ascarite column } \\
& \text { c.C. - combustion column }
\end{aligned}
$$




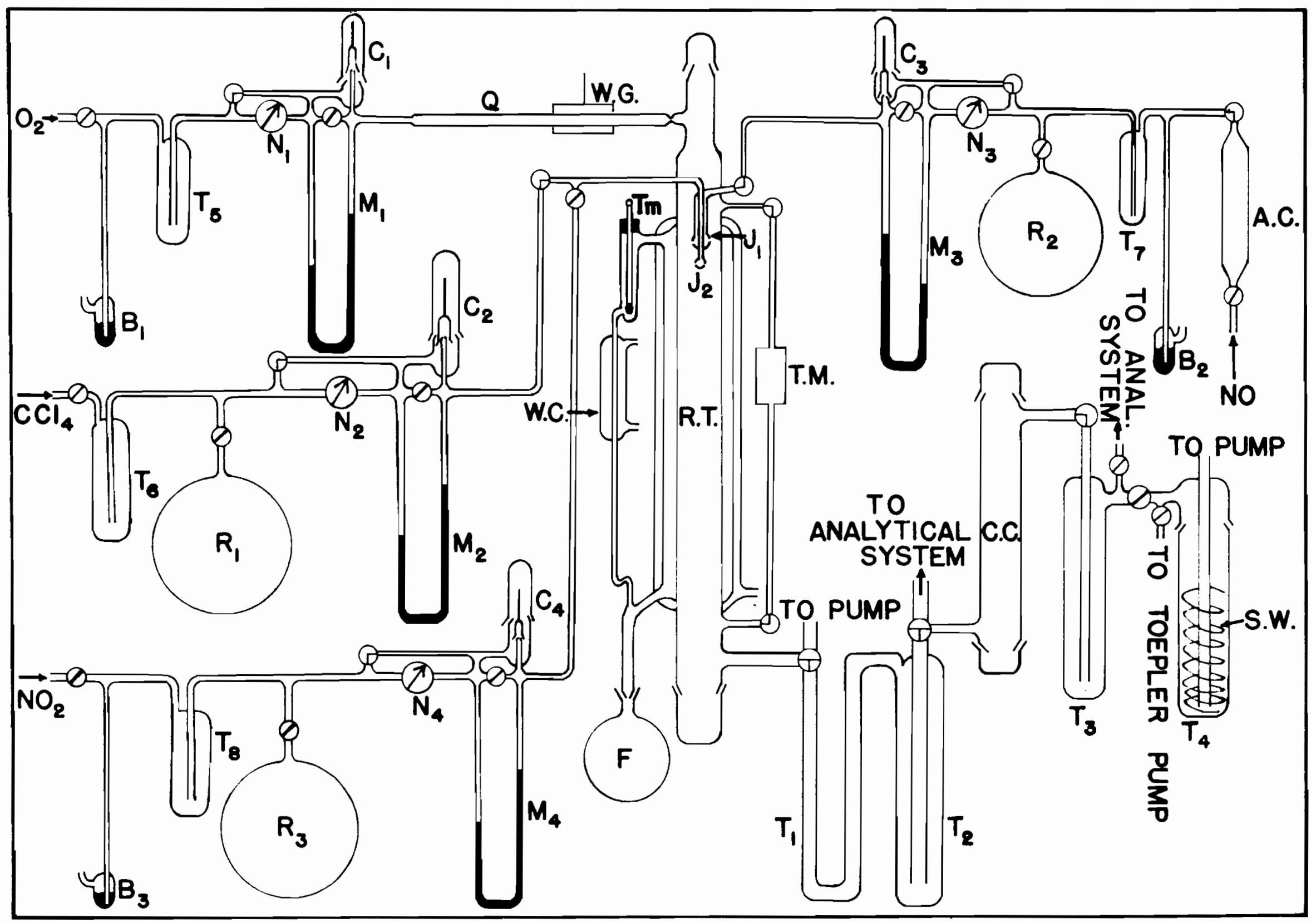


above the reaction vessel to prevent any possible back diffusion of reactants into the discharge zone.

The reactants were introduced into the reaction vessel through multiple jets, $J_{1}$ and $J_{2}$ situated one centimeter and five centimeters respectively below the top of the jacket. The multiple jetsconsisted of a small glass bulb in which five equally spaced small holes were blown in a plane transverse to the direction of the oxygen stream.

The flows of gases in the system were controlled by Edwards fine-control needle valves, N. The pressure difference across a removable capillary, $c$, was measured by a U-tube manometer, $M$, filled with mercury. The mercury was covered with about one centimeter of 'octoil' to prevent mercury vapour from getting into the systom. The calibration of oxygen flow was done by collecting the gas passing through the vacuum pump at steady state conditions. This method gave very good reproducibility and was found to agree with the 'PV' method (70) achieved by measuring the pressure drop in a known storage volume. The flows of carbon monoxide and nitric oxide were calibrated by the 'PV' method, while the flows of nitrogen dioxide and carbon tetrachloride were determined by trapping the gases at liquid air temperature in blank experiments in which the usual $\mathrm{O}_{2}$ flow was maintained in the reaction system but without operation of the discharge. A constant flow of gas was maintained during an experiment by regulating the pressure head. The pressure head of oxygen was maintained at atmospheric pressure by releasing the excess gas through the bubbler, $B_{1}$. The 
The pressure heads of carbon monoxide, nitric oxide, nitrogen dioxide and carbon tetrachloride were maintained approximately constant by the use of large reservoirs, R. In the case of high flow rate and long duration experiment, a slight manual adjustment of the needle valve was necessary to compensate for the small drop in pressure in the ballast volume during the course of an experiment.

The pressure in the reaction system was measured at the top and at the bottom of the reaction vessel with a 'tilting McLeod gauge', T.M. This instrument, obtained from the Virtis Company, New York, measured pressures from .005 to 5 millimeters with a reproducibility of $1 \%$. The gauge could be isolated by stopcock when it was not in use in order to exclude mercury vapour from the apparatus.

The condensable gases were trapped in most experiments with liquid air; two traps, $T_{1}$ and $T_{2}$, arranged in series, were used to prevent small amounts of condensable gases from escaping with the excess of the non-condensable gases. The level of liquid air was maintained approximately constant in order to keep the flow conditions steady during an experiment.

The reaction system was kept under vacuum at all times except when it became necessary to re-grease stopcocks or to clean and repair the system. Silicon grease was used for all experiments. A known amount of carbon tetrachloride was circulated through the system three times, and no appreciable loss of the reagent due to adsorption by the grease has been noticed. It is unlikely that other gases in 
the reaction system would afrect appreciably the silicon grease under the present experimental conditions.

The reaction vessel was usually cleaned with chromic acid cleaning solution and then washed successively with a large quantity of distilled water. The system was dried in vacuum under prolonged pumping. PRODUCTION OF OXYGEN ATOMS

A 'Raytheon Microwave Generator', No. KV-1048B, was used to obtain an electrodeless discharge. This unit generates a continuous 2450 megacycle wave with a maximum output of 125 watts. When the output is directed at the discharge tube through a wave guide, a discharge can be initiated with a 'Tesla-coil' spark under the proper conditions of pressure and flow. A resonance type of wave guide, which was held at a fixed position on the discharge tube, has been used for all oxperiments in order to obtain a constant discharge efficiency. It was found that $(70)$, in the absence of mercury in the system, the temperature of the discharge tube did not affect the oxygen atom concentration considerably. Hence the discharge tube was operated without artificial cooling.

Because of the large fluctuations in the 110 volt A.C. power supply, the power output of the generator was somewhat unsteady during the day time. A 'sola' constant voltage transformer, which was rated to keep the voltage constant within $0.5 \%$, was used. The effect of power output on the atom concentration has been measured and shown in Fig. 2 . A change in power output from 25 to 112.5 watts increased the atom concentration by only about $20 \%$ under the usual operating 
FIGURE 2

$\frac{\text { THE EFFECT OF POWER OUTPUT ON }}{\text { OXYGEN DISCHARGE }}$
$O_{2}$ flow - $135 \mu_{\mathrm{moles} / \mathrm{sec}}$
Pressure - $2.1 \mathrm{~mm} \mathrm{Hg}$
Oxygen atom flow measured by an
isothermal calorimetric detector




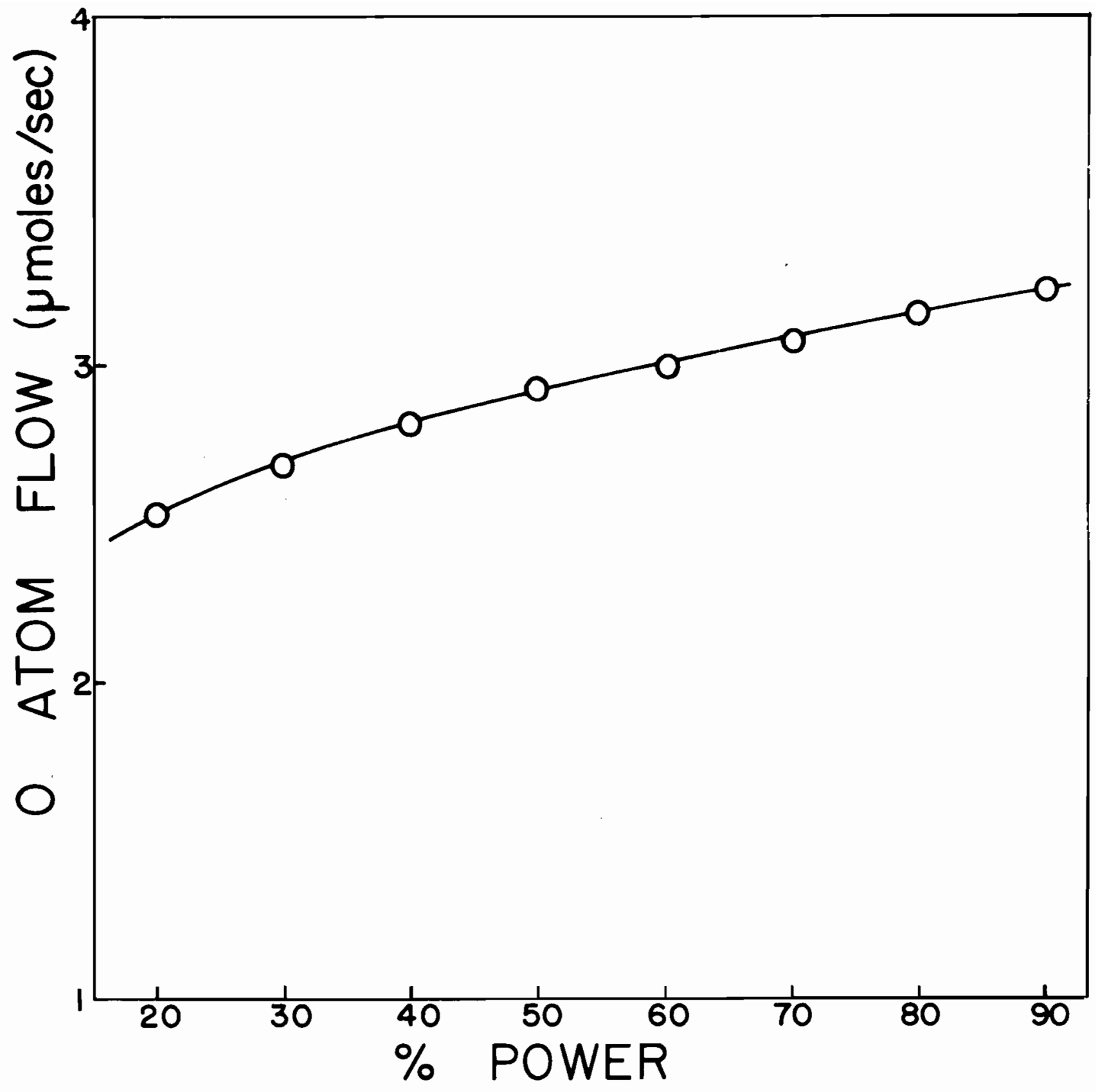


conditions.

A slightly unsteady operation of the discharge was noted for the first half hour of operation. This might be due to unsteadiness of the microtherm unit, or of tho discharge tube. For this reason, the whole apparatus was set in operation for at least half-an-hour before any measurements were made. MEASUREMENT OF OXYGEN ATOMS

For a quantitative kinetic study of oxygen atom reactions, an accurate measurement of oxygen atoms is primarily important. Although a number of techniques have been reported for measuring the concentration of oxygen atoms, much controversy still exists. A calorimetric method was first employed in the present work. This mothod was originally developed by Langmuir(71) to measure the rise in temperature of a metal surface due to the recombination of hydrogen atoms and was later modified by Tollefson and Le Roy (72) for quantitative measurements. It was further modified in this laboratory (15) and used to measure the concontration of oxygen atoms. Consequently it was named the 'isothermal calorimetric detector' technique. The detector was constructed of a spiral of platinum wire, which was coated with a metal of high catalytic activity for recombining oxygen atoms. The spiral was made movable in the reaction vessel by mounting it on a rack and pinion. A known electrical currentio is passed through the wire, and Its resistance, $R$, is measured with a Wheatstone bridge. When the oxygen is activated by discharge, oxygen atoms flow over 
the detector, recombine on the wire, heat it, and thus change its resistance. To compensate for the heat liberated by the recombination of atoms, the current through the wire is reduced to some value 1 , so that 1ts resistance, and consequently its temperature, is restored to the initial value. The difference in electrical energy required to maintain the wire isothermally can readily bo calculatea from the following relation:

$$
\Delta W=n\left(1_{0}^{2}-i^{2}\right)
$$

since the detector is operated isothermally, the heat losses due to radiation, conductivity, etc. in the presence or in the absence of atoms, should be unchanged. Therefore, if the detector recombines all the atome from the gas stream, the flow rate of atoms, Fo, can be calculated from the equation

$$
F_{0}=\Delta w / \Delta H \ldots \ldots \ldots \ldots \ldots \ldots \ldots
$$

where $\Delta W$ is the difference in electrical energy (cal/sec) given by equation (1), $\Delta H$ is the heat of recombination of the atoms, $58.5 \mathrm{Kcal}$ per mole of oxygen atoms.

Cobalt, nickel, copper, zinc and silver were tested for their efficiency for oxygen atom recombination in this laboratory. Cobalt was considered to be the most suitable and was adopted in the preliminary work. Unfortunately, later experiments revealed that, although the detector recombined all atoms present, it also measured the heat from any other species present in the gas stream. The additional measured heat was attributed to the presence of considerable amounts of excited molecular oxygen (15). The presence of 
such species would make the evaluation of measurements of the absolute concentration of oxygen atoms erroneous. Furthermore, experiments also indicated that the efficiency of the detector was affected by the presence of species from the reaction of oxygen atoms with carbon tetrachloride. For these reasons, this technique was not used in the present work.

In the search for another method to measure the absolute concentration of oxygen atoms, a chemical method was tested. This method was first described by Avramenko and Kolesnikova $(73)$ and since then used for their studies of oxygen atom reactions. They reported that,in the reaction of oxygen atoms with carbon monoxide at a temperature of about $100^{\circ} \mathrm{C}$ and at a pressure ranging from 1 to 20 millimeters of mercury, carbon dioxide was found to be the only reaction product. By adding sufficient amounts of carbon monoxide into the gas stream to react with all oxygen atoms, the amounts of carbon dioxide formed would be equal to the amounts of the atoms present. The initial concentration of oxygen atoms could then be calculated by using the formula

$$
(0)_{0}=\frac{\left(\mathrm{CO}_{2}\right)_{\max }}{t \cdot s \cdot W}
$$

where $(0)_{0}$ is the initial concentraction of oxygen atoms expressed by the number of oxygen atoms per cubic centimeter; $\left(\mathrm{CO}_{2}\right)_{\max }$ is the amount of $\mathrm{CO}_{2}$ formed under conditions in which all atoms are consumed by the reaction; $t$ is the time of the reaction in seconds; $S$ is the crosa-sectional area of the reaction vessel in square centimeters; W is the linear velocity of the flow in centimeters per second. 
However, experiments performed at a temperature of $100^{\circ} \mathrm{C}$ and at a pressure of about $2 \mathrm{~mm} \mathrm{Hg}$ have shown that the reaction of oxygen atoms with carbon monoxide was quite slow under the present experimental conditions. It was found that the reaction is at least twenty times slower in the present system than in Avramenko's experiment. The differences in the experimental conditions may probably account for the discrepancy between the two investigations. A large excess of water vapour was present in Avramenko's experiment, while excess of oxygen was present in the present system. It is generally regarded that the reaction of oxygen atoms with carbon monoxide is a third-order reaction; water molecules may serve as a more efficient third body than oxygen in this reaction.

It is obvious that a successful chemical method for measuring the atom concentration requires a substance that will react very rapidly with oxygen atoms in a strictly stoichiometric fashion. It is also essential that the products do not react with oxygen atoms at a comparable rate. spealman and Rodebush $(74)$ were the first to suggest that nitrogen dioxide might come close to fulfilling these requirements. The reactions concerned are:

$$
\begin{aligned}
& \mathrm{NO}_{2}+\mathrm{O} \rightarrow \mathrm{NO}+\mathrm{O}_{2} \\
& \mathrm{NO}+\mathrm{O} \rightarrow \mathrm{NO}_{2}+\mathrm{hv}
\end{aligned}
$$

According to the authors, reaction (1) proceeds with a rate 
of about 1,000 times faster than reaction (2). Recently, the rate of reaction (1) has been messured by three different methods $(13,75,76)$, and is indeed very fast. Therefore, it can be expected that oxygen atoms will be entirely consumed by the reaction (I) if sufficient amounts of nitrogen dioxide are present in the reaction system.

The fact that reaction (2) is light-producing, provides a visual method for determining the oxygen atom concentrations. As nitrogen dioxide is added to a gas stream containing o-atoms, the intensity of the glow increases to a maximum. At this point, the amount of nitrogen dioxide added is probably equal to one-half the amount of oxygen atoms. As more nitrogen dioxide is added, the intensity of the glow decreases, until it sharply retreats to the nitrogen dioxide inlet. This is an endpoint of the oxygen atom titration. At this point the nitrogen dioxide flow should equal the oxygen atom flow.

This method seems quite straight forward, but experiments under the present conditions showed that it was not sensitive enough to follow a small change inatom concentrations. When oxygen atoms are passed through a reaction vessel, it is expected that the concentration of atoms should be higher at the top than at the bottom of the vessel, due to the decay of atoms through recombinations. However, by keeping the nitrogen dioxide flow constant, differences in the titration end-points along the reaction vessel could not be detected visually. Furthermore, 
because of the corrosive nature of the nitrogen dioxide and the formation of $\mathrm{N}_{2} \mathrm{O}_{4}$, the calibration of the flow rate of nitrogen dioxide cannot be done accurately. Obviously a more sensitive procodure was required for accurate atom measurements.

Ingtead of finding the end-point of the gas phase titration visually, a'NO $2^{-c l e a n u p ' m e t h o d ~ w a s ~ a d o p t e d ~ t o ~}$ measure the concentration of oxygen atoms. A relatively large excess of nitrogen dioxide is admitted into the o-atom stream to ensure complete atom consumption in the primary reaction. The nitric oxide formed from the reaction is trapped down stream at liquid air temperature. (With excess nitrogen dioxide present, NO reacts with $\mathrm{NO}_{2}$ to form $\mathrm{N}_{2} \mathrm{O}_{3}$ which can be trapped quantitatively at liquid air temperature). The trapped nitric oxide was determined by the amount of oxygen consumed in converting the mixture of oxides to nitrogen dioxide through the reaction

$$
2 \mathrm{NO}+\mathrm{O}_{2} \rightarrow 2 \mathrm{NO}_{2}
$$

According to reaction (1), the amount of nitric oxide formed should equal the oxygen actom concentration. By this technique, small changes in atom concentration could be determined (the detailed discussion will be given later), and results obtained were quite reproducable. Therefore, this method was used in the present work for the absolute concentration measurements. THE DECAY OF OXYGEN ATONS THROUGH RECOMBINATION 
significant rate through recombination in the gas phase and on the walls of the reaction vessel. For a quantitative kinetic study of any oxygen atom reaction, it is desirable to know the relative proportion of atoms recombining to those participating in the reaction. Therefore, the measurement of the rate of oxygen atom decay through recombinations was studied in the absence of added reactant.

The oxygen atom concentration was measured by the ' $\mathrm{NO}_{2}$-cleanup' method in the present work. A movable jet technique shown in Fig. 3 was developed to follow the rate of atom decay along the reaction vessel. This jet, of similar construction to $\mathrm{J}_{2}$ in Fig. 1 , was joined to a $60 \mathrm{~cm}$. length of $6 \mathrm{~mm}$ diameter glass tubing. This tube could be moved axially along the reaction vessel by rotation of the tygon-covered rod $T$, which pressed against it. The lower end of the glass tubing was joined to a small diameter tygon tubing which could be curled in B to give the necessary flexibility of operation. An inner guide $Q$ was installed to keep the tygon tubing moving in line with the glass tubing. The other end of the tygon tubing was connected to an inner ground joint I which was further connected to the nitrogen dioxide flow-line. To keep the jet aligned in the central position in the reaction vessel, a guide, $P$, consisting of three equally spaced glass rods of equal length was built around the glass tubing $2 \mathrm{~cm}$ below the jet. It was also found necessary to place a coil of silver wire at a to protect the tygon from being attacked by oxygen atoms flowing 
Figure 3

Reaction Tube and the Movable Inlet Jets Assembly 


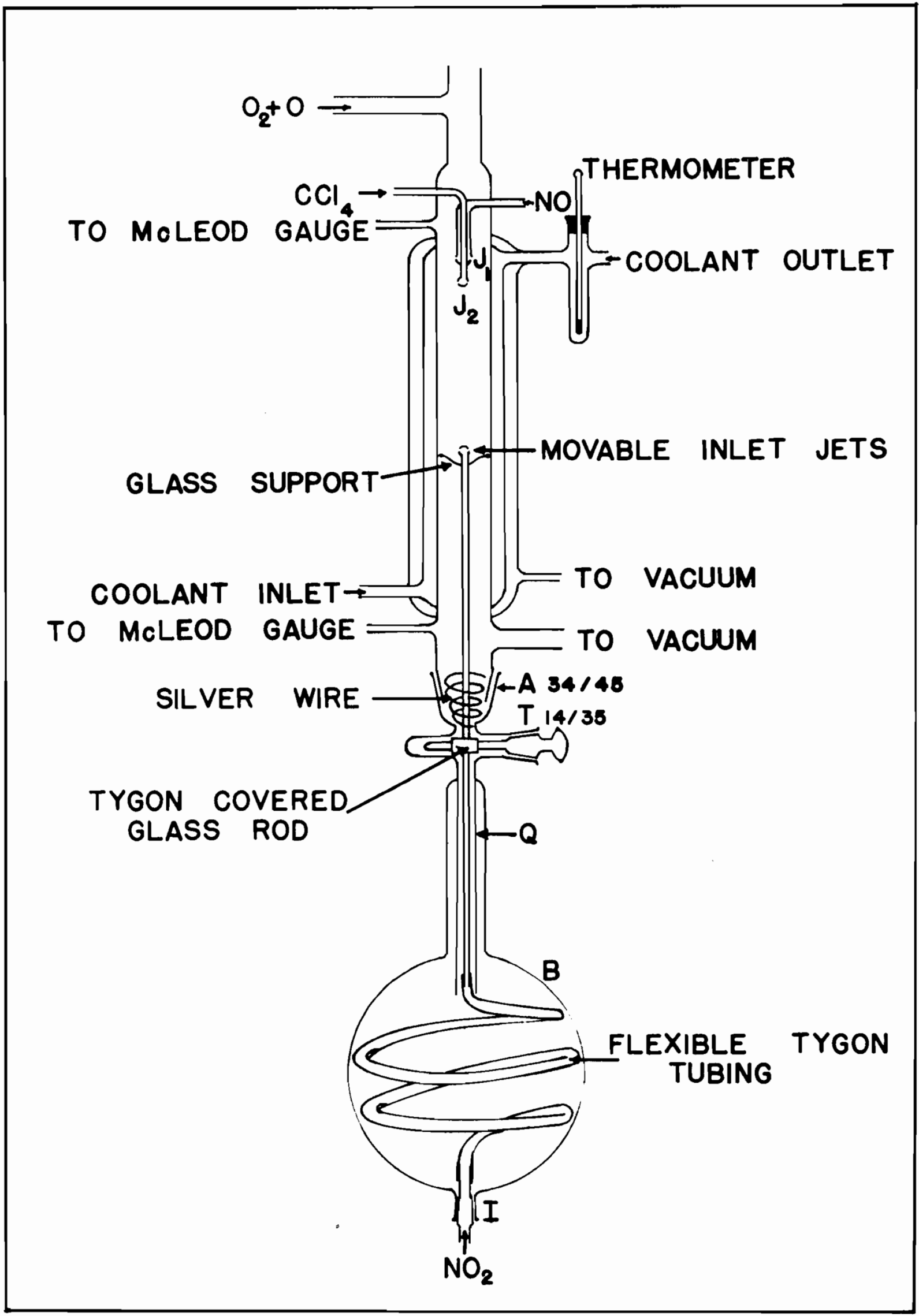


in the reaction vessel. With this device, the jet could be located at any position in the centre of the reaction vessel and through which nitrogen dioxide could be admitted into the gas stream. The concentration of oxygen atoms at various positions (corresponding to various times) could be determined. The rate of the atom decay could thus be calculated. A photometric method was also used in the present work to follow the atom concentrations. The detailed discussion of this technique will be given in a later section. THE REACTION OF OXYGEN ATOMS WITH CARBON TETRACHLORIDE

Preliminary experiments showed that the reaction of oxygen atoms with carbon tetrachloride is slow. In order to obtain more accurate rate measurements of the reaction, a longer reaction time is necessary. This was achieved by reducinc the flow rate of the gas stream in the reaction vessel. Care was taken to prevent the reactant from getting into the discharge zone by back diffusion. This restricts the range of reactant which could be used. Back diffusion into the discharge was also minimized by the design of the reaction system in which the discharge and the reaction zone were separated by distances of $20 \mathrm{~cm}$ and a constriction placed right after the discharge to increase the linear velocity in that region. The effect of back diffusion could be calculated by the use of Hertz's law (77), and could be tested experimentally. The result will be discussed below. 
is that unreacted 0-atoms will pass through the reaction vessel and condense in the cold trap as ozone. To prevent this, silver wire was placed at the outlet of the reaction tube to destroy all the atoms before they reach the trap. The effectiveness of the wire was indicated by the sharp discontinuity of the glow at this point. However, a change in colour of the wire indicated that catalytic reactions may have taken place on the surface of the wire. If this occurs, uncertainties would be introduced in the interpretation of reaction products. Therefore, experimental conditions were created which resulted in a complete consumption of oxygen atoms in the length of the reaction vessel.

The range of flow-rates of the reactant used for experiments were chosen in accordance with the following considerations:

Since the reaction of oxygen atoms with carbon tetrachloride is very exothermic and its activation energy is high, it is necossary to limit the reactant flow-rates to prevent a temperature rise which would increase the rate of reactions.

(2) Because of the relatively slow flow of the gas in the reaction vessel, the flow-rate of the reactant has to be limited to prevent the back-diffusion of the reactant into the discharge zone.

(3) In order to maintain relatively constant flow conditions for a series of experiments, it is necessary that 
the introduction of the reactant does not affect the pressure and the flow considerably.

To prevent the formation of ozone in the cold trap, which is known to affect the product analysis, a sufficient amount of carbon tetrachloride should be admitted into the reaction system to result in complete consumption of oxygen atoms in the length of the reaction vessel.

In a typical experiment, the oxygen flow was in operation for at least half-an-hour to ensure that steady conditions had been achieved. The initial atomic oxygen concentration was determined by the 'NO $2^{-c l e a n-u p ' m e t h o d . ~}$ Carbon tetrachloride was then added through $\mathrm{J}_{2}$ and permitted to attain constant flow. This was particularly necessary for low reactant flows. During tnis period, the gas leaving the reaction vessel was made to bypass the product traps. The duration of experiment was chosen to obtain sufficient reaction products for accurate analysis, and usually ranged from 20 minutes to about $1 \frac{1}{2}$ hours. The condensable gases were trapped downstream in $\mathrm{T}_{1}$ and $\mathrm{T}_{2}$ at liquid air temperature. The non-condensable product was combusted in a combustion column downstream, and the combusted product was then trapped in $\mathrm{T}_{3}$ at liquid air temperature. When the experiment was finished, the flow of the reactant was discontinued, and the gas leaving the reaction vessel was again made to bypass the traps. The trapped products were then transferred to a measuring system for analysis. 
IDENTIFICATION AND ANALYSIS OF REACTION PRODUCTS

Preliminary experiments were carried out to

identify the products of the reaction at various ratios of oxygen atoms and carbon tetrachloride concentrations. The formation of chlorine from the reaction could be easily identified by the appearance of the light green colour in the trapped product in $T_{1}$. This product was further identified by lts reaction with mercury and mercuric sulfide. The formation of phosgene was identified by a NaI-acetone method $(78)$. After chlorine was removed quantitatively from other reaction products by its reaction with mercury, the remainder of the sample was transferred into a sample tube in which about $20 \mathrm{ml}$ of $2 \%$ solution of sodium iodide in acetone was previously frozen at liquid air temperature. When the transference was completed, the solution was allowed to warm up to room temperature and was shaken to absorb all the phosgene. The formation of iodine was used as an indication for phosgene through the following reaction:

$$
2 \mathrm{NaI}+\mathrm{COCl}_{2} \rightarrow 2 \mathrm{NaCl}+\mathrm{I}_{2}+\mathrm{CO} \text {. }
$$

Identifications were also made mass spectrometrically, which indicated that chlorine, carbon dioxide and phosgene were the only condensable products. This was further confirmed by a vapour pressure-temperature measurement of the products in a Le Roy still (79).

Identification of the non-condensable product was carried out in the following procedure. A fraction of the non-condensable gas was sampled downstream in a Toepler pump 
attached to the flow system. Excess oxygen was removed from the sample by absorption in a sodium hyposulfite solution containing indigo carmine $(80)$. The indigo carmine acts both as a catalyst and as an indicator of the remaining absorbing power of the solution. This solution effectively removes oxygen from a gas mixture even at low temperatures and does not evolve any other gas. The resulting sample was then subjected to mass spectrometric analysis. The results showed that carbon monoxide was present in the noncondensable gas. This product was also identified by combusting the gas in a copper oxide furnace. A detailed description of this technique will be given in the next section.

The quantitative measurements of the reaction products were performed in the analytical system attached to the apparatus. The determination of chlorine wes first accomplished by removing all chlorine from the sample with mercury. The amount of chlorine was then estimated by measuring the pressure difference in a known volume. Preliminary experiments revealed that mercury reacts slightly with phosgene when they were brought in contact for a prolonged period of time. Furthermore, there was the danger of the measuring system being contaminated by mercury vapour during the course of transference of the sample. Blank experiments have shown that mercuric sulfide removes chlorine effectively and quantitatively at room temperature and does not react with phosgene to an appreciable extent. 
Therefore, mercuric sulfide was employed instead of mercury for all experiments. The pressures were measured with an absolute pressure gauge (ACSO Accu-Vac Absolute Vacuum Gauge, Model A-140) which has a range from zero to $40 \mathrm{~mm}$ Hg and was not affected by chlorine or phosgene. The gauge was frequently checked against a calibrated Mcleod gauge. The carbon dioxide and phosgene were separated by the use of a Le Roy still, and the amounts of each component measured by a gas burette. When the take-off pressures, indicated in Fig. 4, were used for the separations, prepared mixtures containing known proportions of carbon dioxide, phosgene and carbon tetrachloride, showed that the separation was accurate to within 2 to 3 percent.

Carbon monoxide was combusted in a combustion column, CC (see Fig. I) which had an outer diameter of $34 \mathrm{~mm}$ and a length of $40 \mathrm{~cm}$, and was packed with copper turnings which were cleaned and converted to copper oxide at high temperature. This column was operated at a constant temperature of about $350^{\circ} \mathrm{C}$. The combustion product was trapped in $\mathrm{T}_{3}$ at liquid air temperature and was measured by the $P-V$ method. Results for synthetic samples indicated that this technique is satisfactory for the measurements of carbon monoxide.

\section{THE REACTION OF OXYGEN ATOMS WITH PHOSGENE}

In the study of elementary reactions of atoms with organic molecules, the overall course of the reaction may be 
Figure 4

\section{Vapour Pressure - Temperature Relations for Various substances}




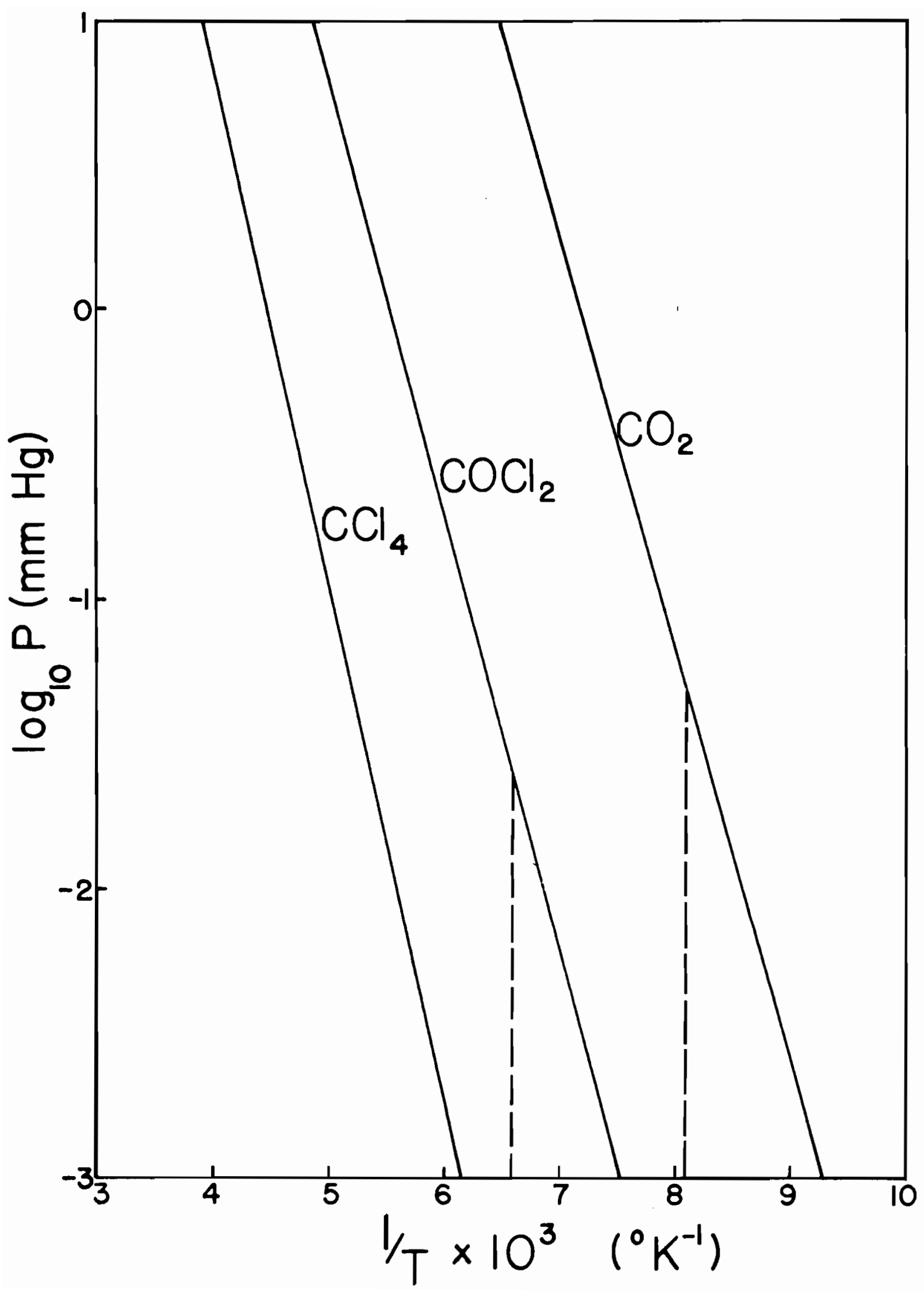


complicated by the subsequent reactions of the products. The reaction of oxygen atoms with phosgene was therefore studied in the system with conditions appoximately the same as that described above. Phosgene was distilled once and passed through a column of antimony trisulfide to removo traces of chlorine $(81)$. The gas was then introduced into the gas stream through $J_{1}$ and allowed to react with the oxygen atoms. The reaction was carried out at $16^{\circ} \mathrm{C}$ and at a pressure of $2 \mathrm{~mm} \mathrm{Hg}$. The initial flow of oxygen atoms was about $1 \mu$ molo per second. The change in intensity of the excited $\mathrm{NO}_{2}$ afterglow in the system was taken as an approximate indication of the extent of the reaction. It was observed that the intensity of the afterglow decreased tremendously when a small amount of phosgene (less than 0.5 mole per second) was introduced into the reaction vessel. With a slight increase of the phosgene, the greenish-yellow glow was completely replaced by a bright purple flame which filled the entire reaction tube downstream. With a sight further adition of the reactant, the flame retracted to a position a few centimeters below the inlet jots. This observation indicates that the reaction of oxygen atoms with phosgene is very fast. No attempt was made at a quantitative analysis of the producta, but chlorine and carbon dioxide were detected qualitatively. THE REACTION OF OXYGEN ATOMS WITH CARBON TETRACHLORIDE IN AN OXYGEN-FREE SYSTEM

The customary method of production of 0-atoms by electrical discharge in molecular oxygen for kinetic studies 
may be criticized on the ground that the process might be obscured by the readily occurring reactions of any radicals produced with molecular oxygen present in excess. For this reason, Avramenko obtained O-atoms from electrical discharge of water vapour (11), and Cvetanovic produced O-atoms from mercury photosensitized decomposition of $\mathrm{N}_{2} \mathrm{O}^{(8)}$ for their studies of O-atom reactions.

An alternative method for producing 0-atoms in an $\mathrm{O}_{2}$-freo system has recently been developed in this laboratory. This system is produced by aubjecting molecular nitrogen to a microwave discharge, and roacting the $\mathrm{N}$-atoms produced with nitric oxide. Molecular nitrogen was dissociated in the manner describod previously for molecular oxygen. A constant flow of NO was admitted through $J_{1}$ as shown in Fig. 1 to titrate the active nitrogen to a dark end-point. At this condition, the reaction system contains only 0-atoms and nitrogen molecules, and the concentration of 0-atom formed can aimply be deduced from the flow rate of NO required to titrate the N-atoms. The carbon tetrachloride was introduced into the gas stream through $\mathrm{J}_{2}$ which is located about 4 centimeters below $J_{1}$. The rest of the procedure for this experiment is essentially the same as that described previously. The most important oporation for a satisfactory experiment is the maintenance of the constancy of the No flow. For a prolonged experiment, a slight manual adjustment had to be made occasionally to compensate the slight change in the flow. 
MEASUREMENT OF THE RATE CONSTANTS OF THE PRIMARY

REACTION OF O-ATOMS WITH CARBON TETRACHLORIDE

Although the reaction of 0 -atoms with carbon

tetrachloride is a complex one involving several intermediate steps and leading to the formation of a variety of products, the primary reaction can be represented as

$$
0+\mathrm{CCl}_{4} \stackrel{\mathrm{k}_{1}}{\longrightarrow} \text { products. }
$$

If the carbon tetrachloride is neither reformed nor consumed in subsequent reactions (the justification of this assumption will be given in the later section), the rate of disappearance of carbon tetrachloride can then bo represented by a simple bimolecular equation,

$$
-\frac{d\left(\operatorname{col}_{4}\right)}{d t}=k_{1}(0)\left(\operatorname{col}_{4}\right) \ldots \ldots \ldots \ldots
$$

Interpretation of this equation between time limits $t_{1}$ and $t_{2} g i v \theta B$

$$
\ln \frac{\left(\cos _{4}\right)_{1}}{\left(\operatorname{col}_{4}\right)_{2}}=k_{1} \int_{1}^{2}(0) d t \quad \ldots \ldots \ldots \ldots
$$

Therefore, to obtain the rate constant $k_{1}$, it is only necessary to measure the concentration of carbon tetrachloride at two different times, and the o-atom concentration as a function of time. As a result of subsequent reactions, the 0-atom concentration is a complex function of time. However, in a well-defined flow system, time can be related to distance, and the o-atom concentration can then be measured along the length of the reaction vessel. As mentioned earlier, preliminary experiments 
revealed that the reaction of O-atoms with carbon tetrachloride was very slow, and that metallic surfaces could not be used in the present system to destroy 0-atoms in order to stop the reaction and thus to define the reaction time. The experimental conditions were therefore chosen to result in a complete consumption of 0-atoms within the length of the reaction tube. Since 0-atom concentration decays to zero, no explicit knowledge of $t_{2}$ is required to ovaluate the integral in equation (2). The values of $\left(\mathrm{CCl}_{4}\right)_{1}$ and $\left(\mathrm{CCl}_{4}\right)_{2}$ simply represent the concentrations of carbon tetrachloride at the inlet and that remaining after all atoms are consumed. The former and the latter were here referred to as the initial and the final concentrations respectively. The initial concentrations could be determined by blank experiments, while the final concentrations were determined by measuring the unreacted carbon tetrachloride. The measurements of carbon tetrachloride were made by a P-V method which was found to agree with the gravimetric determination. Excollent mass balances were also obtained, as will be shown later. For groator accuracy and convenience in the measurement of the final concentration of carbon tetrachloride, the values of $\left(\mathrm{CCl}_{4}\right)_{2}$ were obtained by subtracting the amount of the total product from the initial concentration of carbon tetrachloride. This method was found to be more reliablo than measuring the unconsumed reactant directly. The O-atom concentrations were measured 
photometrically in the manner suggested by Kaufman (13). Since the trace of No, formed from the nitrogen impurity in the oxygen discharge, provides sufficient light intensity for accurate phototube readings, measurements carried out in the present work were made without further addition of No except in experiments in which the effect of NO on the reaction was tested. A IP2l photomultiplier tube was used in conjunction with an Eldorado PH2OO electronic unit which amplified the photocurrent and registered it on a meter. The phototube housing was mounted on rails and could be moved parallel to the reaction veseel. A collimating slit was used to limit detection of light from a 2-mm section of the reaction tube. Since the reaction of 0-atoms with carbon tetrachloride proceeds without any visible reaction flame, no filter was required. To convert the relative photometer readings to absolute atom concentrations, the atom concentration at the inlet $J_{2}$ was determined chemically by ' $\mathrm{NO}_{2}$-clean-up' technique as described previously. This value was set oqual to the maximum phototube reading obtained, and the other 0-atom concentrations arrived at by proportion. The integral on the right-hand side of oquation (2) was then ovaluated graphically by measuring the area under the decay curve of a plot of 0-atom concentration versus time. Since all the parameters in this equation are known, the rate constant $k_{1}$ can be obtained. In order to obtain detailed information regarding the kinetics of the reaction, it was studied at various 
reactant concentration ratios, temperatures and total

pressures. Results will be shown in the later section.

MEASUREMENT OF THE RATES OF THE OVERALL

DISAPPEARANCE OF THE O-ATOMS

It is well known that secondary reactions play an important role in the gas phase reactions. The initial reaction products may react with other active species in the system to complicate the overall course of the reaction. It is therefore of interest to investigate the overall reaction rate of the active centres, in the hope of shedding light on the mechanism of the reaction. Because of the complex nature of the overall processes, results may not give accurate quantitative information, but qualitative trends may still provide valuable information. The overall reaction of 0-atoms with carbon tetrachloride can be represented schematically as follows:

$$
\begin{aligned}
& 0+\mathrm{COl}_{4} \stackrel{\mathrm{k}_{1}}{\longrightarrow} \mathrm{P}_{1}+\mathrm{P}_{2}+\ldots . \\
& 0+\mathrm{P}_{1} \stackrel{\mathrm{k}_{2}}{\longrightarrow} \mathrm{P}_{1}^{\prime}+\ldots \ldots \\
& 0+\mathrm{P}_{2} \stackrel{\mathrm{k}_{3}}{\longrightarrow} \mathrm{P}_{1}^{\prime \prime}+\ldots \ldots \\
& 0+\mathrm{x} \longrightarrow \text { ? etc. }
\end{aligned}
$$

If 0 -atoms are consumed mainly as the result of reaction with carbon tetrachloride by processes which are first order in 0-atoms, such as those indicated in the scheme above, the overall reaction rate for the first order disappearance of 0-atoms can be represented by 


$$
-\frac{d(0)}{d t}=k_{0}(0)\left(\operatorname{col}_{4}\right)
$$

where $k_{0}$ is the overall rate constant of the reaction, which Is a complex function of all relevant rate constants. Since the reaction of 0 -atoms with carbon tetrachloride is very slow, at relatively high initial concentrations of carbon tetrachloride, the change in concentration of carbon tetrachloride with time is negligibly small. Consequently, under these conditions, the concentration of carbon tetrachloride is practically constant during the course of reaction. Integration of equation (3) between limits of $(0)=(0)_{0}$ at $t=0$, and $(0)=(0)_{t}$ at $t=t$, gives

$$
\ln \frac{(0)_{0}}{(0)_{t}}=k_{0}\left(\operatorname{col}_{4}\right) t
$$

where $(0)_{0}$ and $(0)_{t}$ are the initial concentration and the concentration at time $t$ respectively. A plot of $\log \frac{(0)_{0}}{(0)_{t}}$ againgt $t$ should be linear if the first order decay of o-atoms in the reaction is prodominant. The slope of the curve is then equal to $\mathrm{k}_{0}\left(\mathrm{COl}_{4}\right)$. If $\left(\mathrm{COl}_{4}\right)$ is put equal to the initial concentration of carbon tetrachloride, $k_{0}$ can be calculated.

\section{The 0-atom profiles in the oxygen discharge} systems were measured in the manner described in the foregoing section. In the oxygen-free system, a slight excess of nitric oxide was admitted into tho roaction system in order to produce chemiluminescence for the photometric measurement of 0-atoms. Since excess NO will also consume 
O-atoms through the processes

$$
\begin{aligned}
& \mathrm{O}+\mathrm{NO}+\mathrm{M} \rightarrow \mathrm{NO}_{2}+\mathrm{M} \\
& \text { and } \quad \mathrm{NO}_{2}+\mathrm{O} \rightarrow \mathrm{NO}+\mathrm{O}_{2}
\end{aligned}
$$

a high value for $k_{0}$ will be obtained. An approximate method was adopted to correct for this effect. The method involves adding known quantities of No to the system and measuring the effective $k_{0}^{\prime}$. The true value of $k_{0}$ was then estimated by extrapolation. Since equation (4) is a typical first order equation, only relative atom concentrations were required to evaluate $k_{0}$.

It should be noted that the natural decay of oxygen atoms through recombination proceeds with a significant rate. In addition to this, the rates of reactions

$$
\begin{aligned}
& 0+\mathrm{O}_{2}+\mathrm{M} \rightarrow \mathrm{O}_{3}+\mathrm{M} \\
& \mathrm{O}+\mathrm{O}+\mathrm{M} \rightarrow \mathrm{O}_{2}+\mathrm{M}
\end{aligned}
$$

In the presence of carbon tetrachloride and the products resulting from the reaction of oxygen atoms with carbon tetrachloride, which may serve as a third body for the above reactions, are virtually unknown. Hence, the overall reaction rate constant determined by the present method is only an approximate indication of the rate of disappearance of the oxygen atoms.

$$
\text { Some of the typical overall first order decay }
$$
curves are shown in Fig. 5. The reasonably linear plots of these graphs indicate that first order decay processes of 
Figure 5

FIRST ORDER PLOT OF THE OVERALL O-ATOM DECAY

IN THE PRESENCE OF CARBON TETRACHLORIDE 


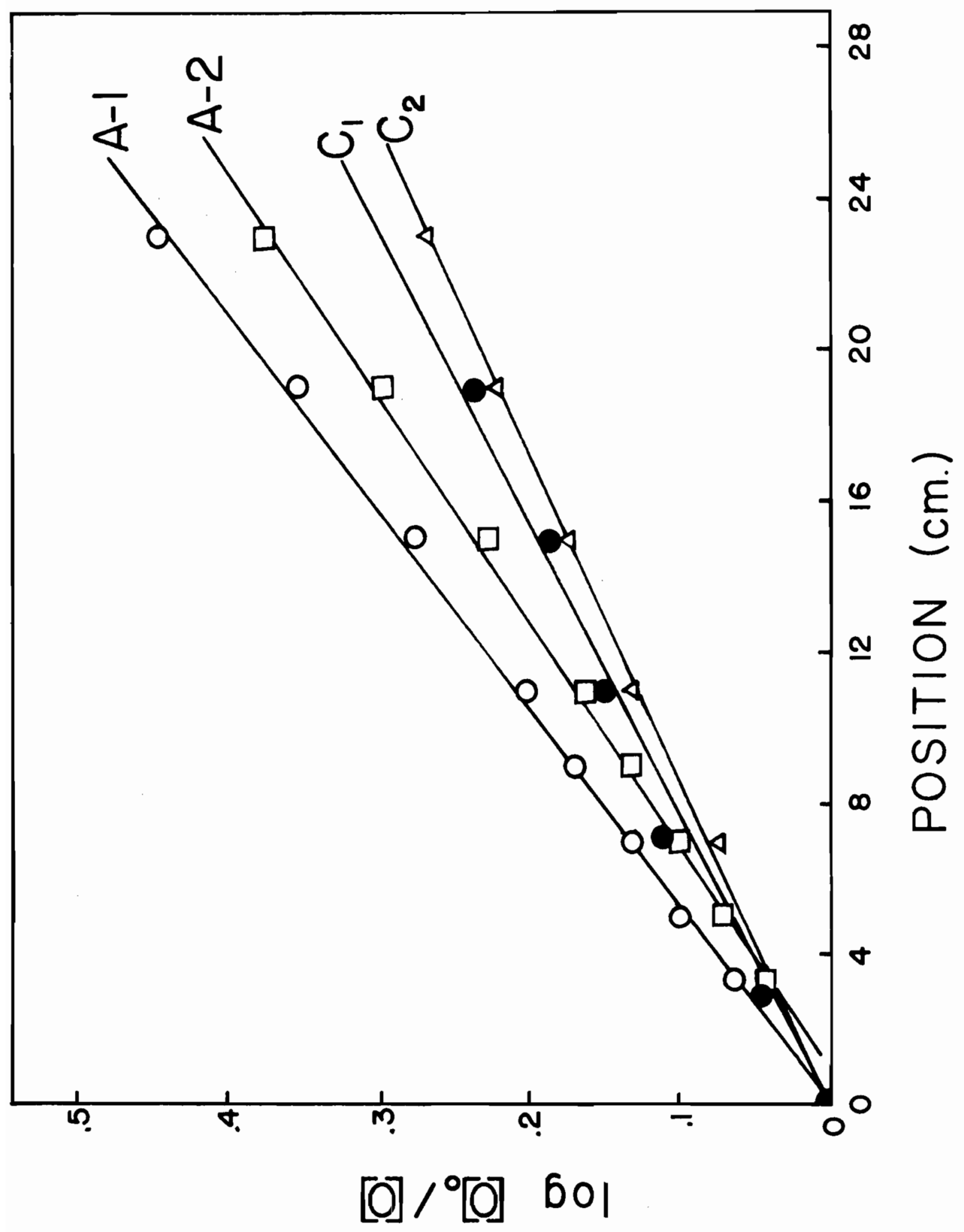


the oxygen atoms are predominant in this reaction system. The rate constants obtained over various conditions are given in Table I. Experiments from $A$ to $D$ series were performed in the oxygen-containing system, while experiments in E series were performed in the oxygen-free system. It should be noted that the rate constants obtained in experiments E-1 and E-2 have been corrected for the excess of nitric oxide added to the reaction.

MEASUREMENT OF THE HEAT OF REACTION

For an exothermic reaction, heat is generated during the course of reaction, if the heat of reaction is not removed sufficiently rapidly by collisions with the walls of the reaction vessel, the temperature of the gas stream could be elevated. Such a rise in temperature could conceivably affect the rate of reaction and yield a high value for the measured rate constant. This is particularly true when the reaction under study has a high activation energy, as was found to be the case in the present reaction. According to thermodynamic data (soe Appendix A), the reaction of oxygen atoms with carbon tetrachloride is quite exothermic. For this reason, the experiments were performed with low concentrations of both reactants.

The rise in temperature resulting from the heat of reaction was measured by a thermocouple placed in a well which was introduced from the bottom of the reaction tube into the reaction zone. This well was constructed from a length of $3 \mathrm{~mm}$ O.D. Pyrex glass tubing, with the upper end 


\section{TABIEI}

\section{RATES OF THE OVERALL DISAPPEARANCE OF O-ATOMS}

\begin{tabular}{|c|c|c|c|c|}
\hline $\begin{array}{l}\text { Experi- } \\
\text { mental } \\
\text { No. }\end{array}$ & $\begin{array}{l}\text { Tempera- } \\
\text { ture } \\
\text { oc }\end{array}$ & $\begin{array}{l}\text { Pressure } \\
\text { mm Hg }\end{array}$ & $\begin{array}{l}\left(\mathrm{ccl}_{4}\right)_{0} \times 10^{-15} \\
\text { molecules cc-1 }\end{array}$ & $\begin{array}{c}k_{\circ} \times 10^{15} \\
\text { cc molecules } \\
-1 \sec ^{-1}\end{array}$ \\
\hline$A-1$ & 10 & 4.2 & 3.26 & 1.86 \\
\hline 2 & 10 & 4.2 & 2.17 & 2.51 \\
\hline B-1 & 100 & 2.2 & 4.22 & 0.82 \\
\hline 2 & 100 & 2.2 & 3.30 & 0.98 \\
\hline$c-1$ & 4 & 2.2 & 5.95 & 0.46 \\
\hline 2 & 4 & 2.2 & 4.67 & 0.42 \\
\hline D-1 & 19 & 3.0 & 5.50 & 0.92 \\
\hline 2 & 19 & 3.0 & 3.90 & 1.01 \\
\hline$* \mathrm{E}-1$ & 19 & 3.0 & 6.21 & 0.10 \\
\hline 2 & 19 & 3.0 & 4.27 & 0.14 \\
\hline
\end{tabular}

* This series of experiments was carried out in the oxygen-free system. 
closed and the lower end ring-sealed to a $34 / 45$ tapered joint which could be attached to the botton of the reaction tube. The top of this well extended to a few millimeters below the $\mathrm{CCl}_{4}$ inlet jets. Through the glass tubing, a calibrated Chromel-Alumel thermocouple could bo freely moved along the reaction tube. This offered a means of measuring the temperatures of the gas stream at the centre of the reaction zone as a function of the distance from the mixing jets $\mathrm{J}_{2}$. The presence of the thermocouple well in the reaction zone resulted in a small decrease in oxygen atom concentration due to wall recombination, but was found to have a negligible effect on the flow condition.

Experiments were performed at a pressure of about $2 \mathrm{~mm} \mathrm{Hg}$. The temperature was measured under the following conditions:

(1) $\mathrm{O}_{2}$ flow $55 \mu$ moles per second

(2) $\mathrm{O}_{2}$ flow $55 \mu$ moles per second o-atom flow l llmole per second

(3) $\mathrm{O}_{2}$ flow $55 \mu$ moles per second o-atom flow $1 / l$ mole per second $\mathrm{COI}_{4}$ flow $4 \mu$ moles per second.

The temperatures measured as a function of the distance from $\mathrm{CCl}_{4}$ inlet jets are shown graphically in Fig. 6 . It is found that the maximum temperature increase in the reaction is about $1.5^{\circ} \mathrm{C}$. Regarding the shapes of the curves shown in Fig. 6, it seems quite possible that the temperatures regietered for curve 3 might include part of the heat due to 
Figure 6

\section{TEMPERATURE PROFILE OF REACTION TUBE}

UNDER THE FOLLOWING CONDITIONS

(1) $\mathrm{O}_{2}$ flow $55 \mu$ moles/sec.

(2) $\mathrm{O}_{2}$ flow $55 \mu$ moles/sec. o-atom flow $1 / \mu$ mole/sec.

(3) $\mathrm{O}_{2}$ flow $55 \mu$ moles/sec. 0-atom flow $1 /$ mole/sec. $\mathrm{CCl}_{4}$ flow $4 \mu$ moles/sec. 
the recombination of oxygen atoms on the surface of the glass which surrounded the thermocouple. Furthermore, it should be noted that the temperature recorded is the temperature in the centre of the reaction tube. The temperature would expect to be lower near the walls of the reaction vessel. Therefore, the actual temperature rise resulting from the heat of reaction should be considerably lower than $1.5^{\circ} \mathrm{C}$. 


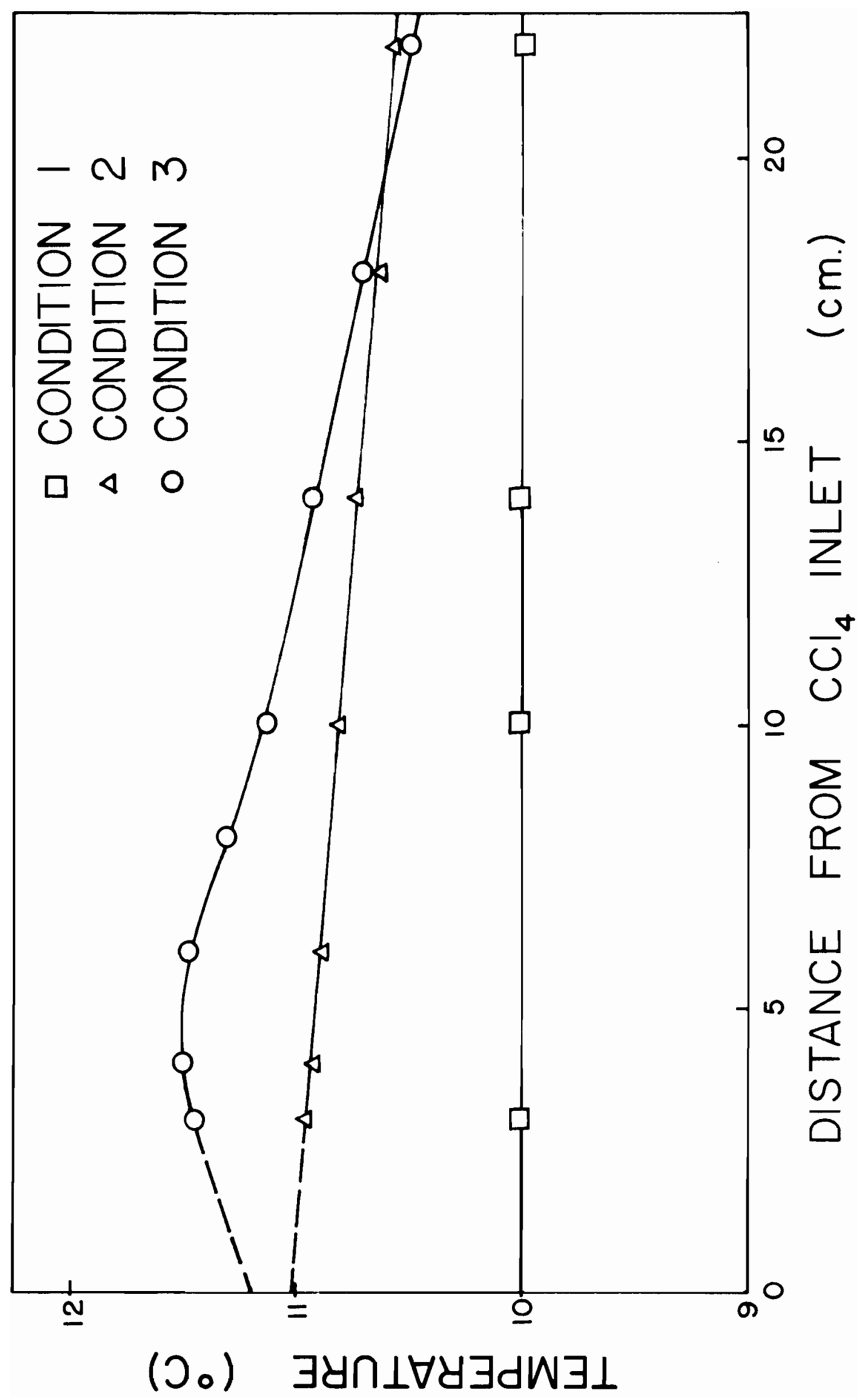




\section{RESULTS AND DISCUSSION}

\section{THE RECOMBINATION OF OXYGEN ATOMS}

Preliminary experiments have shown that the natural decay of oxygen atoms was slow under the normal pumping conditions, and the concentration changes along the reaction tube were thus small. In order to increase the accuracy of the measurements, the flow rates were reduced by placing a constriction in front of the pump.

In the first series of experiments, the decay of oxygen atoms was followed by two different techniques, namely, the ' $\mathrm{NO}_{2}$-clean-up' method and the photometric method. The ' $\mathrm{NO}_{2}$-clean-up' method, which involves the use of the movable jet, measures the absolute atom concentration changes, whereas the photometric method measures only the relative concentration of the atoms. The measurements were carried out at $10^{\circ} \mathrm{C}$ and at a pressure of $2 \mathrm{~mm} \mathrm{Hg}$. An arbitrary zero was chosen at a position five centimeters below the top of the reaction tube, and the decay of the oxygen atoms was determined as a function of distance down stream along the reaction vessel. The data recorded in the typical experiments are given in Table II (Experimental series F). The first column indicates the distance from the arbitrary zero in centimeters. For purposes of comparison, the readings were normalized to one at the zero position and are shown in the third and fifth columns for the results obtained by the photometric method and by the ' $\mathrm{NO}_{2}-\mathrm{clean-up'}$ method respectively. 
TABLE II

EXPERIMENTAL SERIES F

$o_{2}$ flow $\quad-55.5 \mu$ moles sec -1

Total pressure $-2.0 \mathrm{~mm} \mathrm{Hg}$

Temperature $\quad-10^{\circ} \mathrm{C}$

Photometric

Reading

Position Arbitrary

cm

0
2
3
5
7
9

11

13

15

19

23

25
Unit

40.0

39.2

38.5

37.5

36.0

35.0

33.7

32.8

31.6

$29 \cdot 3$

$27 \cdot 3$

$-$

Normalized $\mathrm{NO}_{2}^{-O l e a n u p}$
Reading Nmoles sec

Normalized

Reading

1

.980

.962

.938

.866

.928

.900

.830

.890

.875

.840

.780

.836

.820

.790

.730

.782

.733

.690

.740

.683

-

.615

.66 
The typical first order oxygen atom decay curvo obtained from this series of experiments is shown in Fig. 7 , where the open circles represent the results obtained by the photometric method and the closed circles by the ' $\mathrm{NO}_{2}$-cleanup' method. The graph shows that a single straight line can be drawn through all these circles. This indicates that these two methods are in mutual agreement.

The use of the movable jet technique for determining the atom concentrations along the tube was considered justifiable for the following reasons:

The jet was introduced into the reaction zone through the bottom of the reaction vessel. Under the 'clean-up' condition, the reaction is essentially comploted at the top of the jet. Therefore no significant amounts of atoms would be consumed through recombination on the surface due to the presence of the jet. The effect on the flow conditions, due to the introduction of the small diameter glass tubing associated with the jet into the reaction vessel, is negligibly small, as indicated by the constancies of the total pressure and the total flow in the system in the presence or absence of the jet. It was also observed that the 'air afterglow' was uniform and well-defined in the reaction region. This suggests that mixing was adequate and that the flow was largely annular.

The decay of the oxygen atoms was studied over a range of pressures to separate the contribution from the hoterogeneous and gas-phase decays. Experiments were 
Figure 7

FIRST ORDER PLOT OF OXYGEN ATOM DECAY

MEASURED BY TWO DIFFERENT METHODS

Experimental Series $F$

Open circles 0 - Photometric Method

Closed circles - $\mathrm{NO}_{2}$-clean-up Method 


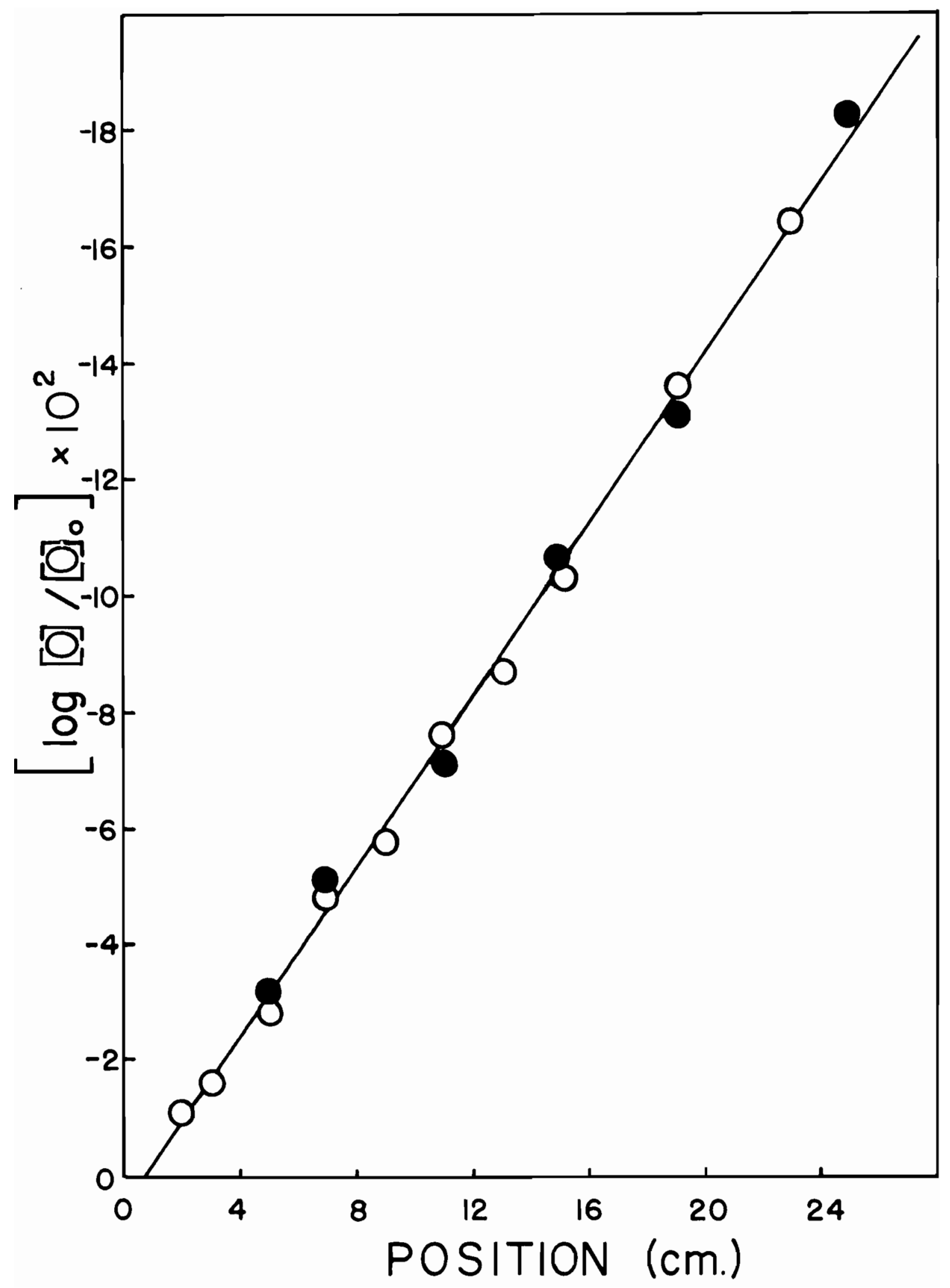


carried out at two different temperatures, $10^{\circ}$ and $100^{\circ} \mathrm{C}$. since series $F$ showed that oxygen atoms could be measured equally well by both the ' $\mathrm{NO}_{2}-c l e a n-u p '$ and the photometric method, the latter method alone was used in this series of experiments. Results obtained are formulated in Table III (Experimental Series G) and Table IV (Experimental Series H). Some of the typical decay curves are given in Fig. 8. The values of $k_{0}$ shown in the last column in both Table III and Table IV were the slopes of the corresponding first order plots.

Similar plots were obtained by Elias, Ogryzlo and Schiff(15) who concluded that the overall decay is first order with respect to the oxygen atoms and that the following mechanism was consistent with their results

$$
\begin{aligned}
& 0+\text { wall } \rightarrow \frac{1}{2} \mathrm{O}_{2}+\text { wall } \\
& 0+\mathrm{O}_{2}+\mathrm{M} \rightarrow \mathrm{O}_{3}+\mathrm{M} \\
& 0+\mathrm{O}_{3} \rightarrow 2 \mathrm{O}_{3}
\end{aligned}
$$

where $M$ is any third body. Recently, Linnett et al. studied the oxygen atom recombination with the experimental methods similar to those described by Elias, Ogryzlo and Schiff $(15)$ and reported that the decay process was firat order in oxygen atoms, but second order in molecular oxygen. This is essentially the same conclusion drawn by schiff et al. If $M$ is put equal to $\mathrm{O}_{2}$.

This mechanism gives the rate of recombination of

atoms:

$$
-\frac{d(0)}{d t}=k_{1}(0)(w)+k_{2}(0)\left(O_{2}\right)(M)+k_{3}(0)\left(O_{3}\right) \ldots
$$


TABLE III

\section{RATES OF THE NATURAL DECAY OF O-ATOMS \\ EXPERINENTAL SERIES G \\ Temperature $-10^{\circ} \mathrm{C}$}

\begin{tabular}{|c|c|c|c|c|}
\hline $\begin{array}{c}\text { Experimental } \\
\text { No. }\end{array}$ & $\begin{array}{c}\mathrm{O}_{2} \text { flow } \\
\mu \text { moles sec }\end{array}$ & $\begin{array}{l}\left(\mathrm{O}_{2}\right) \times 10^{7} \\
\text { moles ce-1 }\end{array}$ & $\begin{array}{l}\left(\mathrm{O}_{2}\right)^{2} \times 10^{14} \\
\operatorname{moles} \mathrm{cc}^{-2}\end{array}$ & $\begin{array}{l}k_{0} \\
s e c^{-1}\end{array}$ \\
\hline G-1 & 172.0 & 2.32 & $5 \cdot 38$ & 4.08 \\
\hline 2 & 143.5 & 2.04 & 4.16 & 3.47 \\
\hline 3 & 116.0 & 1.78 & 3.18 & 2.83 \\
\hline 4 & 78.5 & 1.39 & 1.93 & 1.88 \\
\hline 5 & $55 \cdot 5$ & 1.14 & 1.30 & 1.65 \\
\hline 6 & $22 \cdot 3$ & .736 & 0.54 & 0.74 \\
\hline
\end{tabular}

TABLE IV

RATES OF THE NATURAL DECAY OF O-ATOMS

EXPERIMENTAL SERIES H

Temperature $-100^{\circ} \mathrm{C}$

\begin{tabular}{|c|c|c|c|c|}
\hline $\begin{array}{c}\text { Experimental } \\
\text { No. }\end{array}$ & $\begin{array}{c}\mathrm{O}_{2} \text { flow } \\
\mu \text { moles } \sec ^{-1}\end{array}$ & $\begin{array}{l}\left(\mathrm{O}_{2}\right) \times 10^{7} \\
\text { moles } \mathrm{cc}^{-1}\end{array}$ & $\begin{array}{l}\left(\mathrm{O}_{2}\right)^{2} \times 10^{14} \\
\text { moles } \mathrm{cs}^{-2}\end{array}$ & $k_{0}$ \\
\hline $\mathrm{H}-1$ & 180.5 & 1.86 & 3.44 & 3.87 \\
\hline 2 & 157.0 & 1.68 & 2.80 & 3.69 \\
\hline 3 & 116.2 & 1.38 & 1.89 & 3.37 \\
\hline 4 & 94.0 & 1.19 & 1.43 & 3.00 \\
\hline
\end{tabular}


Figure 8

FIRST ORDER PLOT OF THE OXYGEN ATOM DECAY

Experimental Series $G$

$\log \frac{(0)}{(0)_{0}}$ va. Position 


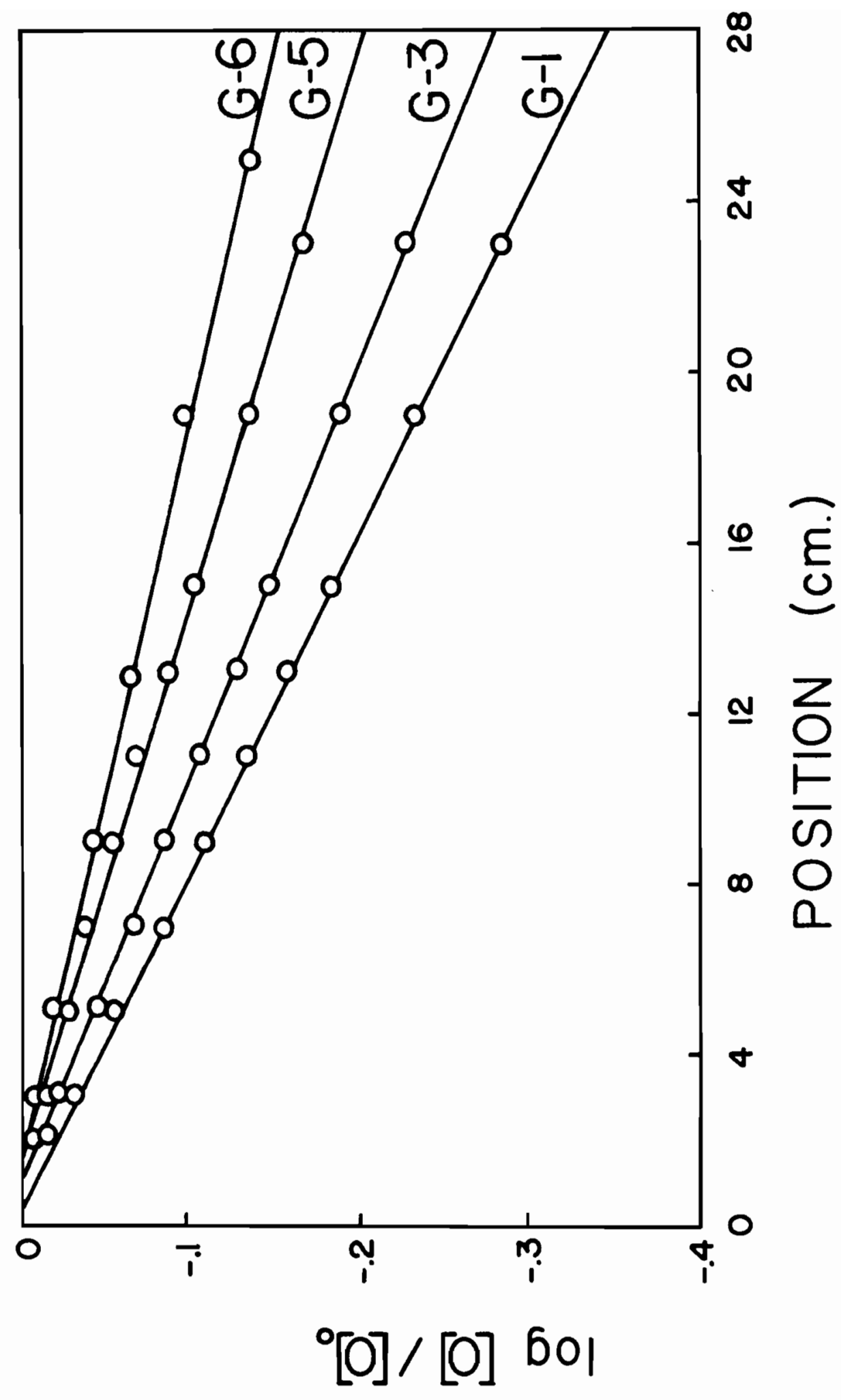


If a steady state concentration for $\left(\mathrm{O}_{3}\right)$ is assumed:

$$
\frac{d\left(O_{3}\right)}{d t}=k_{2}(O)\left(O_{2}\right)(M)-k_{3}(0)\left(O_{3}\right)=0 \ldots \ldots
$$

If equation (2) is substituted into equation (1), the following equation results:

$$
-\frac{d(0)}{d t}=k_{1}(0)(W)+2 k_{2}(0)\left(O_{2}\right)(M) \ldots \ldots \ldots \ldots
$$

Equation (3) can be rearranged and integrated between limits of $(0)=(0)$ at $t=0$, and $(0)=(0)$ at $t=t$.

The resulting equation is

$$
\begin{aligned}
& \frac{1}{t} \ln \frac{(0)_{0}}{(0)}=k_{1} W+2 k_{2}\left(O_{2}\right)(M) \ldots \ldots \ldots \ldots \ldots \ldots \ldots \ldots \ldots \ldots \\
& \text { As shown by schiff et al. }(15) \text {, if the mechanism }
\end{aligned}
$$
proposed for the decay process is valid, a plot of the lefthand side of equation (4) against the $\left(\mathrm{O}_{2}\right)(\mathrm{M})$ should yield a atraight line with intercept equal to $k_{1} W$ (the rate constant for oxygen atom decay on the walls of the reaction vessel, and hereafter referred to as $\mathrm{k}_{1}$ for simplicity), and with the slope equal to $2 \mathrm{k}_{2}$.

$$
\text { since the left-hand aide of oquation (4) is the }
$$

measured overali rate constant, equation (4) can be written 28

$$
k_{0}=k_{1}+2 k_{2}\left(o_{2}\right)(M) \ldots \ldots \ldots \ldots \ldots \ldots
$$

In the present experiments, $N$ was assumed to be $O_{2}$. The values for $k_{0}$, shown in Tables III and IV are plotted against $\left(\mathrm{O}_{2}\right)^{2}$ in Fig. 9. Reasonable straight lines were obtained for both temperatures. 
Figure?

Exporimental series $G$ and $H$

$k_{0}$ As a FUNCTION OF $\left(\mathrm{O}_{2}\right)^{2}$ 


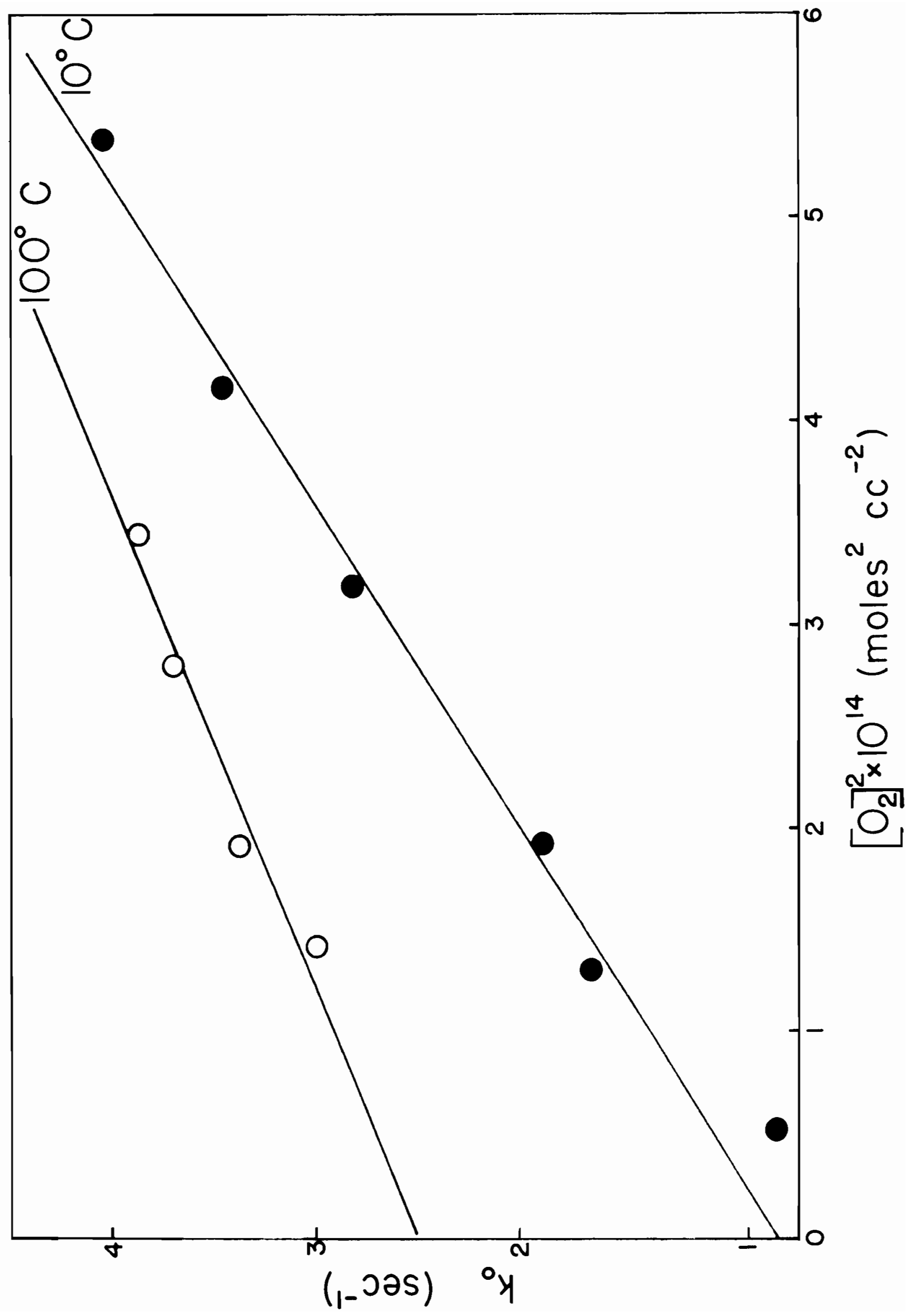


The rate constants obtained from these plots are:

From Experimental Series G

$$
\begin{aligned}
& k_{1}=0.7 \mathrm{sec}^{-1} \\
& k_{2}=0.32 \times 10^{14} \mathrm{cc}^{2} \mathrm{~mole}^{-2} \mathrm{sec}^{-1}
\end{aligned}
$$

From Experimental Series

$$
\begin{aligned}
& k_{1}=2.5 \mathrm{sec} \\
& k_{2}=0.21 \times 10^{14} \mathrm{cc}^{2} \mathrm{~mole}-2 \mathrm{sec}^{-1}
\end{aligned}
$$

The surface recombination coefficient on Pyrex can be calculated from $k_{1}$. The following relationship is obtained from kinetic theory:

$$
r=\frac{2 k_{1} r}{\bar{c}}=\frac{2 k_{1} r}{\sqrt{\frac{8 R T}{\pi M}}}
$$

where

$$
\begin{aligned}
& k_{1}=\text { wall decay rate constant } \\
& r=\text { radius of the reaction tube (1.3 cm) } \\
& R=\text { gas constant }\left(8.314 \times 10^{7}\right. \text { ergs per degree per mole) } \\
& T=\text { absolute temperature } \\
& M=\text { molecular weight of oxygen atom } \\
& \bar{C}=\text { average velocity of oxygen atoms }
\end{aligned}
$$

The surface recombination coefficients calculated in this manner were found to be $0.30 \times 10^{-4}$ at $10^{\circ} \mathrm{C}$ and $0.93 \times 10^{-4}$ at $100^{\circ} \mathrm{C}$.

The surface recombination coefficient has been measured by a number of workers by various methods. The present results can be compared with the value of $1.2 \times 10^{-4}$ obtainod by Linnett and Maraden(12); $0.2 \times 10^{-4}$ by 
Kaufman (13), and $0.77 \times 10^{-4}$ by Elias, Ogryzlo and Schiff(15). Kiotiakowski and Volpi $(17)$ deduced a minimum value of $2 \times 10^{-4}$ from indirect measurements of nitrogen atom reactions. Herron and schiff(14) reported a value of $1.1 \times 10^{-4}$ based on the asumption that all recombinations occur on the walls only, and their figure therefore represents an upper limit. All these values for $Y$ were presumably determined at room temperature. However, the value reported by Harteck and Dondes $(83)$ from the study of docomposition of ozone on glass wool is completely out of line with other results. The value of $Y$ at $100^{\circ} \mathrm{C}$ was found to be $0.93 \times 10^{-4}$ in the present work, while Harteck and Dondes found this value to be 0.1 at the same temperature. Based on their results, Greaves and Linnett $(84)$ have concluded that the figure obtained by Harteck and Dondes was an imposible one. The values of $\mathrm{k}_{2}$ obtained in the present work are in agreement with the value of $0.79 \times 10^{14} \mathrm{cc}^{2} \mathrm{~mole}^{-2} \mathrm{sec}^{-1}$ obtained by Benson and Axworthy (10) from the study of the thermal decomposition of ozone, but is slightly lower than that of $1.0 \times 10^{14} \mathrm{cc}^{2}$ mole $\mathrm{sec}^{-1}$ obtained by Elias, Ogryzlo and Schiff(15) and that of $2 \times 10^{14} \mathrm{cc}^{2} \mathrm{~mole}^{-1} \mathrm{sec}^{-1}$ reported by Kaufman (13). It is surprising that the recent result of Linnett et al. (82), using experimental methods essentially the same as those used by Elias, Ogryzlo and schiff(15) gave a value of $4.6 \times 10^{14} \mathrm{cc}^{2}$ mole $e^{-2} \sec ^{-1}$ for $k_{2}$. Moreover, if this value is corrected for diffusion, it becomes $6.0 \times 10^{14} \mathrm{cc}^{2}$ mole $e^{-2} \mathrm{sec}^{-1}$. No explanation was 
given by these authors to account for the difference in their result from those of other workers.

In the present work, reaction 2 was found to have a negative temperature coefficient. A value of $-0.50 \pm .15 \mathrm{Kcal}$ per mole was obtained for the Arrhenius activation onergy of the process. This figure is in good accord with the value of $-0.6 \mathrm{Kcal}$ per mole obtained by Benson and Axworthy (10) from the study of the thermal decomposition of ozone, and with the value of $-0.7 \mathrm{Kcal}$ per mole reported by Schiff et al. (15) from the otudy of atom recombination by means of an isothermal calorimetric detector technique.

An inspection of Fig. 9 shows that the wall recombination process is also temperature dependent. This suggests that the surface activity of the Pyrex in the recombination process increases three-fold in the temperature range from $10^{\circ}$ to $100^{\circ} \mathrm{C}$. Elias, Ogryzlo and Schiff(15) have investigated the effect of temperature on the rate of oxygen atom recombination at two temperatures, $20^{\circ}$ and $-60^{\circ} \mathrm{O}$. They concluded that the temperature coefficient for both the overall gas phase recombination and wall recombination is zero. However, it is doubtful whether the assumption of a steady-state ozone concentration, on which the evaluation of the rate constants was based, is justified at a temperature of $-60^{\circ} \mathrm{C}$. In the study of oxygen atom recombination at low pressures with the side-arm technique, Linnott and Marsien (12), using a catalytic probe for atom measurements, reported that the rate of the atom recombination increases only slightly 
between temperatures ranging from $20^{\circ}$ to $400^{\circ} \mathrm{C}$. However, in the study of recombination of oxygen atoms on silica, Greaves and Linnett $(82)$ have found that the surface activity increases about eighty times from temperatures $20^{\circ}$ to $600^{\circ} \mathrm{O}$. By using a simple equation

$$
r=r_{0} e^{-E / R T}
$$

tho validity of which is open to question, the 'activation energy' was found to be about I Kcal per mole at room temperatures, which increases to $13 \mathrm{Kcal}$ per mole at about $300^{\circ} \mathrm{C}$ but decreases thereafter at about $400^{\circ} \mathrm{C}$. Therefore, it was concluded that there is no single activation energy for the process. Similar results were also obtained by Lavrovakaya and Voevodskii (85) from observations of the temperature rise of a silica-cated probe. They reported a value of $6.5 \mathrm{kcal}$ per mole for the 'activation energy' for temperatures in the range of $30^{\circ}$ to $270^{\circ} \mathrm{C}$. If equation (7) is applied to the present results, a value of about $1.3 \mathrm{Kcal}$ per mole can be assigned for the 'activation energy' at temperatures between $10^{\circ}$ and $100^{\circ} \mathrm{C}$ for the process. In viow of all these evidences, it seems reasonable to believe that the Pyrex surface recombination would have a considerable temperature coefficient. However, in the study of the reaction of oxygen atoms with carbon monoxide, Avramenko(11) found the yields of carbon dioxide to docrease with increasing temperatures. The author attributed this effect to the higher temperature recombination coefficient 
of oxygen atoms on the walls of the reaction vessel, as compared with the temperature coefficient of the reaction of oxygen atoms with carbon monoxide in the gas phase. This implies that the activation energy for the surface recombination process is considerable.

A new treatment for the evaluation of $k_{1}$ and $k_{2}$ has recently been suggested by Linnett et al. (82). The mothod involves the correction of the axial diffusion in the flow system for the evaluation of the rate constants. The theoretical model employed by the authors assumes onedimensional flow and includes axial diffusion, but neglects radial diffusion. For a first order reaction, the equation of continuity for the reacting species in a steady state is

$$
-D \frac{d^{2} n}{d x^{2}}+\nabla_{0} \frac{d n}{d x}+k_{0} n=0
$$

where $D=$ the binary diffusion coefficient

$$
\begin{aligned}
V_{0} & =\text { the linear flow velocity } \\
n & =\text { concentration of the reactive species } \\
k_{0} & =\text { rate constant for the reaction. }
\end{aligned}
$$

Neglecting the small change in $V_{0}$ due to the reaction and subject to boundary conditions

$$
n=0 \text { at } x=x, n=n_{0} \text { at } x=0
$$

the solution of equation (8) is

$$
n=n_{0} e^{-k x / v_{0}} \ldots \ldots \ldots \ldots \ldots \ldots
$$

where

$$
k_{0}=k\left(1+k D / v_{0}^{2}\right)
$$

Obviously, when the value of $\mathrm{kD} / \mathrm{V}_{0} 2$ becomes much less 
than 1, equation (10) is reduced to

$$
k_{0}=k
$$

where $k$ is the rate constant of the reaction without the diffusion correction. It was claimed that this treatment describes the experimental situation more adequately. The experimental results obtained in Experimental

Series $G$ were subjected to this correction. A value of $D=2.69 \times 10^{2 / P},(P=$ pressure in $\mathrm{mm} \mathrm{Hg})$ which was estimated theoretically by Andrussov (86), was used. The corrected date are shown in Table V. A plot of $k_{0}$ versus $\left(\mathrm{O}_{2}\right)^{2}$ is given in Fig. 10. The intercept of the graph gives a value of $0.63 \mathrm{sec}^{-1}$ for $k_{1}$. This, in turn, corresponds to a value of $0.27 \times 10^{-4}$ for the surface recombination coefficient. The slope of the curve yields a value of $0.34 \times 10^{-14} \mathrm{cc}^{2} \operatorname{mole}^{-2} \mathrm{sec}^{-1}$ for $\mathrm{k}_{2}$. However, these results are well within the experimental error of the values $0.30 \times 10^{-4}$ for $Y$ and $0.32 \times 10^{14} \mathrm{cc}^{2}$ mole $\mathrm{sec}^{-1}$ for $k_{2}$ obtained without the diffusion correction. It appears that the axial diffusion is not an important effect under the present experimental conditions. The diffusion correction would be even smaller at higher linear flow velocities; hence, corrections were not made for results obtained in Experimental series $\mathrm{H}$, which were carried out at $100^{\circ} \mathrm{C}$. The rate constants in the foregoing discussion were evaluated with the assumption that the recombination of atoma by second order process is negligibly small in comparison with that by first order processes. However, 


\section{Table V}

EXPERIMENTAL SERIES G (WITH DIFFUSION CORRECTION)

Temperature $10^{\circ} \mathrm{C}$

\begin{tabular}{|c|c|c|c|c|}
\hline $\begin{array}{l}\text { Experi- } \\
\text { mental } \\
\text { No. }\end{array}$ & $\begin{array}{c}\mathrm{O}_{2} \text { flow } \\
\mu_{\mathrm{mole}} \mathrm{sec}^{-1}\end{array}$ & $\begin{array}{l}\left(\mathrm{O}_{2}\right)^{2} \times 10^{14} \\
\operatorname{moles} \mathrm{cc}^{-2}\end{array}$ & $\mathrm{kD} / \mathrm{Vo}^{2} \times 10^{2}$ & $k_{0} s \theta c^{-1}$ \\
\hline$G-1$ & 172.0 & $5 \cdot 38$ & 1.37 & 4.15 \\
\hline 2 & 143.5 & 4.16 & 1.47 & 3.53 \\
\hline 3 & 116.0 & 3.18 & 1.62 & 2.88 \\
\hline 4 & 78.5 & 1.93 & 1.85 & 1.91 \\
\hline 5 & 55.5 & 1.30 & 2.20 & 1.68 \\
\hline 6 & 22.3 & 0.54 & 4.70 & 0.78 \\
\hline
\end{tabular}


Figure 10

Experimontal Series $G$

$\mathrm{k}_{0}$ AS A FUNCTION OF $\left(\mathrm{O}_{2}\right)^{2}$

(with diffusion correction) 


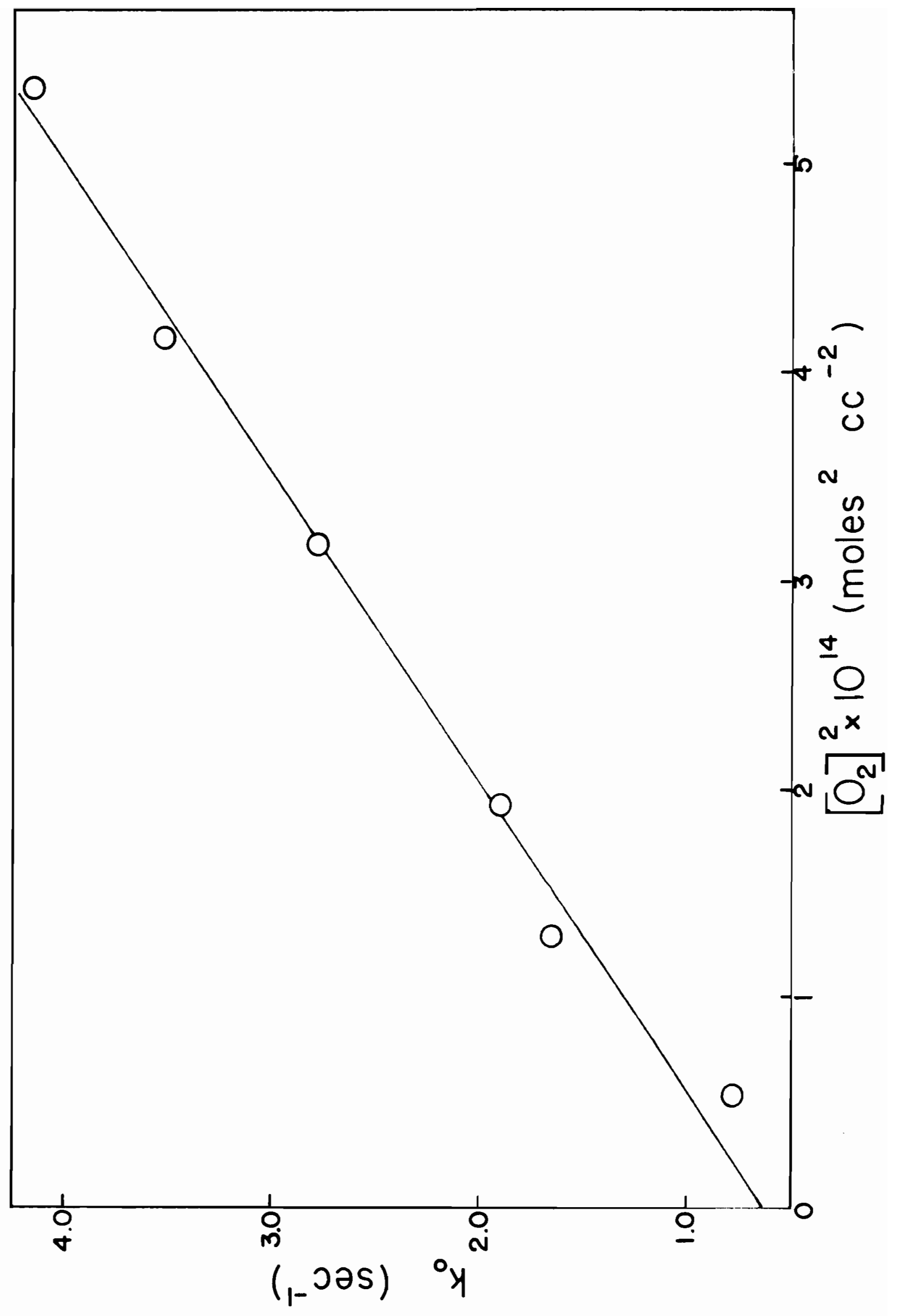


the rate constant of the reaction

$$
O+O+M \rightarrow O_{2}+M
$$

has been measured recently by several workers. Golden and Myerson (87) investigated this reaction in a static system and reported a value of $3 \times 10^{14} \mathrm{cc}^{2} \mathrm{~mole}^{-2} \mathrm{sec}^{-1}$ for $k_{4}$. Kretschmer and Peterson (88) in a somewhat similar experiment obtained an upper limit value of $2 \times 10^{14} \mathrm{cc}^{2} \mathrm{~mole}^{-2} \mathrm{sec}^{-1}$ for the rate constant of the reaction. Harteck et al. (89) have studied reaction (4) in a flow system with the oxygen atoms produced in a discharge through oxygen-argon mixtures. They found a value for $k_{4}$ of $1.0 \times 10^{15} \mathrm{cc}^{2} \mathrm{~mole}^{-2} \mathrm{sec}^{-1}$ at $300^{\circ} \mathrm{C}$. More recentiy, Morgan, Elias and Schiff $(16)$ measured the direct atom recombination in an oxygen-free system. They reported a value of $3.2 \times 10^{15} \mathrm{cc}^{2}$ mole sec ${ }^{-1}$ for the rate constant of the reaction. If one accepts these velues, then it follows that the oxygen atom decay through the second order process is significant in the present study.

$$
\text { If reaction (4) is included in the oxygen atom }
$$
recombination mechanism and $M$ is put equal to $O_{2}$, the overall rate of decay is

$$
-\frac{d(0)}{d t}=k_{1}(0)+k_{2}(0)\left(0_{2}\right)^{2}+k_{3}(0)\left(0_{3}\right)+2 k_{4}(0)^{2}\left(0_{2}\right) \ldots
$$

Assuming a steady state concentration for ozone, equation (12) becomes

$$
-\frac{d(0)}{d t}=k_{1}(0)+2\left\{k_{2}+k_{4} \frac{(0)}{\left(o_{2}\right)}\right\}(0)\left(o_{2}\right)^{2}
$$


This rate expression has the form equivalent to equation (3) which was obtained by assuming the rate of reaction (4) as insignificantly small. Thus $k_{2}$ in oquation (3) is not constant but can be written as $k_{2}^{\prime}$ where

$$
k_{2}^{\prime}=k_{2}+k_{4} \frac{(0)}{\left(0_{2}\right)}
$$

Here $k_{2}$ is the true rate constant, while $k_{2}^{\prime} i s$ the measured rate constant for reaction (2). Equation (14) indicates that $k_{2}^{\prime}$ depends on the ratio of $(0) /\left(\mathrm{O}_{2}\right)$. Consequently, this might account for the very large value reported by Linnett and co-workers (82). These authors obtained a very high dissociation of oxygen by introducing water vapour into the discharge but neglected diroct recombination by reaction (4). Variations in the value of $k_{2}$ reported in the literature by other workers might also be accountable by the differences in the percentage of atoms used in the investigations. The percentage of atoms used in the present work was very low (about $1.3 \%$ ). The rate constant of reaction (2) obtained, which is the lowest among values reported in the literature, is therefore likely to be more reliable. If the present measured $k_{2}^{\prime}$ is used, $0 /\left(\mathrm{O}_{2}\right)$ is put -qual to 0.013 , and Harteck's value is used for $k_{4}\left(1 \times 10^{15}\right.$ $c c^{2}$ mole $e^{-2} \sec ^{-1}$ ), the true $k_{2} \operatorname{con}$ be calculated to be $0.19 \times 10^{14} \mathrm{cc}^{2}$ mole $\mathrm{e}^{-2} \mathrm{sec}^{-1}$. However, if $\mathrm{k}_{4}$ obtained by schiff ot al. (16) is used, the true $k_{2}$ will have a negative value. This implies that either schiff's value is too high for $k_{4}$ or the present value is too low for $k_{2}^{\prime}$. In order to 
resolve this discrepancy, further work is required.

The rate of oxygen atom recombination through

reactions (2) and (3) relative to that through reaction

when $M=O_{2}$ is

$$
\frac{k_{2}\left(o_{2}\right)}{k_{4}(0)}
$$

If the above-mentioned values are used, the ratio in equation (15) is oqual to 1.43. The rate of atom decay through reaction (1) compared with that through reactions (2) and (3) can also be related in a similar way:

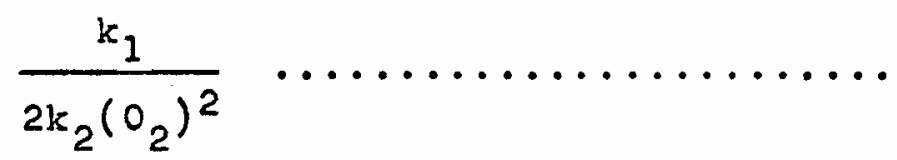

Using the present results, the ratio in equation (16) has a value of 1.42 for the oxygen pressure at about $2 \mathrm{~mm} \mathrm{Hg}$. A simple calculation shows that $22.5 \%$ of atoms would decay through the second order recombination process at $10^{\circ} \mathrm{C}$ in the present system. Of course this percentage would change olightly with pressure, as evident from equation (16). Elias, Ogryzlo and schiff $(15)$ compared the rates in a similar manner based on their results and concluded that, if $10 \%$ of the recombination had occurred by the second order process, curvature would have been found in the first order plots. Therefore, they deduced a maximum value of $4 \times 10^{14} \mathrm{cc}^{2}$ mole $e^{-2} \mathrm{sec}^{-1}$ for $k_{4}$. The upper limit value of $k_{4}$ reported by Kretschmer and Potersen (88) was determined by the some principle, nomely, determining the curvaturos of the first order plots. 
The effect of the second order process on the

overall atom decay may be realized more readily by constructing an ovorall rate oquation which includes reaction (4) in the atom decay mechanism and examining the sensitivity of the rate expression for the first order plot. Integration of equation (13) gives $-\frac{1}{t} \ln \frac{k_{1}+2 k_{2}\left(o_{2}\right)^{2}+2 k_{4}\left(o_{2}\right)(0)}{(0)}=k_{1}+2 k_{2}\left(o_{2}\right)^{2}+\frac{c}{t} \ldots$.

Here $C$ is an integration constant. This equation is equivalent to equation (4) which was generally used for the first order plots, providing that the sum of $\left[\mathrm{k}_{1}+2 \mathrm{k}_{2}\left(\mathrm{O}_{2}\right)^{2}+2 \mathrm{k}_{4}\left(\mathrm{O}_{2}\right)(\mathrm{O})\right]$ maintains relatively steady with the change of the oxygen atom concentration. It was found to be the case under the present experimental conditions. The characteristic of equation (17) leads to the conclusion that the usual firgt order plot is not sensitive enough to show the deviation due to the occurrence of the second order process under the usual experimental conditions. Therefore, it is obvious that the order of the decay process cannot be tested adequately by the first order plots and that $k_{4}$, estimated by determining the curvature of the first order plots, would be in error. THE REACTION OF OXYGEN ATOMS WITH CARBON

\section{TETRACHLORIDE}

The reactions of oxygen atoms with carbon tetrachloride were carried out in a flow system shown in Fig. 1. In order to maintain constant flow conditions, 
the concentrations of each reactant in the reaction system were kept relatively small in comparison with that of the carrier gas which was oxygen in the case of the oxygensystem, and nitrogen in the case of the oxygen-free system. The flow rates of the carrier gas were held constant for each series of experiments. The atom concentration measured by the 'NO${ }^{-c l e a n-u p ' ~ t e c h n i q u e ~ a t ~ t h e ~ o u t l e t ~ j e t s ~}$ $I_{2}$ was taken as the initial concentration of the oxygen atoms. This initial atom concentration was also kept constant throughout the entire series of experiments by maintaining constant discharge conditions (i.e. power, wave guide position, gas flow rate and pressure). Measuroments of the atom concentrations during the course of the series indicated that these conditions were fulfilled.

No visible reaction flame was ever observed to accompany the reaction under any of the experimental conditions tried in the present work. When the reaction was performed in the oxygen-free system, the 'air afterglow' was completely suppressod. Under theso conditions, any reaction flame should be easily identified, but none was observed. No appreciable amounts of products, which were liquid or solid at room temperature, were obtained from the reaction of oxygen atoms with carbon tetrachloride. This is evidenced by the observations that no deposits were ever seen on the walls of the reaction vessel or remaining in the traps after transference of all condensable products. This was true even after an experiment in which a large 
excess of carbon tetrachloride was used. The wall condition was frequently examined with respect to the destruction of oxygen atoms by measuring the natural oxygen atom decay in the reaction vessel. The results indicated that the surface condition remeined unchanged during tho course of the work.

The identification of the reaction products was made by various methods and over a considerable range of reactant concentrations. It was found that chlorine, carbon monoxide, carbon dioxide and phosgene were the only products.

\section{VARIATION OF PRODUCTS WITH THE REACTANT} CONCENTRATIONS

This series of experiments was carried out at a pressure of about $2 \mathrm{~mm} \mathrm{Hg}$ and at a temperature of $4^{\circ} \mathrm{C}$. The flow rate of oxygen was $55 \mu$ moles per second. The initial flow of oxygen atomg estimated by the 'NO $2^{-c l e a n-u p ' ~ m e t h o d ~}$ was $0.931 \mu$ moles per second and was kept constant for the entire series of experiments, while the flow rate of carbon tetrachloride was varied from 0.34 to $4.12 \mu$ moles per second. Results are recorded in Table VI (Experimental series I). The total chlorine equivalent shown in the seventh column represents the combined products of chlorine and phosgene formed in the reaction. Similarly, the total carbon equivalent in the eighth column represents the summation of products of carbon monoxide, carbon dioxide and phosgene formed in the reaction. The amount of the 
TABLE VI

\begin{tabular}{|c|c|}
\hline \multicolumn{2}{|c|}{ EXPERIMENTAL SERIES I } \\
\hline $\begin{array}{l}\mathrm{O}_{2} \text { flow } \\
0-\text { atom flow }\end{array}$ & $\begin{array}{l}-55 \mu \text { moles sec } \\
-1 \\
-0.931 \mu \text { moles sec }\end{array}$ \\
\hline Total pressure & $\sim 2 \mathrm{~mm} \mathrm{Hg}_{\mathrm{g}}$ \\
\hline Temperature & $-4^{\circ} \mathrm{C}$ \\
\hline
\end{tabular}

\begin{tabular}{|c|c|c|c|c|c|c|c|c|c|c|c|}
\hline $\begin{array}{c}\text { Experi- } \\
\text { mental } \\
\text { No. }\end{array}$ & $\begin{array}{c}\mathrm{CCl}_{4} \\
10^{-6} \\
\text { moles } \\
\sec ^{-1}\end{array}$ & $\begin{array}{l}\mathrm{Cl}_{2} \\
10^{-8} \\
\text { moles } \\
\mathrm{sec}^{-1}\end{array}$ & $\begin{array}{c}\mathrm{Co} \\
10^{-8} \\
\text { moles } \\
\mathrm{sec}^{-1}\end{array}$ & $\begin{array}{l}\mathrm{CO}_{2} \\
10^{-8} \\
\text { moles } \\
\mathrm{sec}^{-1}\end{array}$ & $\begin{array}{l}\mathrm{COCl}_{2} \\
10^{-8} \\
\text { moles } \\
\mathrm{sec}^{-1}\end{array}$ & $\begin{array}{l}\text { Total } \mathrm{Cl}_{2} \\
\text { equivalent } \\
10^{-8} \\
\text { moles } \\
\sec ^{-1}\end{array}$ & $\begin{array}{l}\text { Total } \\
\text { carbon } \\
\text { equivalent } \\
10^{-8} \\
\text { moles } \\
\text { sec }^{-1}\end{array}$ & $\mathscr{Q C O}$ & $\% \mathrm{CO}_{2}$ & $\not \mathrm{COCl}_{2}$ & $\frac{\mathrm{CO}_{2}+\mathrm{COCl}_{2}}{\mathrm{CO}}$ \\
\hline I - 1 & 4.13 & 2.91 & .515 & .515 & .458 & 3.368 & 1.488 & 34 & 34 & 31 & 1.89 \\
\hline 2 & 3.83 & 2.56 & .487 & .570 & .485 & 3.045 & 1.542 & 32 & 37 & 31 & 2.16 \\
\hline 3 & 3.45 & - & - & .513 & .346 & - & - & - & - & - & - \\
\hline 4 & 3.42 & 2.56 & .427 & .542 & .342 & 2.905 & 1.311 & 32 & 41 & 26 & $2: 06$ \\
\hline 5 & 2.72 & 2.55 & .363 & .511 & .299 & 2.849 & 1.173 & 32 & 43 & 26 & 2.23 \\
\hline 6 & 2.55 & 1.93 & .320 & .516 & .280 & 2.205 & 1.116 & 29 & 46 & 25 & 2.48 \\
\hline 7 & 2.25 & 2.05 & .311 & .448 & .235 & 2.285 & .994 & 32 & 45 & 24 & 2.20 \\
\hline 8 & 1.90 & 1.55 & .242 & .435 & .243 & 1.793 & .920 & 26 & 47 & 26 & 2.80 \\
\hline 9 & 1.43 & 1.47 & .230 & .386 & .214 & 1.689 & .830 & 29 & 47 & 26 & 2.60 \\
\hline 10 & .39 & .97 & .115 & .301 & .129 & 1.046 & .545 & 20 & 55 & 23 & 3.74 \\
\hline 11 & .34 & .82 & .098 & .280 & .098 & 0.921 & .477 & 20 & 59 & 20 & 3.84 \\
\hline
\end{tabular}


total chlorine equivalents should be twice that of the total carbon oquivalents. Hence, the comparison of the values listed in the seventh and eighth columns represents the mass balance between the chlorine-containing and the carbon-containing compounds. Colums 9,10 and 11 indicate the percentage of product formed for carbon monoxide, carbon dioxide and phosgene respectively. The percentage of product was calculated by dividing the amount of product formed by the corresponding total carbon equivalent, which was taken as an indication of the amount of the carbon tetrachloride reacted. The ratio of the combined amounts of carbon dioxide and phosgene to the amounts of carbon monoxide is shown in column 12. The rates of formation of each product with the variation of the flow rates of the carbon tetrachloride are shown graphically in Fig. 11. The total chlorine equivalent and the total carbon equivalent formed as a function of the carbon tetrachloride flow rates are plotted in Fig. 12.

MASS BALANCE

In order to ensure that all the carbon tetrachloride consumed in the experiment was accountable in the products, it was essential to determine the mas balance. Three separate experiments were carried out with conditions about the same as those given in the Experimental Series I, but with special care in the analysis of the unreacted carbon tetrachloride as well as of the products formed. Results are shown in Table VII (Experimental series J). In 
Figure 11

PRODUCT YIELD AS A FUNCTION OF

CARBON TETRACHLCRIDE FLOW RATE

Experimental Series I 


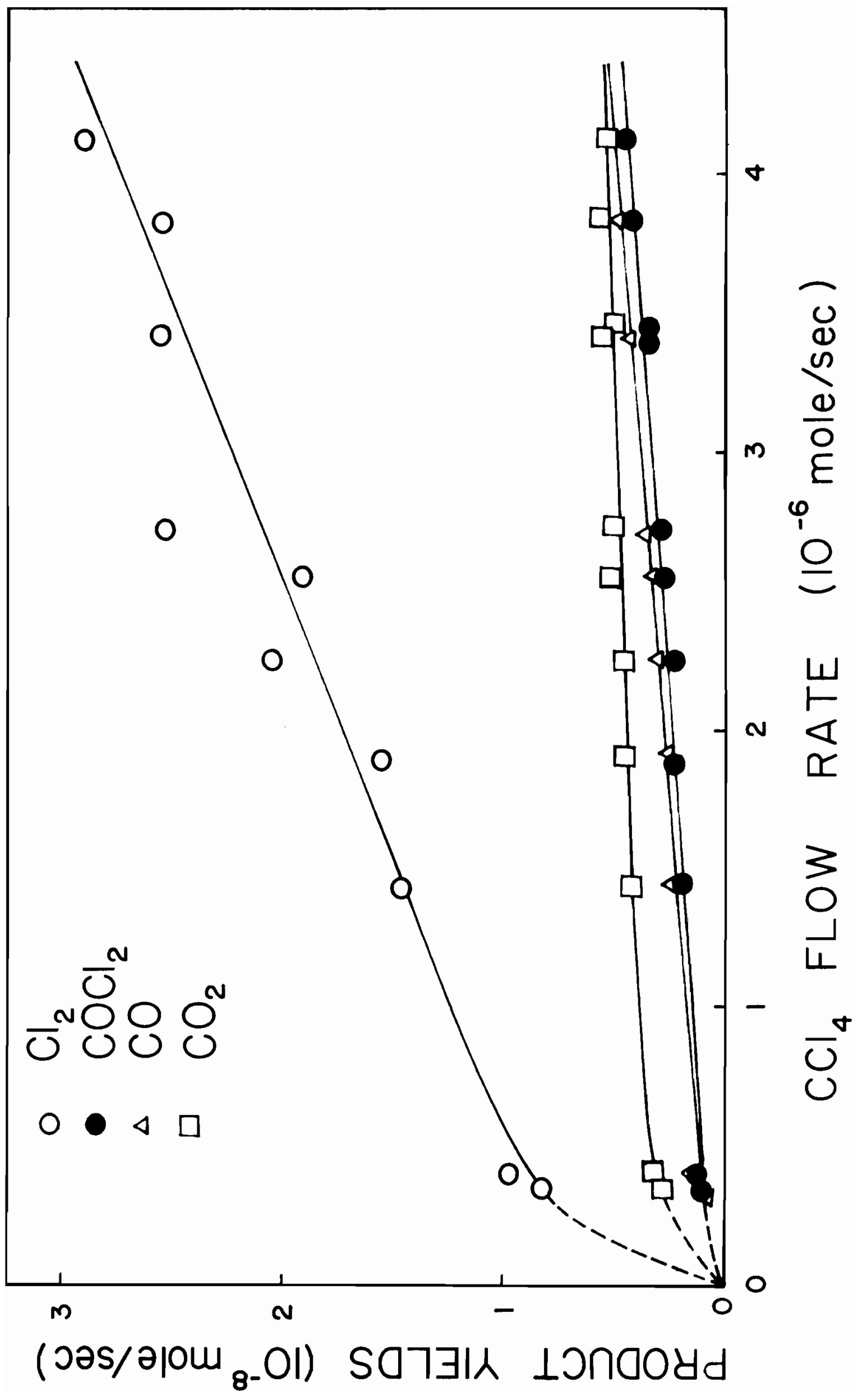


Figure 12

TOTAL PRODUCT EQUIVALENT YIELD AS A

FUNCTION OF CARBON TETRACHLORIDE FLOW RATE

Experimental Series I 


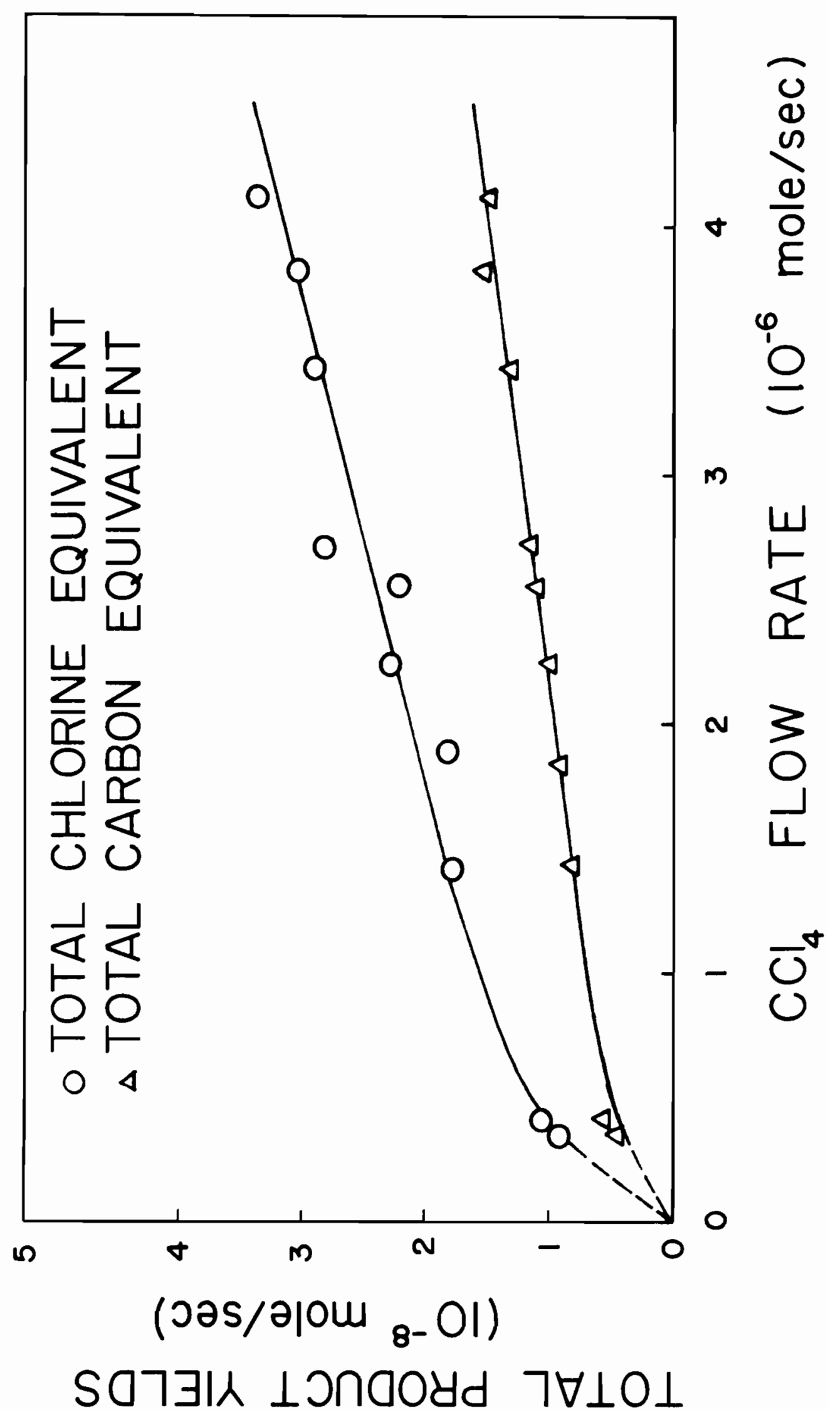


TABLE VII

\section{EXPERIMENTAI SERIES J}

Temperature $\quad-4^{\circ} \mathrm{C}$

Total Pressure $\sim 2 \mathrm{~mm} \mathrm{Hg}$

$\mathrm{O}_{2}$ Flow

o-atom Flow

- $55 \mu$ moles $\sec ^{-1}$

$-0.931 \mu$ moles sec ${ }^{-1}$

\begin{tabular}{|c|c|c|c|c|}
\hline $\begin{array}{l}\text { Experi- } \\
\text { mental } \\
\text { No. }\end{array}$ & $\begin{array}{c}\mathrm{CCl}_{4} \text { flow } \\
10^{-6} \text { moles } \mathrm{sec}^{-1}\end{array}$ & $\begin{array}{c}\mathrm{CCl}_{4} \text { consumed } \\
10^{-8} \text { moles } \mathrm{sec}^{-1}\end{array}$ & $\begin{array}{l}\text { Product formed } \\
10^{-8} \text { moles } \mathrm{sec}^{-1}\end{array}$ & deviation \\
\hline$E-1$ & 4.00 & $1 \cdot 50$ & 1.47 & 2.0 \\
\hline 2 & 3.715 & 1.50 & 1.40 & 6.6 \\
\hline 3 & 2.05 & 1.00 & 0.98 & 2.0 \\
\hline
\end{tabular}


column 4, the total carbon equivalent was taken as the amount of product formed from the reaction. The last column gives the deviations between the amounts of carbon tetrachloride reacted and that of product formed. The mass balance indicates that the carbon tetrachloride reacted yields an equivalent amount of products. Conversely, it may be inferred that no major product has escaped analysis. EFFECT OF REACTION TEMPERATURE

A change in temperature might affect the proportion of various products because of possible differences in the activation energies of secondary reactions. such changes might afford an insight into the mechanism. For this reason, a series of experiments were carried out at $100^{\circ} \mathrm{C}$ while the total pressure was maintained at about $2.1 \mathrm{~mm}$ Hg. The flow rate of oxygen was $55 \mu$ moles per second, and the flow rate of oxygen atoms was $0.267 \mu$ moles per second. Results obtained are formulated in the manner similar to that in the Experimental serios I, and are shown in Table VIII (Experimental Sories $K$ ). It must be noted that the products obtained from reactions with low flow rates of carbon tetrachloride were not reported because of the formation of ozone in the product traps, which affected the accuracy of the analysis. The product formed is shown graphically in Fig. 13 as a function of the flow rates of carbon tetrachloride. The rate of formation of the total product equivalent with the flow rates of carbon tetrachloride are plotted in Fig. 14. 


\section{TABLE VIII}

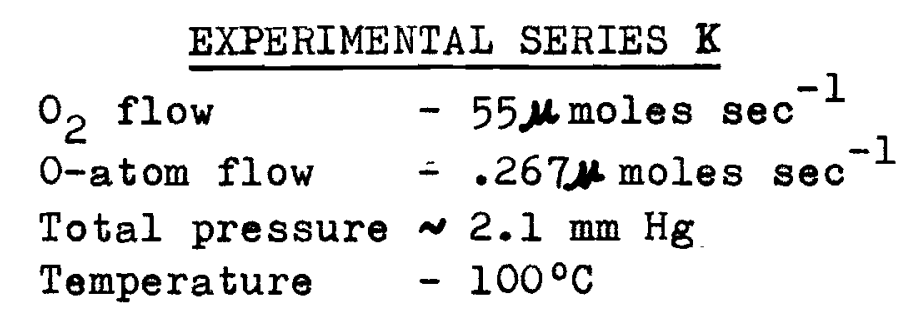

\begin{tabular}{|c|c|c|c|c|c|c|c|c|c|c|c|}
\hline $\begin{array}{c}\text { Experi- } \\
\text { mental. } \\
\text { No. }\end{array}$ & $\begin{array}{l}\mathrm{CCl}_{4} \\
10^{-6} \\
\mathrm{moles}^{-1} \\
\mathrm{sec}^{-1}\end{array}$ & $\begin{array}{l}\mathrm{Cl}_{2} \\
10^{-8} \\
\text { moles } \\
\sec ^{-1}\end{array}$ & $\begin{array}{c}\mathrm{CO} \\
10^{-8} \\
\text { moles } \\
\mathrm{sec}^{-1}\end{array}$ & $\begin{array}{c}\mathrm{CO}_{2} \\
10^{-8} \\
\text { moles } \\
\mathrm{sec}^{-1}\end{array}$ & $\begin{array}{l}\mathrm{COCl}_{2} \\
10^{-8} \\
\text { moles } \\
\text { sec }^{-1}\end{array}$ & $\begin{array}{l}\text { Total } \mathrm{Cl}_{2} \\
\text { equivalent } \\
10^{-8} \\
\text { moles } \\
\mathrm{sec}^{-1}\end{array}$ & $\begin{array}{l}\text { Total } \\
\text { carbon } \\
\text { equivalent } \\
10^{-8} \\
\text { moles } \\
\text { sec-1 }^{-1}\end{array}$ & $\% \mathrm{CO}$ & $\% \mathrm{CO}_{2}$ & $\% \mathrm{COCl}_{2}$ & $\frac{\mathrm{CO}_{2}+\mathrm{COCl}_{2}}{\mathrm{CO}}$ \\
\hline$K-1$ & 4.54 & 3.77 & .742 & .514 & .800 & 4.50 & 2.056 & 36 & 25 & 39 & 1.77 \\
\hline 2 & 4.42 & 3.65 & .734 & .514 & .757 & 4.407 & 2.005 & 36 & 25 & 39 & 1.74 \\
\hline 3 & 4.08 & - & .710 & .490 & .782 & - & 1.982 & 36 & 26 & 39 & 1.80 \\
\hline 4 & 3.71 & 3.19 & .640 & .533 & .660 & 3.85 & 1.833 & 35 & 29 & 36 & 1.87 \\
\hline 5 & 3.61 & 2.82 & .575 & .533 & .640 & 3.46 & 1.748 & 33 & 30 & 37 & 2.00 \\
\hline 6 & 3.45 & 2.94 & .560 & .512 & .634 & 3.574 & 1.706 & 33 & 30 & 37 & 2.05 \\
\hline 7 & 3.05 & 2.57 & .494 & .472 & .536 & 3.106 & 1.502 & 33 & 32 & 35 & 2.04 \\
\hline 8 & 2.33 & 2.20 & .430 & .451 & .430 & 2.630 & 1.311 & 33 & 34 & 32 & 2.05 \\
\hline 9 & 1.85 & 2.07 & .341 & .457 & .371 & 2.441 & 1.169 & 29 & 39 & 32 & 2.43 \\
\hline 10 & 1.52 & 1.76 & .313 & .427 & .342 & 2.107 & 1.082 & 29 & 39 & 32 & 2.45 \\
\hline
\end{tabular}


Figure 13

PRODUCT YIELD AS A FUNCTION OF

CARBON TETRACHLORIDE FLOW RATE

Experimental Series K 


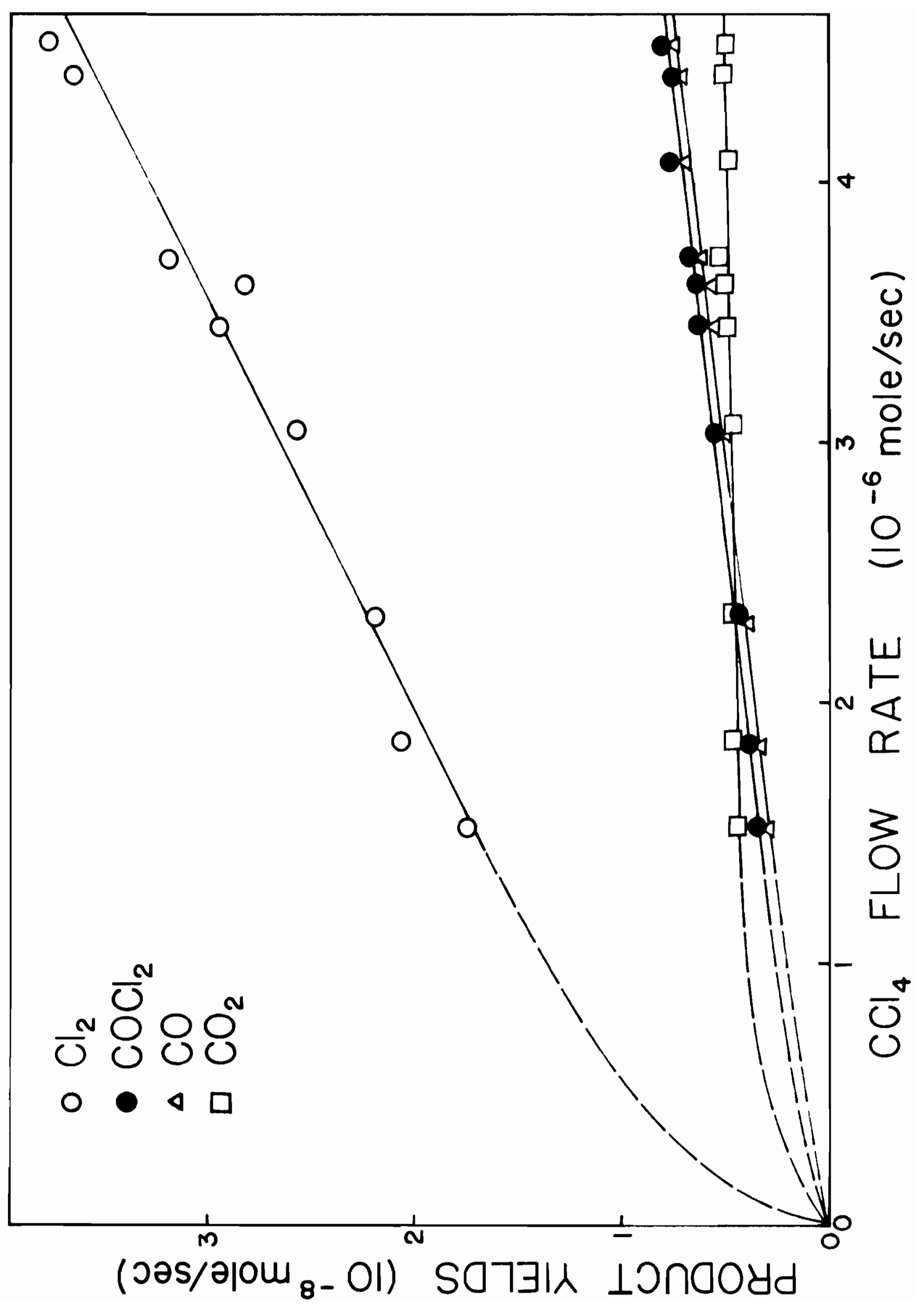


Figure 14

TOTAL PRODUCT EQUIVALENT YIELD AS A

FUNCTION OF CARBON TETRACHLORIDE FLOW RATE

Experimental Series $\mathrm{K}$ 


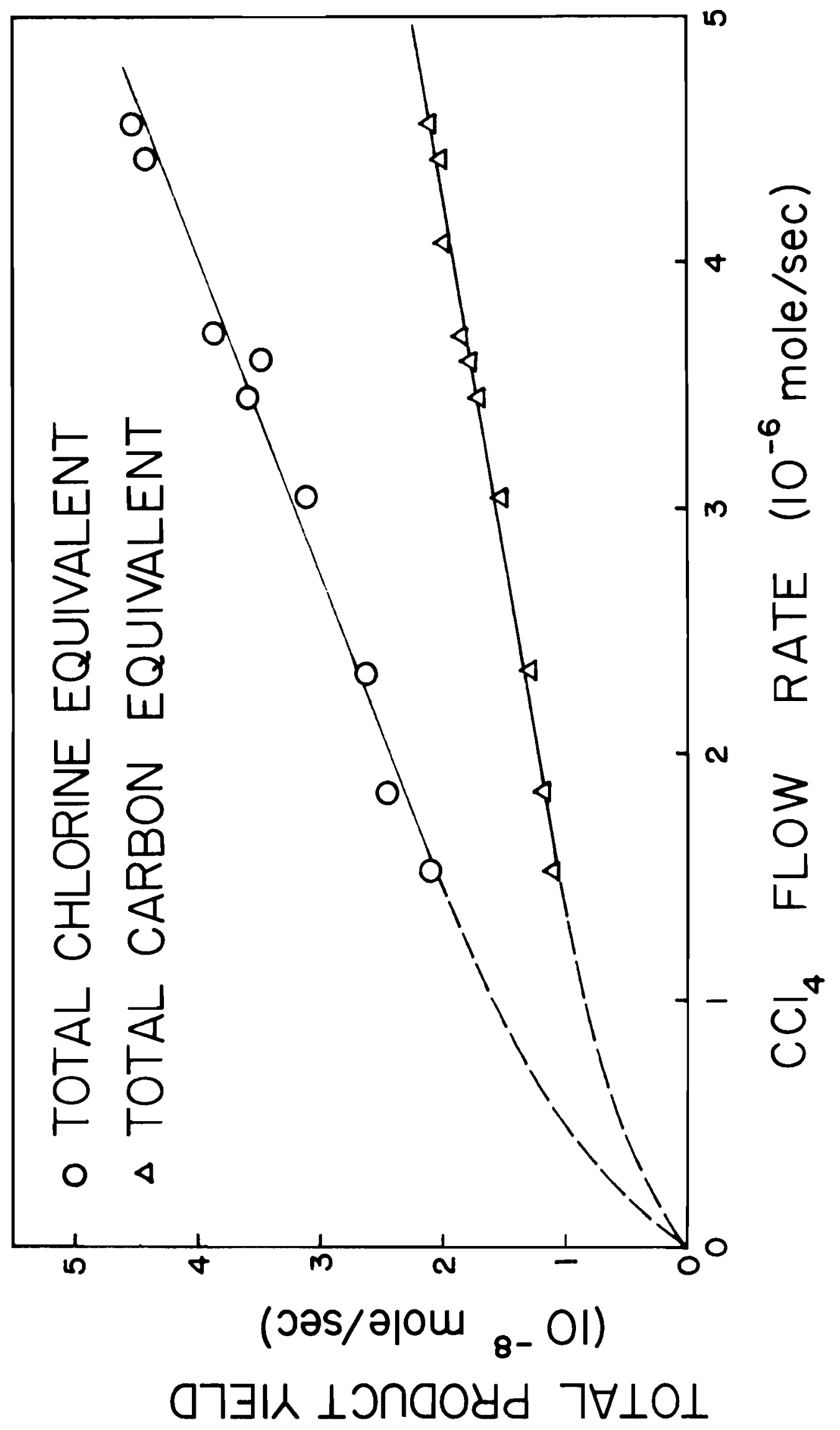


EFEECT OF TOTAL PRESSUPE

The total reaction pressure usually plays an important role in the gas phase reaction. This is due to the fact that certain products formed, which possess excess energy because of the heat of reaction, require deactivation by collisions. Cvetanovic(62) has emphasized the pressure effect on the reactions of oxygen atoms with olefins. The experiments in the Experimental Series $L$ were carried out at $10^{\circ} \mathrm{C}$ and at a pressure of approximately $4.1 \mathrm{~mm} \mathrm{Hg}$, i.e. at twice the pressure of serios I. The initial flow rate of oxygen was $171 \mu$ moles per second and that of oxygen atoms $1.99 \mu$ moles per second. The rates of formation of each product were also measured as a function of the flow rates of carbon tetrachlorido. Results obtained are listed in Table IX, and are shown graphically in Fig. 15. The total product equivalent yields plotted against the flow rates of carbon tetrachloride are given in Fig. 16.

Figures 11,13 and 15 show similar characteristics. The yields of carbon dioxide increase rapidly at low $\mathrm{CCl}_{4}$ flow rates, but much more slowly at higher flow rates. The yields of phosgene and carbon monoxide do not show a rapid initial rise, but rise continuously. At high $\mathrm{CCl}_{4}$ flow rates, their rate of increase is greater than that of carbon dioxide. The yields of chlorine show rapid initial riso and then rise with an approximately constant slope at high $\mathrm{CCl}_{4}$ flow rates. Figures 12,14 and 16 show that the yields of the total chlorine equivalent and the total carbon 
TABLE IX:

EXPERIMENTAL SERIES I

$\begin{array}{ll}\mathrm{O}_{2} \text { flow } & -171 \mu \text { moles } \mathrm{sec}^{-1} \\ \text { O-atom flow } & =1.99 \mu \text { moles } \mathrm{sec}^{-1} \\ \text { Total pressure } & \sim 4.1 \mathrm{~mm} \mathrm{Hg} \\ \text { Temperature } & -10^{\circ} \mathrm{C}\end{array}$

\begin{tabular}{|c|c|c|c|c|c|c|c|c|c|c|c|}
\hline $\begin{array}{c}\text { Experi- } \\
\text { mental } \\
\text { No. }\end{array}$ & $\begin{array}{l}\mathrm{CCl}_{4} \\
10^{-6} \\
\text { moles } \\
\mathrm{sec}^{-1}\end{array}$ & $\begin{array}{l}\mathrm{Cl}_{2} \\
10^{-8} \\
\text { moles } \\
\mathrm{sec}^{-1}\end{array}$ & $\begin{array}{c}\mathrm{CO} \\
10^{-8} \\
\text { moles } \\
\mathrm{sec}^{-1}\end{array}$ & $\begin{array}{l}\mathrm{CO}_{2} \\
10^{-8} \\
\text { moles } \\
\mathrm{sec}^{-1}\end{array}$ & $\begin{array}{l}\mathrm{COCl}_{2} \\
10^{-8} \\
\text { moles } \\
\mathrm{sec}^{-1}\end{array}$ & $\begin{array}{l}\text { Total } \mathrm{Cl}_{2} \\
\text { equivalent } \\
10^{-8} \\
\text { moles } \\
\text { sec }^{-1}\end{array}$ & $\begin{array}{l}\text { Total } \\
\text { carbon } \\
\text { equivalent } \\
10^{-8} \\
\text { moles } \\
\text { sec }^{-1}\end{array}$ & $\% \subset 0$ & $\% \mathrm{CO}_{2}$ & $\% \mathrm{COCl}_{2}$ & $\frac{\mathrm{CO}_{2}+\mathrm{COCl}_{2}}{\mathrm{CO}}$ \\
\hline$I-I$ & 3.76 & 2.29 & .515 & .480 & .235 & 2.525 & 1.230 & 42 & 39 & 19 & 1.39 \\
\hline 2 & 3.42 & - & .455 & .556 & .193 & - & 1.204 & 38 & 46 & 26 & 1.64 \\
\hline 3 & 3.23 & 1.94 & .363 & .533 & .235 & 2.175 & 1.131 & 32 & 47 & 21 & 2.12 \\
\hline 4 & 2.91 & 1.93 & $\cdot 386$ & .470 & .214 & 2.149 & 1.070 & 36 & 44 & 20 & 1.77 \\
\hline 5 & 2.46 & 1.56 & .322 & .406 & .214 & 1.774 & 0.942 & 34 & 43 & 23 & 1.92 \\
\hline 6 & 0.28 & 0.84 & .164 & .269 & .096 & .939 & 0.529 & 31 & 51 & 18 & 2.22 \\
\hline
\end{tabular}


Figure 15

PRODUCT YIELD AS A FUNCTION OF

CARBON TETRACHLORIDE FLOW RATE

Experimental Series L 


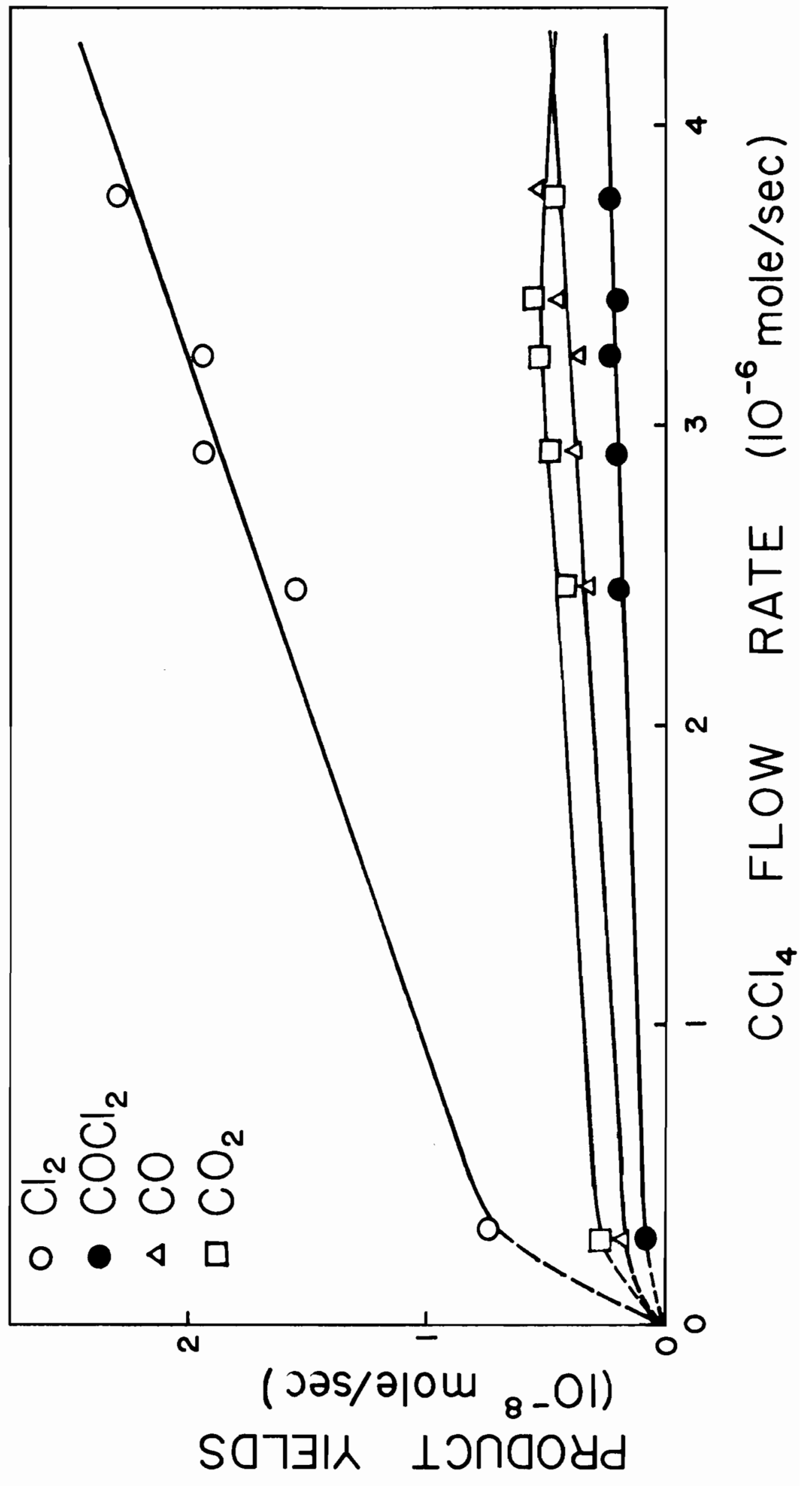


Figure 16

TOTAL PRODUCT EQUIVALENT YIELD AS A

FUNCTION OF CARBON TETRACHLORIDE FLOW RATE

Experimental Series L 


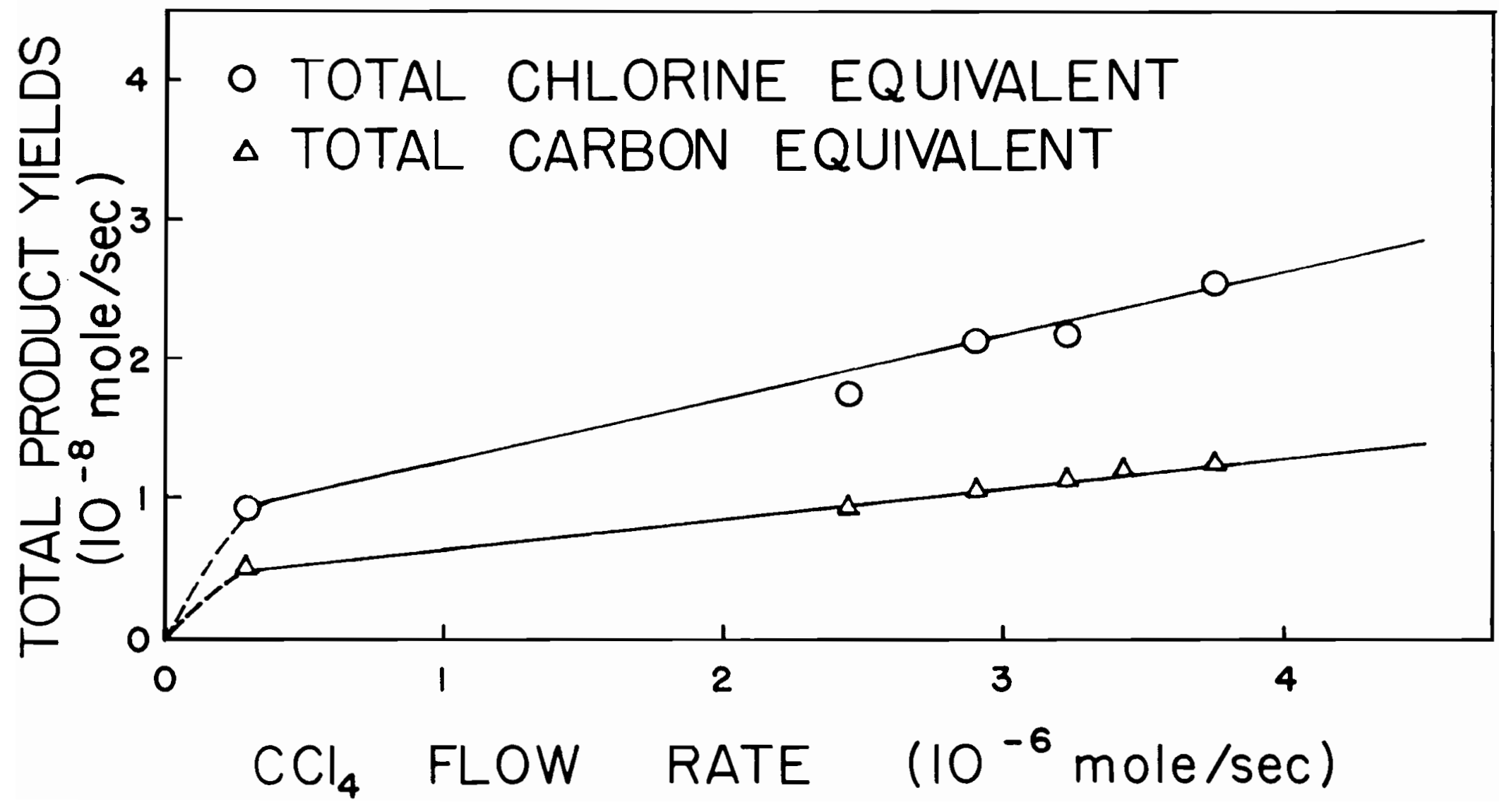


-quivalent increase rapidly at low $\mathrm{CCl}_{4}$ rates and increase continuously but more slowly at higher flow rates. In spite of some scatter, the ratio between the total chlorine and total carbon are reasonable in all cases. Inspection of Tables VI, VIII and IX shows that the percentage of carbon dioxide tends to increase slowly with decreasing $\mathrm{CCl}_{4}$ flow rate, while the percentage of carbon monoxide tends to decrease with decreasing $\mathrm{CCl}_{4}$ flow rate. The percentage of phosgene also decreases with decreasing $\mathrm{CCl}_{4}$ flow rate in the Experimental series $I$ and $x$, but no definite trend is shown in the Experimental series L. There is, however, an apparent increasing trend in the ratio $\frac{\mathrm{CO}_{2}+\mathrm{COOl}_{2}}{\mathrm{CO}}$ isted in the last column of Tables VI, VIII and IX.

REACTION OF OXYGEN ATOMS WITH CARBON TETRACHLORIDE IN THE ABSENCE OF MOLECULAR OXYGEN

This series of experiments was carried out at $4^{\circ} \mathrm{C}$ and at a total pressure of about $2 \mathrm{~mm} H \mathrm{H}$. Three experiments were performed and thoir results are given in Table $X$ (Experimental series $M$ ). In these exporiments, it is noted that the yields of carbon dioxide are much greater than those of phosgene, and that the percentages of each product do not change with flow rates of carbon tetrachloride. This, of course, means that the ratio $\frac{\mathrm{CO}_{2}+\mathrm{COCl}_{2}}{\mathrm{CO}}$ will also be independent of $\mathrm{CCl}_{4}$ flow rate. This is in contrast to the results obtained in the oxygen containing systems. THE MECFANISM OF THE REACTION OF O-ATOMS WITH CARBON TETRACHLORIDE

In discussing the results of the present study, it 


\section{TABLE X}

\section{EXPERIMENTAL SERIES M}

$\begin{array}{ll}\mathrm{N}_{2} \text { flow } & -55 \mu \text { moles } \mathrm{sec}^{-1} \\ \text { O-atom flow } & \sim 0.5 \mu \text { moles sec} \\ \text { Total pressure } & \sim 2 \mathrm{~mm} \mathrm{Hg} \\ \text { Temperature } & -4^{\circ} \mathrm{C}\end{array}$

\begin{tabular}{|c|c|c|c|c|c|c|c|c|c|c|c|}
\hline $\begin{array}{c}\text { Experi- } \\
\text { mental } \\
\text { No. }\end{array}$ & $\begin{array}{l}\mathrm{CCl}_{4} \\
10^{-6} \\
\text { moles } \\
\mathrm{sec}^{-1}\end{array}$ & $\begin{array}{l}\mathrm{Cl}_{2} \\
10^{-8} \\
\text { moles } \\
\mathrm{sec}^{-1}\end{array}$ & $\begin{array}{c}\mathrm{Co} \\
10^{-8} \\
\text { moles } \\
\mathrm{sec}^{-1}\end{array}$ & $\begin{array}{c}\mathrm{CO}_{2} \\
10^{-8} \\
\mathrm{moles}^{-1} \\
\mathrm{sec}^{-1}\end{array}$ & $\begin{array}{l}\mathrm{COCl}_{2} \\
10^{-8} \\
\text { moles } \\
\mathrm{sec}^{-1}\end{array}$ & $\begin{array}{l}\text { Total } \mathrm{Cl}_{2} \\
\text { equivalent } \\
10^{-8} \\
\text { moles } \\
\mathrm{sec}^{-1}\end{array}$ & $\begin{array}{l}\text { Total } \\
\text { carbon } \\
\text { equivalent } \\
10^{-8} \\
\text { moles } \\
\mathrm{sec}^{-1}\end{array}$ & $\% \mathrm{CO}$ & $\% \mathrm{CO}_{2}$ & $\% \mathrm{COCl}_{2}$ & $\frac{\mathrm{CO}_{2}+\mathrm{COCl}_{2}}{\mathrm{CO}}$ \\
\hline$M-1$ & 4.90 & 3.38 & .624 & .91 & .33 & 3.710 & 1.864 & 33 & 49 & 18 & 1.98 \\
\hline 2 & 3.56 & 2.55 & .472 & .682 & .298 & 2.848 & 1.452 & 33 & 47 & 21 & 2.07 \\
\hline 3 & 3.20 & 2.57 & .47 & .66 & .256 & 2.826 & 1.386 & 34 & 47 & 19 & 1.93 \\
\hline
\end{tabular}


will be assumed that atomic oxygen in its ground state is the only chemically active species in the reaction of activated oxygen with carbon tetrachloride. In the measurements of the dependence of the product yields on the carbon tetrachloride concentration, it was implicitly assumed that the total flow remained essentially constant and that the experimental conditions were reproducible for the entire series of experiments. The first assumption seems reasonable because the reactions were carried out at very low conversions, so that flow conditions would not be changed appreciably by the formation of the reaction products. Similarly, since oxygen was the main constituent of the gas mixture, the small amounts of carbon tetrachloride added should not affect the total flow appreciably. For the lowegt oxygen flow rate used in the present work, the error in assuming constant total flow would bo about $7 \%$ for the highest carbon tetrachloride flow rate attained. The second assumption is also reasonable from the observation that the amount of oxygen atoms entering the reaction vessel and the rate of its natural decay in the reaction tube were reproducible to within 2 to $3 \%$ for measurements made at the commencement and at the end of the entire series of experiments. This also indicates that the contamination of the walls of the reaction vessel, due to the formation of solid products, was negligibly small, otherwise the rate of atom decay would likely be affected. 
As noted by Bodenstein and Wolgost $(90)$, flow conditions have considerable influence on the kinetic behaviour for reactions in flow systems. If there is no turbulence in the reaction vessel, the composition of the reaction mixture will be a function of time (or distance from the reactant inlet), and the total amount of product formed in a given reaction will be an integral over all the infinitesimal concentration increments in a given time element. This type of flow is known as 'stream-line flow'. On the other hand, if there is complete turbulence in the reaction volume, the composition of the reaction mixture will be essentially that of the gases leaving the reaction vessel. The absolute amount of product formed will be proportional to the time spent in the reaction volume and to the initial concentration of the reactants. This type of flow is referred to as 'turbulent flow'. These are the two extremes possible and, obviously, actual conditions will be somewhere in between these two extremes. On the other hand, any mathematical treatment for intermediate conditions becomes too complex for practical solution. However, in the measurements of the absolute concentration of oxygen atoms for the typical experiments, the sharp end-point of the excited $\mathrm{NO}_{2}$ glow in the gas phase titration seems to indicate that the flow conditions in the present system were much closer to stream-line than to turbulent flow. Furthermore, in the study of recombination of oxygen atoms, it was evident that the axial diffusion was indeed small under the 
present experimental conditions. In the discussion thet follows, the flow therefore is regarded as stream-line flow. It is generally agreed that reactions involving atoms or radicals in systems containing large excess of oxygen are complicated by the secondary reactions which result from the interaction between radicals formed from the primary reaction and molecular oxygen. This effect is expected to be more marked at elevated temperatures. In his atudies of oxygen atom reactions, Cretanovic (58) has presented rather convincing evidence for this. However, in the present study, it was found that change of reaction temperatures and change of the oxygen content in the system (including experiments performed in the oxygen-free system) produced only a slight change in proportion of each product, but did not alter the essential nature of the reaction products. The absence of pronounced effect of the presence of oxygen molecules and of the reaction temperature suggest that radicals do not necessarily play a large role in the primary reaction. In view of the similarity in the reaction behaviour (such as the absence of a reaction flame, the absence of solid product formation, and the constancy of the products), it seems reasonable to consider that the primary reaction remains the same for all experimental conditions investigated.

Inspection of Figs. 11, 13 and 15 shows that the general shapes of the corresponding product yields - carbon tetrachloride input curves are similar in these three cases, 
and that the rates of formation of $\mathrm{CO}_{2}$ seem to approach a steady value at high $\mathrm{CCl}_{4}$ flow rates in each case, while the rates of formation of $\mathrm{Cl}_{2}, \mathrm{CO}$ and $\mathrm{COCl}_{2}$ increase continuously oven at the highest $\mathrm{CCl}_{4}$ flow rates attained. This would seem to indicate that the primary reaction was not fast enough to consume all oxygen atoms present in tho system and that $\mathrm{CO}_{2}$ was probably formed through secondary processes which brought about complete consumption of all oxygen atoms to produce a saturated yield of $\mathrm{CO}_{2}$. This line of reasoning is in accord with the expectation of the 'method of determination of the sequence of elementary reactions' developed by Avramenko and Kolesnikova $(52,53)$. According to their interpretation, the characteristics of curves obtained imply that $\mathrm{Cl}_{2}, \mathrm{CO}$ and $\mathrm{COCl}_{2}$ are the primary reaction products which require only a single event of reaction between an oxygen atom and a carbon tetrachloride molecule for their formation, while $\mathrm{CO}_{2}$ is not the primary product, and requires more than one event of reaction for its formation (see Appendix B).

The primary step of the reaction of oxygen atoms with carbon tetrachloride can be represented as follows:

$$
\begin{aligned}
0+\mathrm{COl}_{4} & \rightarrow \mathrm{COOl}_{2}+\mathrm{Cl}_{2}+97 \mathrm{Kcal} \\
& \rightarrow \mathrm{CO}+2 \mathrm{Cl}_{2}+70 \mathrm{Kcal}
\end{aligned}
$$

However, because of the high electron density resulting from four chlorine atoms bonded to a carbon atom, and the electronegativity of the oxygen atom, a collision complex might bo formed as an intermediate, and the subsequent 
decomposition of the complex might yield the primary products. Accordingly, reaction (1) and (2) might bo modified:

$$
\begin{aligned}
0+\mathrm{CCl}_{4} \rightarrow \mathrm{X} & \rightarrow \mathrm{COCl}_{2}+\mathrm{Cl}_{2} \\
& -\mathrm{OO}+2 \mathrm{Cl}_{2}
\end{aligned}
$$

where X represents the collision complex.

$$
\text { An alternative scheme may be postulated for the }
$$

initial roaction to account for the products.

$$
\begin{aligned}
& 0+\mathrm{CCl}_{4} \rightarrow \mathrm{X} \rightarrow \mathrm{COCl}_{2}^{*}+\mathrm{Cl}_{2} \\
& \mathrm{COCl}_{2}^{*} \rightarrow \mathrm{OO}+\mathrm{Cl}_{2}
\end{aligned}
$$

where $\mathrm{COCl}_{2}^{*}$ is an excited $\mathrm{COCl}_{2}$ which possesses excess energy. The subsequent decomposition of the excited phosgene then gives $\mathrm{CO}$ and $\mathrm{Cl}_{2}$. From the sterooscopic point of view, one might imagine that the collision complex has a form like

$$
01-\sum_{01}^{01}-0_{0}^{01}
$$

Roaction (3) thus results from elimination of one chlorine molecule from the complex. Also, the $\operatorname{cocl}_{2}^{*}$ could be deactivated by collisions

$$
\operatorname{coOl}_{2}^{*}+\mathrm{M} \rightarrow \mathrm{COCl}_{2}+\mathrm{M}
$$

Here $M$ is any third body. Consequently, reaction (4) might be suppressed at high total reaction pressures. This, in turn, would result in a decrease of the percentage of co formed in the reaction. However, this effect was not observed when the total pressure was increased by a factor 
of 2. Furthermore, according to thermodynamic data, both reactions (1) and (2), or (1') and (2'), are highly exothermic, and the decomposition of the complex through either path is energetically possible. Considering tho weak binding of the $\mathrm{C}-\mathrm{Cl}$ bond, there is no roason why the complex could only dissociate through reaction (3) rather than through reactions (I) and (2) independently. It appears, therefore, unlikely that reaction (3) is the primary mode of dissociation of the collision complex. As noted in the introduction section, the abstraction reaction was frequently suggested as a primary step in the reactions of oxygen atoms with saturated hydrocarbons and aldehydes. However, the present experimental results show that there is no evidence for the initial reaction

$$
0+\mathrm{CCl}_{4}-\mathrm{CCl}_{3}+\mathrm{ClO}
$$

Should reaction (6) be the primary step, $\mathrm{CCl}_{3}$ radical would be the primary product of the reaction. The following reaction

$$
\mathrm{COI}_{3}+\mathrm{COl}_{3} \rightarrow \mathrm{C}_{2} \mathrm{Cl}_{6}
$$

would be expected to occur to a certain extent. Melville et al. (91) have determined the rate constant for this reaction and reported a value of $5 \times 10^{10} \mathrm{ccmole}^{-1} \mathrm{sec}^{-1}$ at $30^{\circ} \mathrm{C}$. The formation of carbon hexachloride from the reaction would also be expected to leave some solid deposit on the walls of the reaction vessel. This has been observed by sobering and Winkler (66) in the study of the 
reaction of active nitrogen with carbon tetrachloride. The authors ascribed the white solid deposit to the dimerization of the $\mathrm{CCl}_{3}$ radicals. However, no traces of polymor vere ever observed in the present study. Moreover, on a separate experiment, a large excess of carbon tetrachloride was introduced into the reaction zone in an attempt to eliminate all subsequent reactions. But no solid deposit was observed. It should also be noted that the mass balances between the amount of carbon tetrachloride consumed and that of the product formed, and the mass balances between carbon and chlorine in the reaction products, seem to support the conclusion that no major product has escaped analysis.

Furthermore, if $\mathrm{CCl}_{3}$ radicals were the primary product, they would react with the large excess of oxygen present in the system as

$$
\mathrm{COl}_{3}+\mathrm{O}_{2} \rightarrow \mathrm{COCl}_{2}+\mathrm{ClO}^{2}
$$

Franke and schumacher (92) have found the activation energy of this reaction to be 1 to $2 \mathrm{Kcal}$ per mole. Assuming this to be the case, it is then difficult to explain the formation of $c 0$ in the present reaction, since the thermal decomposition of phosgene is known to be negligibly small at these temperatures. More significantly, should reaction (6) be the initial attack, it is almost impossible to account for the products obtained in experiments performed in the oxygen-free system. Therefore, it seems reasonable to rule out the abstraction reaction as the primary step. Obviously, 
this would not be in accord with the principle of least motion enunciated by Rice and Teller (40). However, in the study of reactions of oxygen atoms with olefins, Cretanovie $(57)$ has so far found no evidence for any direct hydrogen abatraction by oxygen atoms. For the reactions of active nitrogen with alkyl chlorides, Dunford, Evans and Hinkler(93) have concluded that the main path of these reactions was not hydrogen or chlorine atom abstraction but involved direct attack at a shielded carbon atom.

In the study of reaction of active nitrogen with carbon tetrachloride, Sobering and Winkler $(66)$ have postulated the following mechanism to account for their results.

$$
\begin{aligned}
& \mathrm{N}+\mathrm{N} \cdot \mathrm{CCl}_{4} \rightarrow \mathrm{N}_{2}+\mathrm{CCl}_{4}^{*} \\
& \mathrm{CCl}_{4}^{*} \rightarrow \mathrm{COl}_{3}+\mathrm{Cl}
\end{aligned}
$$

where $\mathrm{N} \cdot \mathrm{CCl}_{4}$ is the collision complex and $\mathrm{CCl}_{4}^{*}$ is the excited carbon tetrachloride. By analogy, a similar scheme for the reaction of oxygen atoms with carbon tetrachloride might be represented as

$$
\begin{aligned}
& 0+0 \cdot \operatorname{col}_{4} \rightarrow \mathrm{O}_{2}+\operatorname{col}_{4}^{*} \\
& \operatorname{col}_{4}^{*}-\operatorname{col}_{3}+\mathrm{Cl}
\end{aligned}
$$

However, based on the arguments presented above, reactions (9) and (10) might also be excluded from the mechanism of the present study.

In order to explain the formation of carbon dioxide as a reaction product, the following reactions may be considered at first. 


$$
\begin{aligned}
& \mathrm{CO}+\mathrm{O}+\mathrm{M}-\mathrm{CO}_{2}+\mathrm{M} \\
& \mathrm{COCl}_{2}+\mathrm{O}-\mathrm{CO}_{2}+\mathrm{Cl}_{2}
\end{aligned}
$$

The reaction of oxygen atoms with carbon monoxide has been investigated by Harteck $(6)$ and Kaufman $(13)$ and was found to be slow at room temperatures. This reaction was studied at $100^{\circ} \mathrm{C}$ and at a pressure of about $2 \mathrm{~mm} \mathrm{Hg}$ in the present study. Experimental results indicate that the reaction is indeed slow. Hence, the contribution of this reaction to the formation of $\mathrm{CO}_{2}$ can be considered to be insignificant. This is particularly true for reactions carried out at lower temperatures.

Reaction (12) was investigated briefly in the present work. The rapid disappearance of oxygen atoms, indicated by the change of intensity of the 'air afterglow', seems to suggest that this reaction is very fast. Examination of Tables VI, VIII and IX reveals that in all cases the percentages of $\mathrm{CO}_{2}$ formed increase with decreasing input flow ratea of carbon tetrachloride, while the percentages of $\mathrm{COCl}_{2}$ obtained decrease with decreasing $\mathrm{CCl}_{4}$ flow rates. These observations indicate that part of the phosgene formed in the primary process is converted into carbon dioxide by its subsequent reaction with the oxygen atoms. Since the concentrations of oxygen atoms are higher at lower carbon tetrachloride input flow rates, the rates of transformation of $\mathrm{COCl}_{2}$ to $\mathrm{CO}_{2}$ would be expected to be higher. This accounts for the higher percentages of $\mathrm{CO}_{2}$ 
and lower percentages of $\mathrm{COOl}_{2}$ obtained experimentally at lower $\mathrm{CCl}_{4}$ input concentrations. However, the variations of the

$$
\frac{\mathrm{CO}_{2}+\mathrm{COCl}_{2}}{\mathrm{co}}
$$

ratios with the change in $\mathrm{COl}_{4}$ input flow rates, as shown in the last column in Tables VI, VIII and IX, seem to suggest that reaction (12) is not the only process responsible for the formation of $\mathrm{CO}_{2}$. Since the primary steps involve only reactions (1) and (2), as discussed above, if reaction (12) were the only process responsible for the $\mathrm{CO}_{2}$ yield, the ratios of $\left(\mathrm{CO}_{2}+\mathrm{COCl}_{2}\right) / 00$ would be expected to remain constant over various flow rates of carbon tetrachloride. But this ratio was found to increase with decreasing carbon tetrachloride flow rates. Although the change is small and the results show some scatter, a definite trend is evident in all cases. This means that either the sum of $\mathrm{CO}_{2}$ and $\mathrm{COCl}_{2}$ is increased, or the amount of co is decreased, or there is a greater transformation of co into $\mathrm{CO}_{2}$. The reaction

$$
0+\mathrm{OCCl}_{4}^{*} \rightarrow \mathrm{CO}_{2}+2 \mathrm{Cl}_{2}
$$

was first considered as a possibility, since reaction (13) would lead to a higher value for the sum of $\mathrm{CO}_{2}$ and $\mathrm{COCl}_{2}$ at lower flow rates of carbon tetrachloride. Although there is no direct information about the rate of this reaction, the short life of the collision complex and the relatively low atom concentrations used in the present work 
seem to make this process unlikely. Furthermore, if reaction

(13) alone was responsible for the change in $\frac{\mathrm{CO}_{2}+\mathrm{COCl}_{2}}{\mathrm{CO}}$ ratio, the percentages of carbon monoxide formed should remain constant with carbon tetrachloride concentration. But $\%$ co was found to decrease with decreasing carbon tetrachloride flow rates. Therefore, it seems most probable that processes involving the transformation of $\mathrm{CO}$ into $\mathrm{CO}_{2}$ may occur in the presence of excess oxygen atoms. Processes other than (11) must be considered.

In the study of recombination of oxygen atoms, Kaufman (13) has found a very fast disappearance of oxygen atoms in the presence of chlorine. It was reported that the reaction is truly catalytic, a small amount of chlorine recombining more than a tenfold excess of oxygen atoms. He found the decay to be first order in the oxygen atom and in the chlorine and the overall bimolecular rate constant to have a value of $6 \times 10^{10} \mathrm{cc} \mathrm{mole^{-1 }} \mathrm{sec}^{-1}$. The tremendous speed of this reaction led the author to believe that the catalytic recombination must involve a very long chain mechanism, and the following processes were suggested:

$$
\begin{aligned}
& 0+\mathrm{Cl}_{2} \rightarrow \mathrm{ClO}+\mathrm{Cl} \\
& \mathrm{O}+\mathrm{ClO} \rightarrow \mathrm{O}_{2}+\mathrm{Cl} \\
& \mathrm{Cl}+\mathrm{O}_{2}+\mathrm{M} \rightarrow \mathrm{ClOO}+\mathrm{M} \\
& 0+\mathrm{ClOO}-\mathrm{ClO}+\mathrm{O}_{2}
\end{aligned}
$$

If reaction (14) is fast, it can be expected that reaction (15), which is similar but much more exothermic, is faster still. Thus reactions (14) and (15) would produce 
two chlorine atoms in recombining two oxygen atoms. The catalytic efficiency of the added chlorine then requires that $\mathrm{Cl}_{2}$ or $\mathrm{ClO}$ be regenerated sufficiently rapidly to sustain the rate of the overall process. The simple recombination processes

$$
\begin{aligned}
& \mathrm{Cl}+\mathrm{Cl}+\mathrm{M} \rightarrow \mathrm{Cl}_{2}+\mathrm{M} \\
& 2 \mathrm{ClO} \rightarrow \mathrm{Cl}_{2}+\mathrm{O}_{2}
\end{aligned}
$$

whose rates are known $(94,95)$, are considered too slow to be the chain carrying steps. Similarly,

$$
\mathrm{O}+\mathrm{Cl}+\mathrm{M} \rightarrow \mathrm{ClO}+\mathrm{M}
$$

is ruled out as not being likely to be much faster than the recombination of chlorine atoms. In the system containing a large excess of oxygen, reaction (16) is likely responsible for the chain propagation. The rate constant of this reaction was thus estimated by Kaufman to be approximately $7 \times 10^{16} \mathrm{cc}^{2}$ mole $\mathrm{e}^{-2} \mathrm{sec}^{-1}$. Reaction (17) is highly exothermic and should proceed very rapidly.

A rapid disappearance of oxygen atoms was also evident in the present reaction when oxygen was present. This is revealed by comparing the primary reaction rate constant, $k_{l}$, of the reaction of oxygen atoms with carbon tetrachloride and the overall first order rate constant, $k_{0}$, of oxygen atom disappearance. For reactions carried out at $4^{\circ} \mathrm{C}$ and at a pressure of about $2.1 \mathrm{~mm} \mathrm{Hg}$, the average value of $k_{1}$ was found to be $1.1 \times 10^{-17} \mathrm{cc}$ molecule $e^{-1} \mathrm{sec}^{-1}$, (the detailed discussion of the determination of the primary reaction rate will be presented in the later section), while 
the average value of $k_{0}$ was $44 \times 10^{-17} \mathrm{cc}$ molecule $\mathrm{e}^{-1} \mathrm{sec}^{-1}$ under the same experimental conditions. The ratio of $k_{0}$ to $k_{1}$, which is referred to as $R_{l}$ in the following discussion, gives a value of 40 . This implies that the actual rate of oxygen atom disappearance is 40 times faster than its consumption by the primary process. This figure is high even when consideration is taken of secondary reactions. Apparently, one of the products has a very marked catalytic effect in the recombination of atomg. In viow of Kaufman's results, chlorine is probably the responsible product. With reactions performed at $10^{\circ} \mathrm{C}$ and at a pressure of about $4.2 \mathrm{~mm}$ $\mathrm{Hg}$, it was found that the average value of $\mathrm{k}_{1}$ equals $1.6 \times 10^{-17} \mathrm{cc}$ molecule $\mathrm{esc}^{-1}$ and the average value of $\mathrm{k}_{0}$ is about $220 \times 10^{-17} \mathrm{cc}$ molecule $\mathrm{esc}^{-1}$. The ratio of $\mathrm{k}_{0}$ to $k_{1}$, referred to as $R_{2}$, gives a value of 135 . Neglecting the effect of the small difference of the temperature in these two series of experiments, the major difference lies in doubling the oxygen pressure in the reaction system, which brings about an increase by a factor of 3.4 in the ratio of $R_{2}$ to $R_{1}$. It will be shown later that the partial pressure of oxygen does not affect the primary reaction appreciably. Therefore, it seems likely that molecular oxygen also takes part in the chain propagation reaction, which is responsible for the rapid disappearance of the oxygen atoms. The effect of temperature on this catalyzed recombination of oxyzen atoms can be seen by comparison of the results obtained from experiments carried out at $4^{\circ} \mathrm{C}$ and 
those at $100^{\circ} \mathrm{C}$, while the total pressure being about the same, $2.1 \mathrm{~mm} \mathrm{Hg}$, for both series. With experiments carried out at $100^{\circ} \mathrm{C}$, the average $\mathrm{k}_{l}$ is $9.5 \times 10^{-17} \mathrm{cc}$ molecule $\mathrm{sec}^{-1}$ and the average $k_{0}$ is about $90 \times 10^{-17} \mathrm{cc}$ molecule $\mathrm{sec}^{-1}$. The ratio of $k_{0}$ to $k_{1}$, referred to as $R_{3}$, is approximately 10. The value of $R_{3}$ is only about $t$ of $R_{1}$ which was measured at about the same pressure but at $4^{\circ} \mathrm{C}$. This indicates that the primary reaction has a higher temperature coefficient than the secondary processes which are responsible for the decay of the oxygen atoms. This may be seen more directly from the ratios

$$
\begin{aligned}
& \frac{\mathrm{k}_{1}\left(\text { at } 4^{\circ} \mathrm{C}\right) \operatorname{Pr} 2.1 \mathrm{~mm} \mathrm{Hg}}{\mathrm{k}_{1}\left(\text { at } 100^{\circ} \mathrm{C}\right) \operatorname{Pr} 2.1 \mathrm{~mm} \mathrm{Hg}}=\frac{1.1 \times 10^{-17}}{9.5 \times 10^{-17}} \sim \frac{1}{9} \ldots \ldots \\
& \frac{\mathrm{k}_{0}\left(\text { at } 4^{\circ} \mathrm{C}\right) \operatorname{Pr~} 2.1 \mathrm{~mm} \mathrm{Hg}}{\mathrm{k}_{0}\left(\text { at } 100^{\circ} \mathrm{C}\right) \operatorname{Pr} 2.1 \mathrm{~mm} \mathrm{Hg}}=\frac{44}{90} \sim \frac{1}{2} \ldots \ldots \ldots
\end{aligned}
$$

Equations (1) and (2) show that $k_{1}$ is more temperature dependent than $k_{0}$. Since only small amounts of products were formed in the low conversion of $\mathrm{CCl}_{4}$, these results indicate that reactions which consume oxygen atoms are relatively fast and have very small activation energies. All these observations agree with the mechanism proposed by Kaufman.

This mechanism cannot, however, be operative in an oxygen-free system. The overall rate constant for 0 -atom disappearance would then be expected to be much lower than that obtained in systems containing alarge excess of oxygen. 
The average value of $k_{0}=1.2 \times 10^{-16} \mathrm{cc}$ molecule $\mathrm{sec}^{-1}$ obtained in an oxygen-free system can be compared with the average value of $k_{0}=9.7 \times 10^{-16} \mathrm{cc}$ molecule $\mathrm{sec}^{-1}$ obtained for an oxyzen-containing system under similar conditions of temperature and pressure. Thus, the decrease of the overall rate by a factor of about 8 can be attributed to the absence of the chain propagation process.

$$
\text { Since } k_{1} \text { describes the rate of disappearance of }
$$
the carbon tetrachloride, while $k_{0}$ measures the overall rate of disappearance of the oxygen atoms, it is interesting to compare $k_{0}$ obtained in the $0_{2}$ free system with the rate constent of the primary reaction. However, in an $\mathrm{O}_{2}$-free system, the 0-atom decay is relatively slow, and the contribution from the natural 0-atom decays must be considered. If the natural 0-atom decay is assumed to be first order, the only reactions which consume 0 -atoms in the presence of carbon tetrachloride are:

$$
\begin{aligned}
& 0+w \stackrel{\mathrm{k}_{\mathrm{a}}}{\rightarrow} \frac{1}{2} \mathrm{O}_{2}+w \\
& 0+\mathrm{CCl}_{4} \stackrel{\mathrm{k}_{\mathrm{o}}^{\prime}}{\longrightarrow} \text { products }
\end{aligned}
$$

and the overall atom decay can be given by the expression

$$
\frac{-d(0)}{d t}=k_{a}(0)+k_{0}^{\prime}(0)\left(\mathrm{COI}_{4}\right)
$$

This equation can be integrated to give

$$
\frac{1}{t} \ln \frac{(0)_{0}}{(0)_{t}}=k_{a}+k_{0}^{\prime}\left(\operatorname{col}_{4}\right)
$$

If the left-hand side of equation (1) is plotted against $\left(\mathrm{CCl}_{4}\right)$, a straight line should be obtained with the slope 
equal to $k_{0}^{\prime}$. This was found to be $4.35 \times 10^{-17} \mathrm{cc}$ molecule $e^{-1} \sec ^{-1}$ in the present system. Alternatively, if it is assumed that the only reactions which consume 0 -atoms in the presence of $\mathrm{CCl}_{4}$ are:

$$
\begin{aligned}
& 0+0+M \stackrel{k_{0}}{\rightarrow} O_{2}+M \\
& 0+\mathrm{CCl}_{4} \stackrel{k_{0}^{\prime}}{\longrightarrow} \text { products }
\end{aligned}
$$

The overall atom decay is then

$$
-\frac{a(0)}{d t}=2 k_{0}(0)^{2}(M)+k_{0}^{\prime}(0)\left(\mathrm{CCl}_{4}\right)
$$

Integrating the equation results

$$
2.3 \log \frac{2 k_{0}(M)(0)+k_{0}^{\prime}\left(\mathrm{Ccl}_{4}\right)}{(0)}=k_{0}^{\prime}\left(\mathrm{COl}_{4}\right) t+\text { constant } \ldots
$$

This oquation does not permit a direct solution for $k_{0}^{\prime}$, but this quantity can be obtained by successive approximations. In the first approximation, $k_{0}$ was put equal to $2.7 \times 10^{-33}$ $c c^{2}$ molecule $\mathrm{sec}^{-1}(89)$ and the value of $k_{0}^{\prime}$ equal to $4.35 \times 10^{-17}$ c c molecule $e^{-1} \mathrm{sec}^{-1}$ obtained from equation (1) was used. The left-hand side of equation (2) was then plotted against to give a second approximation, etc. The $k_{0}^{\prime}$ obtained by this method has a value of $4.65 \times 10^{-17} \mathrm{cc}$ molecule $e^{-1} \sec ^{-1}$.

The number of O-stons disappearing by the overall process of the reaction of 0-atoms with carbon tetrachloride in an $\mathrm{O}_{2}$-free system relative to the number of 0 -atoms disappearing by the primary process is given by the ratio 
$\frac{k_{0}^{\prime}\left(O_{2}-\text { free system }\right)_{T}}{k_{1}\left(O_{2} \text {-containing system }\right)_{T}=292 \%, P=3.0 \mathrm{~mm} \mathrm{Hg}}=\frac{292^{\circ} \mathrm{K}, P=3.0 \mathrm{~mm} \mathrm{Hg}}{1.88 \times 10^{-17}}=2.48$

This indicates that the rate of 0 -atom disappearance is 2.48 times that of $\mathrm{CCl}_{4}$ disappearance. From the product analysis, the overall stoichiometry of a typical experiment in an $\mathrm{O}_{2}-$ free system can be represented as

$$
\mathrm{COl}_{4}+1.490-.3300+.4900_{2}+.18 \mathrm{COOl}_{2}+1.8201_{2}
$$

This implies that the rate of 0-aton disappearance is 1.49 times that of $\mathrm{CCl}_{4}$ disappearance as a result of reaction. The difference between these two figures must then be accounted for by an increased rate of atom recombination. This may be due to $\mathrm{CCl}_{4}$ or its reaction products acting as more efficient third bodies in the reaction

$$
\mathrm{O}+\mathrm{O}+\mathrm{M} \rightarrow \mathrm{O}_{2}+\mathrm{M}
$$

Alternatively, the rate of atom recombination may be increased by the reactions

$$
\begin{aligned}
& 0+\mathrm{Cl}_{2} \rightarrow \mathrm{ClO}+\mathrm{Cl} \\
& \mathrm{OlO}+\mathrm{O} \rightarrow \mathrm{Cl}+\mathrm{O}_{2}
\end{aligned}
$$

which are reported to be fast reactions.

The catalytic effect of chlorine on the oxygen atom recombination in the oxygen-containing system has a bearing on the shapes of the product yield curves shown in Figs. 12, 14 and 16. These curves show an initial fast rise in total product for all three cases. At low $\mathrm{COl}_{4}$ flow rates only small amounts of $\mathrm{Cl}_{2}$ will be formed, little $\mathrm{Cl}_{2}$-catalyzed atom recombination will occur and the rate of 
the initial reaction will be relatively high. At higher $\mathrm{CCl}_{4}$ flow rates, more $\mathrm{Cl}_{2}$ will be produced which will deplete the atom concentration by catalyzed recombination. Consequently, the rate of $\mathrm{CCl}_{4}$ reaction will be decreased. For the same total pressure, the slope of the 'Iinear region' (at carbon tetrachloride flow rates above approximately $0.5 \mu$ moles per second) is higher for experimental series $K$ at $100^{\circ} \mathrm{C}$ than for experimental series I at $4^{\circ} \mathrm{C}$. At a higher temperature, the rate of the primary reaction will increase relative to the atom recombination rate because of its higher activation onergy. This then accounts for the higher slope of the total product curve at $100^{\circ} \mathrm{C}$. At approximately the same reaction temperature, series I at a pressure of $2 \mathrm{~mm} \mathrm{Hg}$ shows a higher slope than series $\mathrm{L}$ at a pressure of $4.1 \mathrm{~mm} \mathrm{Hg}$. The etom concentration is approximately the same in both series and the pressure differs only by the extent of the oxygen concentration. Since the catalytic recombination of oxygen atoms depends on the $\mathrm{O}_{2}$ concentration, It will occur to a greater extent in series $L$ than in series I, which will account for the lower slope in the former case. Applying a steady-state treatment to his experimental results, Kaufman has estimated the rate constant of reaction (15) to be in between $10^{12}$ to $10^{13} \mathrm{CC}$ mole $e^{-1} \sec ^{-1}$. Since reaction (17) is highly exothermic and should proceed without appreciable activation energy, its rate constant would be approximately that of reaction (15). In view of the rapidity of these two processes, the 
steady-state concentration of $\mathrm{ClO}$ and $\mathrm{ClOO}$ radicals should be low. According to Kalifman's interpretation, the actual concentration of chlorine is also low, since most of the chlorine present in the system would be in its atomic form (the ratio of $\left(\mathrm{Cl}_{2}\right)_{0} /(\mathrm{Cl})$ was estimated to be approximately $\frac{1}{2}$ ) when the steady-state of 010 and 0100 is reached. It is known that the reaction between chlorine atoms and carbon tetrachloride is negligibly small at room temperature. schwab (96) has found that the addition of carbon tetrachloride to a system containing chlorine atoms produced by electrical discharge caused no diminution in the chlorine atom concentration. This means that the reactions

$$
\begin{aligned}
& \mathrm{CCl}_{4}+\mathrm{Cl} \rightarrow \mathrm{CCl}_{3}+\mathrm{Cl}_{2} \\
& \mathrm{CCl}_{3}+\mathrm{Cl} \rightarrow \mathrm{CCl}_{4}
\end{aligned}
$$

do not occur to an appreciable extent. According to steacie(41), the activation energy of reaction (22) must therefore be greater than about 12 Kcal per mole. This is consistent with estimates that reaction (22) is ondothermic to the exter.t of about $12 \mathrm{Kcal}(97,98)$.

The reaction of chlorine atoms with phosgene was also investigated by Schrab(96). He found that the addition of phosgene had very little effect on the chlorine atom concentration. Since consumption of atoms would be expected by the sequence

$$
\begin{aligned}
& \mathrm{Cl}+\mathrm{COCl}_{2}-\mathrm{COCl}+\mathrm{Cl}_{2} \\
& \mathrm{Cl}+\mathrm{COCl}-\mathrm{COCl}_{2}
\end{aligned}
$$


the activation energy of reaction (24) must also be relatively high. In the studies of the phosgene synthesis, reaction ( 24 ) is a step in the generally accepted mechanism (99). Bodenstein, Brenschede and schumacher $(100)$ have given an activation energy of $23.0 \mathrm{Kcal}$ per mole for this reaction. Therefore, the reaction between chlorine atoms and phosgene under the present experimental conditions is unimportant.

Carbon monoxide is one of the reaction products in the reaction of oxygen atoms with carbon tetrachloride. The reaction of chlorine atoms with co might therefore be expected to occur in the present system. The reaction

$$
\mathrm{CO}+\mathrm{Cl} \rightarrow \mathrm{COCl}
$$

seems to have been well established in the photochemical synthesis of phosgene. Bodenstein and his collaborators (100) have estimated that the equilibrium constant in the reaction

$$
\mathrm{CO}+\mathrm{Cl} \rightleftharpoons \mathrm{COCl}
$$

is given by

$$
\log K_{0001}=-\frac{5676}{4.571 T}+1.770
$$

In a reinvestigation of the reaction, Burns and Dainton(101) found agreement with Bodenstein's mechanism and obtained the following expression for the equilibrium constant

$$
\log K_{C O C l}=-\frac{6310}{4.571 T}+2.806
$$

From this figure and their estimates for the rate constant of the reverse reaction, the rate constant for the forward reaction (26) can be calculated to be approximately 
$1.6 \times 10^{-12.2}$ cc molecule $e^{-1} \mathrm{sec}^{-1}$ at $4^{\circ} \mathrm{C}$. of course, the equilibrium in reaction (26) depends on the rates of removal of cocl radicals by subsequent reactions and on the rate of its reverse reaction.

The reaction of $\mathrm{COCl}_{\text {with }} \mathrm{Cl}_{2}$ is one of the chaincarrying steps postulated in the mechanism of the photochemical formation of phosgene.

$$
\mathrm{COCl}+\mathrm{Cl}_{2} \rightarrow \mathrm{COCl}_{2}+\mathrm{Cl}
$$

Its rate constant was given by Bodenstein et al. (100) as:

$$
\log k=-\frac{2612}{4.571 T}+\frac{1}{2} \log T+6.23
$$

In a simflar investigation, Burns and Dainton( 101 ) obtained

$$
\log k=-\frac{2960}{4.571 T}+9.4
$$

where the $k^{\prime} s$ are expressed in 1 mole $e^{-1} \sec ^{-1}$. The latter figure corresponds to $4 \times 10^{-14} \mathrm{cc}$ molecule $\mathrm{sec}^{-1}$ at $4^{\circ} \mathrm{C}$ for the rate constant of reaction (27).

In the photolysis of mixtures of chlorine, oxygen and carbon monoxide, Rollefson (102) postulated the following reactions:

$$
\begin{aligned}
& \mathrm{COCl}+\mathrm{Cl}_{2}-\mathrm{COCl}_{2}+\mathrm{Cl} \\
& \mathrm{COCl}+\mathrm{O}_{2} \rightarrow \mathrm{CO}_{2}+\mathrm{ClO}
\end{aligned}
$$

to account for the formations of $\mathrm{COCl}_{2}$ and $\mathrm{CO}_{2}$ in the system, and estimated that

$$
\begin{aligned}
E_{27}-E_{28} & =3000 \pm 200 \mathrm{cal} / \mathrm{mole} \\
\text { and } P_{27} / P_{28} & =30 \pm 5
\end{aligned}
$$


where $E$ is the activation energy and $P$ is the steric factor of the reaction. It is seen that the relative amount of $\mathrm{COCl}_{2}$ and $\mathrm{CO}_{2}$ formed is a function of the ratio of $\mathrm{Ol}_{2}$ to oxygen participating in the reaction and of the reaction temperature. This would seem to explain the earlier observations $(103,104)$ that the proportion of $\mathrm{CO}_{2}$ formed diminishes considerably as the temperature is increased in similar studies.

Adapting these processes in the mechanism of the present study, it would be expected that most of the COCl radicals would be removed by oxygen which is present in large excess relative to chlorine. This would make reaction (28) predominate over reaction (27). Of course, the importance of reaction (28) would be expected to be less at higher temperatures due to the shift in the equilibrium of reaction (26), which results in a lowering of the equilibrium concentration of cool radicals. However, the situation might reverse in the oxygen-free system because of the relative abundance of chlorine in the competition for the COCl radicals.

The terminating step in the mechanism of photochemical synthesis of phosgene is generally accepted to be

$$
\mathrm{Ol}+\mathrm{COCl} \rightarrow \mathrm{CO}+\mathrm{Cl}_{2}
$$

Bodenstein et al. (100) concluded that this reaction goes at almost every collision with a very small energy barrier and that its rate is given by 


$$
\log k=-\frac{1940}{4.571 T}+\frac{1}{2} \log T+9.130
$$

In a reinvestigation of the reaction, Burns and Dainton (101) obtained

$$
\log k=-\frac{830}{4.571 T}+11.6
$$

Here again, the $k^{\prime} s$ are in 1 mole $e^{-1} \sec ^{-1}$. In spite of the low concentrations of $\mathrm{Cl}$ and $\mathrm{COCl}$ in the system, the great speed probably makes reaction (29) compete for the cocl radicals to a certain extent. Nevertheless, the overall effect of this process is solely the catalytic recombination of chlorine atoms by the carbon monoxide. However, reaction (29) might play a significant role as a scavenger for the removal of $\mathrm{COCl}$ and chlorine atoms in reactions carried out in the oxygen-free systems.

$$
\text { Based on the information just discussed, the }
$$
sequence of reactions (26) and (28) would seem likely to occur in the present system as processes involving the transformation of $\mathrm{CO}$ to $\mathrm{CO}_{2}$, which accounts for the variations of of the $\left(\mathrm{CO}_{2}+\mathrm{COOl}_{2}\right) / \mathrm{Co}$ ratios over the flow rates of the input carbon tetrachloride. Inspection of Fig. 17 shows that the ratios of $\frac{\mathrm{CO}_{2}+\mathrm{COCl}_{2}}{\mathrm{CO}}$ are higher in Experimental Series I than in Experimental series $K$, which were carried out at roughly the same pressure, $2.1 \mathrm{~mm} \mathrm{Hg}$, but at temperatures of $4^{\circ} \mathrm{C}$ and $100^{\circ} \mathrm{C}$ respectively. This seems to indicate that the rate of transformation of $\mathrm{CO}^{\circ}$ to $\mathrm{CO}_{2}$ is lower at higher temperature. This experimental fact may be explained by taking the sequence of reactions (26) and (28) 
$-124-$

FIGURE 17

$$
\frac{\mathrm{CO}_{2}+\mathrm{COCl}_{2}}{00} \text { versus } \mathrm{COl}_{4} \text { flow rates }
$$




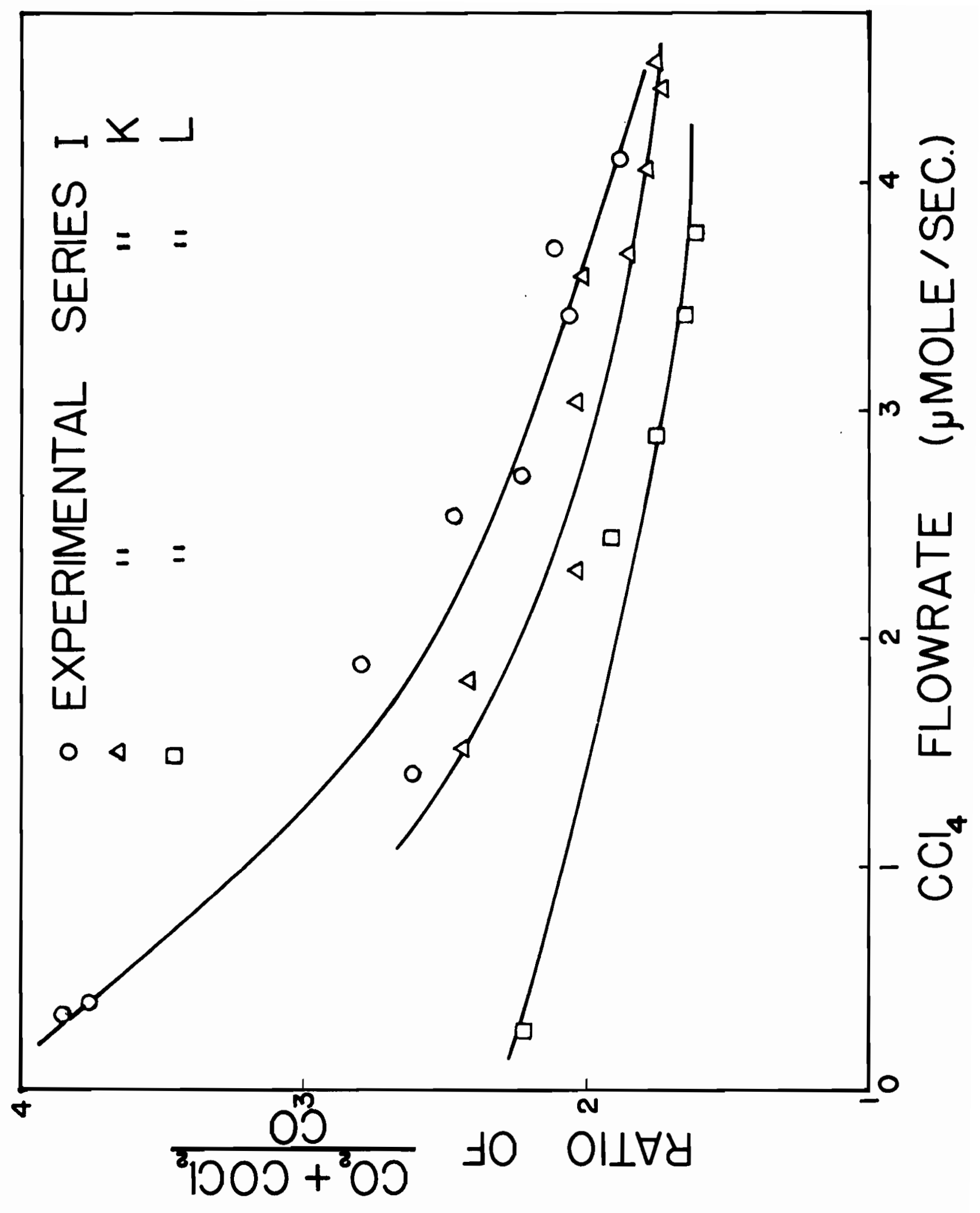


into consideration, since the rate of transformation of co to $\mathrm{CO}_{2}$ depends mainly on the equilibrium concentration of the cocl radicals. At high temperature, the equilibrium in reaction (26) is shifted to a direction which results in a lower concentration of the cocl radicals. Consequently, the rate of reaction (28) is reduced. Fig. 17 also indicates that the ratios of $\frac{\mathrm{CO}_{2}+\mathrm{COCl}_{2}}{\mathrm{CO}}$ are relatively lower in Experimental series $I$, which was carried out at $10^{\circ} \mathrm{C}$ and at a pressure of about $4.2 \mathrm{~mm} \mathrm{Hg}$. At first sight, this seems to argue against the inclusion of reaction (28) in the present mechanism. However, consideration must be made of the speed of reaction (17) and the significance of the dual effect of oxygen pressure on the reaction which competes for chlorine atoms with reaction (26) in the system. It is therefore not surprising that the rate of transformation of CO to $\mathrm{CO}_{2}$ is lower at higher oxygen pressure in spite of the fact that higher oxygen pressure would also favour the rate of reaction (28). Regarding the trends of the graphs shown in Fig. 17, it may be seen that the values of the ratios of $\frac{\mathrm{CO}_{2}+\mathrm{COCl}_{2}}{\mathrm{CO}}$ will become smaller at higher flow rates of carbon tetrachloride. Furthermore, in view of the absolute values of the ratio, it may also be inferred that the rate of decomposition of the collision complex through reaction (I') is not more than twice that through reaction ( $\left.2^{\prime}\right)$. However, this figure appears reasonable from the energetical point of view for these two processes.

Further support of the mechanism is also provided 
from experiments carried out in the oxygen-free system. Table X shows that the percentages of $\mathrm{CO}_{2}$ and $\mathrm{COCl}_{2}$ are quite steady over various flow rates of carbon tetrachloride. This may be due mainly to the fact that the rate of oxygen atom decay is slow in the oxygen-free system. Thus, the concentration of atoms changes only slightly with the flow rates of the reactant in contrast to the $\mathrm{O}_{2}$-rich system. The rate of formation of $\mathrm{COCl}_{2}$ changes slowly with the flow rates of carbon tetrachloride due to the slowness of the primary reaction. The rate of reaction (12), which depends on both the concentrations of oxygen atoms and phosgene, is thus expected to change slowly with the concentration of carbon tetrachloride. This, therefore, can account for the steady change in the percentages of $\mathrm{CO}_{2}$ and $\mathrm{COCl}_{2}$. The relatively greater abundance of oxygen atoms in the oxygenfree system would result in higher percentages of $\mathrm{CO}_{2}$ than of $\mathrm{CoCl}_{2}$. This is in agroement with the experimental results.

$$
\text { The ratios of } \frac{\mathrm{CO}_{2}+\mathrm{COCl}_{2}}{\mathrm{CO}} \text { in the oxygen-free }
$$
system are approximately the same as those in the oxygenrich system. Apparently, reaction (28), which is presumably responsible for the transformation of $\mathrm{CO}$ to $\mathrm{CO}_{2}$ in the presence of excess oxygen, is suppressed in the oxygen-free system. It might be expected that the ratios would therefore be considerably reduced. In order to explain this result, the significance of reaction (27) should be considered since it competes for the cocl radicals 
and involves the transformation of $\mathrm{CO}$ and $\mathrm{Cl}_{2}$ to $\mathrm{COCl}_{2}$. This reaction may be promoted in the absence of oxygen. However, considering the rate constant reported for this reaction and the low concentration of chlorine in the system, it is unlikely that this reaction alone can resolve the problem. In view of the slow rate of decay of oxygen atoms through recombination in the oxygen-free system, the concentration of oxygen atoms should remain relatively high, and the following reaction

$$
\mathrm{COCl}+\mathrm{O} \rightarrow \mathrm{CO}_{2}+\mathrm{Cl}
$$

might be expected to occur. As noted before, reaction (29) goes at almost every collision with a very small energy barrier. Reaction (30), which is similar but probably more exothermic, would also be expected to proceed with little or no activation energy. Also, since the reaction of oxygen atoms with phosgene was found to be fast, it is likely that the reaction of oxygen atoms with the cocl radicals will be even faster. Should this be the case, the rate of transformation of $\mathrm{CO}$ to $\mathrm{CO}_{2}$ may still be maintained in the absence of oxygen to account for the magnitude of the ratios of $\frac{\mathrm{CO}_{2}+\mathrm{COCl}_{2}}{\mathrm{CO}}$. Moreover, the introduction of reaction (30) into the reaction mechanism is found to be consistent with all other experimental facts observed. Hence, reaction (30) may be considered as another chain carrying step in the catalytic recombination processes in the present system. This is also consistent with the experimental fact that the overall rate of disappearance of oxygen atoms is higher than 
the rate of the primary reaction. The constant percentage of co obtained and the roughly constant value of the ratios of $\frac{\mathrm{CO}_{2}+\mathrm{COCl}_{2}}{\mathrm{CO}}$ with the change of the carbon tetrachlorido flow rates might also be explained on similar grounds.

To summarize, it seems probable that the reaction of oxygen atoms with carbon tetrachloride is consistent with the assumption of two primary processes

$$
\begin{aligned}
\mathrm{O}+\mathrm{COl}_{4} & -\mathrm{COOl}_{2}+\mathrm{Cl}_{2} \\
& \rightarrow \mathrm{CO}+2 \mathrm{Cl}_{2}
\end{aligned}
$$

and that the rate of reaction (1) is faster than that of reaction (2) by a factor of not more than two. It appears likely that the formation of carbon dioxide occurs mainly by the reaction

$$
\mathrm{COOl}_{2}+\mathrm{O} \rightarrow \mathrm{CO}_{2}+\mathrm{Cl}_{2}
$$

With a large excess of molecular oxygen present in the system, $\mathrm{CO}_{2}$ may also be formed from the reaction sequence

$$
\begin{aligned}
& \mathrm{O}+\mathrm{Cl}_{2} \rightarrow \mathrm{ClO}+\mathrm{Cl} \\
& \mathrm{ClO}+\mathrm{O} \rightarrow \mathrm{O}_{2}+\mathrm{Cl} \\
& \mathrm{CO}+\mathrm{Cl} \rightarrow \mathrm{COCl} \\
& \mathrm{COCl}+\mathrm{O}_{2} \rightarrow \mathrm{CO}_{2}+\mathrm{ClO}
\end{aligned}
$$

With reactions carried out in the oxygen-free system, significant amounts of $\mathrm{CO}_{2}$ may be formed through the reaction

$$
\mathrm{COCl}+\mathrm{O} \rightarrow \mathrm{CO}_{2}+\mathrm{OI}
$$

According to the experimental results obtained, the rapid disappearance of oxygen atoms in the system can be explained satisfactorily in the light of the mechanism suggested by Kaufman for the catalytic recombination of 0-atoms. 
MEASUREMENT OF THE RATE CONSTANTS OF THE PRIMARY REACTION OF OXYGEN ATOMS WITH CARBON TETRACHLORIDE

The first series of experiments were carried out with the aim of establishing the order of the reaction. The oxygen flow rate was kept constant at $59 \mu$ moles per second, while the initial oxygen atoms, estimated by the ' $\mathrm{NO}_{2}$-clean-up' method, was maintained at $0.578 \mu$ moles per second. This is equivalent to approximately $1 \%$ oxygen atoms in the gas stream. The flow rates of carbon tetrachloride were varied from 0.38 to $4.21 \mu$ moles per second. The change in the total pressure and in the total flow rate, due to tre introduction of the reactant and the partial dissociation of oxygen, were corrected for in the calculation of the rate constant. Total pressures were in the range of 2.95 to $3.15 \mathrm{~mm} \mathrm{Hg}$ and total flows in the range of 60.0 to $63.8 \mu$ moles per second for the lowest and the highest flow rates of carbon tetrachloride input respectively. The decay of oxygen atoms in the presence of carbon tetrachloride was measured photometrically as a function of distance from the inlet jots of the reactant, at which point the atom concentration was taken as the initial concentration. A set of typical oxygen atom decay curves are shown in Fig. 18. The rate constants calculated from equation (2)

$$
\ln \frac{\left(\mathrm{col}_{4}\right)_{1}}{\left(\mathrm{col}_{4}\right)_{2}}=k_{1} \int_{1}^{2}(0) d t
$$

in this series are given in Table XI (Experimental serios $N$ ). The results show no trend in the value of $k_{1}$ when the ratios 
Figure 18

THE OXYGEN ATOM CONCENTRATION (ARBITRARY UNITS) AS

A FUNCTION OF DISTANCE FROM THE $\mathrm{CCl}_{4}$ INLET JETS

Experimentel Series $N$ 


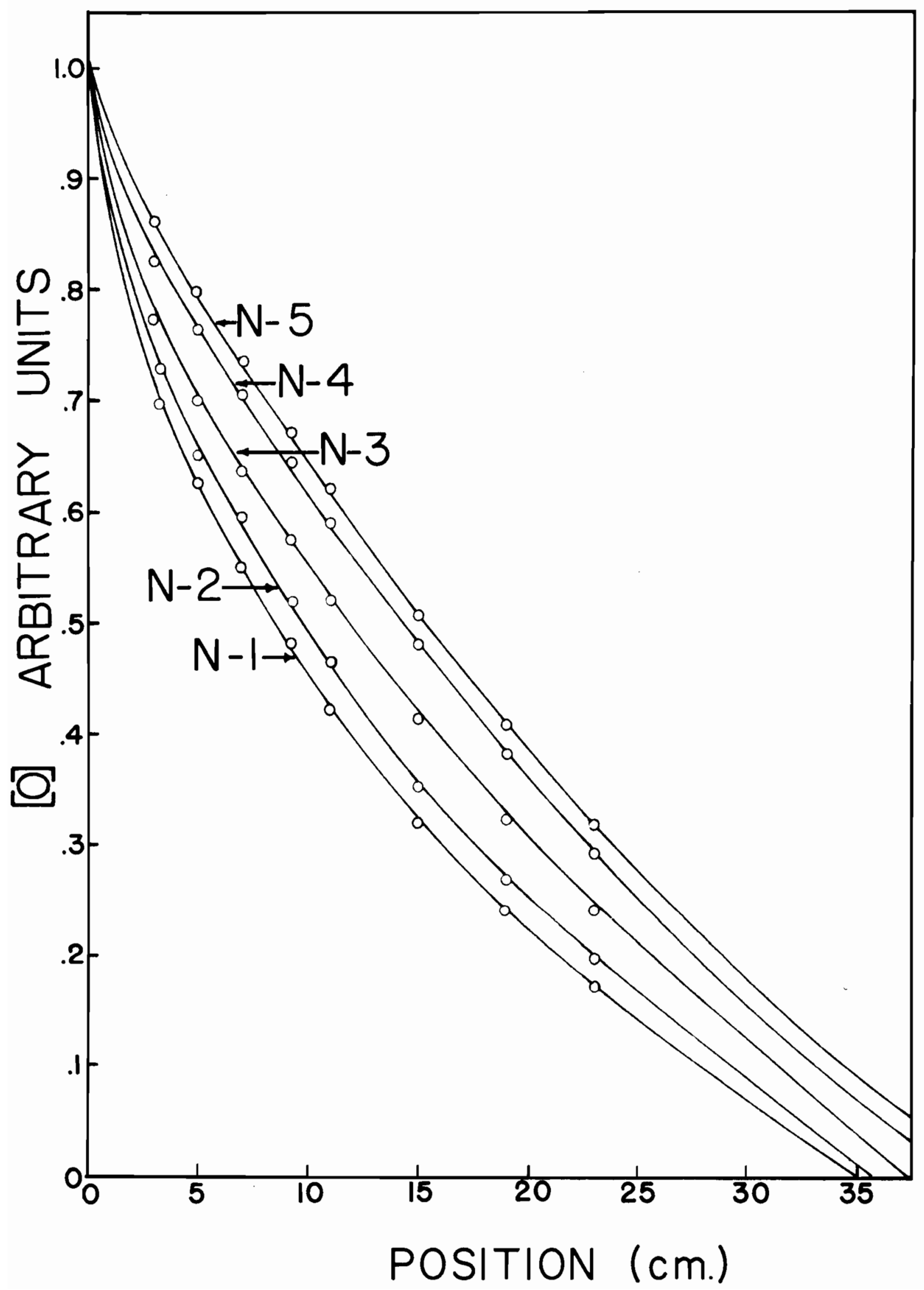


TABLE XI

EXPERIMENTAL SERIES N

Temperature $\quad-19^{\circ} \mathrm{C}$

Total pressure $=2.95$ to $3.15 \mathrm{~mm} \mathrm{Hg}$

Total flow $\quad=60.0$ to $63.8 \mu$ moles $\mathrm{sec}^{-1}$

\begin{tabular}{|c|c|c|c|c|c|}
\hline $\begin{array}{l}\text { Experi- } \\
\text { mental } \\
\text { No. }\end{array}$ & $\begin{array}{l}\mathrm{CCl}_{4} \\
\text { flow } \times 10^{6} \\
\text { moles } \mathrm{sec}^{-1}\end{array}$ & $\begin{array}{l}(0)_{0} \times 10^{-15} \\
\text { molecules } \mathrm{cc}^{-1}\end{array}$ & $\log \frac{\left(\mathrm{CCl}_{4}\right)_{0}}{\left(\mathrm{CCl}_{4}\right)_{\mathrm{f}}} \times 10^{3}$ & $\begin{array}{l}\int(0) d t \times 10^{-14} \\
\text { molecules } c^{-1} \mathrm{sec}\end{array}$ & 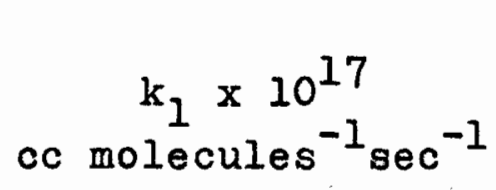 \\
\hline$N-1$ & 4.21 & .944 & 1.207 & 1.46 & 1.90 \\
\hline 2 & 3.42 & .925 & 1.256 & 1.51 & 1.92 \\
\hline 3 & 2.43 & .925 & 1.355 & 1.73 & 1.81 \\
\hline 4 & 1.50 & .924 & 1.551 & 1.95 & 1.83 \\
\hline 5 & 1.04 & .930 & 1.778 & 2.12 & 1.93 \\
\hline 6 & 0.68 & .935 & 1.940 & 2.33 & 1.91 \\
\hline 7 & 0.38 & .942 & 2.100 & 2.47 & 1.95 \\
\hline 8 & 4.91 & .948 & 1.177 & 1.40 & 1.93 \\
\hline 9 & 4.56 & .954 & 1.190 & 1.49 & 1.84 \\
\hline 10 & 2.56 & .923 & 1.324 & 1.70 & 1.81 \\
\hline 11 & 1.58 & .920 & 1.550 & 1.98 & 1.80 \\
\hline
\end{tabular}


of the initial reactant concentrationschange by more than a factor of ten.

The rate constants were also measured over various conditions. The results obtained are shown in Table XII (Experimental Series 0), Table XIII (Experimental Series $P$ ), Table XIV (Experimental Series $Q$ ) and Table XV (Experimental Series R).

It is noted that the value of $k_{1}$ in experiment $0-7$ is slightly higher than other values which were all obtained at higher flow rates of carbon tetrachloride in the series. It is believed that this is caused by the incomplete consumption of oxygen atoms in the length of the reaction vessel. Indeed, small amounts of ozone were found in the product trap, which might have affected the product analysis. The incomplete consumption of atoms would also invalidate the use of equation (2) for the evaluation of the rate constant. In experiments $0-2$ and $R-4$, small amounts of nitric oxide were added to the reaction to increase the phototube readings by a factor of about 10 and 15 respectively for the oxygen atom decay determinations. However, the rate constants obtained from these experiments ere in agreement with other rate constants in the corresponding series, which were obtained without the addition of nitric oxide.

The average rate constants of the primary reaction of oxygen atoms with carbon tetrachloride over various temperatures from the above experiments are summarized in $T a b l e X V I$. 


\section{TABLE XII}

$\frac{\text { EXPERIMENTAL SERIES O }}{\text { Temperature }}-4^{\circ} \mathrm{C}$
Total pressure -2.05 to $2.20 \mathrm{~mm} \mathrm{Hg}$
Total flow -56.3 to $61.0 \mu_{\text {moles sec }}{ }^{-1}$

\begin{tabular}{|c|c|c|c|c|c|}
\hline $\begin{array}{l}\text { Experi- } \\
\text { mental } \\
\text { No. }\end{array}$ & $\begin{array}{l}\mathrm{CCl}_{4} \\
\text { flow } \times 10^{6} \\
\text { moles } \mathrm{sec}^{-1}\end{array}$ & $\begin{array}{l}(0) \times 10^{-15} \\
\text { molecules } \mathrm{cc}^{-1}\end{array}$ & $\frac{\left(\mathrm{CCl}_{4}\right)_{0}}{\left(\mathrm{CCI}_{4}\right)_{\mathrm{f}}} \times 10^{3}$ & $\begin{array}{ll}\int(0) d t \times 10^{-14} \\
\text { molecules } c^{-1} \mathrm{sec}\end{array}$ & $\begin{array}{c}\mathrm{k}_{1} \times 10^{17} \\
\mathrm{cc} \text { molecules }^{-1} \mathrm{sec}^{-1}\end{array}$ \\
\hline $0-1$ & $4 \cdot 76$ & 1.165 & 1.311 & 3.03 & 0.998 \\
\hline $2 *$ & 4.76 & 1.165 & 1.330 & 2.93 & 1.05 \\
\hline 3 & 3.74 & 1.165 & 1.630 & 3.24 & 1.16 \\
\hline 4 & 4.03 & 1.165 & 1.592 & 3.15 & 1.16 \\
\hline 5 & 3.44 & 1.165 & 1.686 & 3.15 & 1.10 \\
\hline 6 & 3.23 & 1.165 & 1.715 & 3.55 & 1.11 \\
\hline 7 & 0.34 & 1.165 & 2.60 & 4.20 & 1.43 \\
\hline
\end{tabular}

* Small amounts of nitric oxide were added into the reaction zone to increase the phototube reading by a factor of about 10 . 


$\begin{aligned} & \text { TABLE XIII } \\ \frac{\text { EXPERIMENTAL SERIES P }}{} & -10^{\circ} \mathrm{C} \\ \text { Temperature } & =4.17 \text { to } 4.2 \mathrm{~mm} \mathrm{Hg} \\ \text { Total pressure } & 4.175 \text { to } 177 \mu \text { moles } \mathrm{sec}^{-1} \\ \text { Total flow } & =170\end{aligned}$

\begin{tabular}{|c|c|c|c|c|c|}
\hline $\begin{array}{l}\text { Experi- } \\
\text { mental. } \\
\text { No. }\end{array}$ & $\begin{array}{l}\quad \mathrm{CCl}_{4} \\
\text { flow } \times 10^{6} \\
\text { moles } \mathrm{sec}^{-1}\end{array}$ & $\begin{array}{l}(0)_{0} \times 10^{-15} \\
\text { molecules } \mathrm{cc}^{-1}\end{array}$ & $\frac{\left(\mathrm{CCl}_{4}\right)_{\mathrm{O}}}{\left(\mathrm{CCl}_{4}\right)_{\mathrm{f}}} \times 10^{3}$ & $\begin{array}{l}\int(0) d t \times 10^{-14} \\
\text { molecules } \mathrm{cc}^{=1} \mathrm{sec}\end{array}$ & $\mathrm{k}_{1} \times 10^{17}$ \\
\hline$P-1$ & 4.02 & 1.61 & 1.421 & 1.975 & 1.67 \\
\hline-2 & 3.16 & 1.61 & 1.541 & 2.16 & 1.65 \\
\hline 3 & 3.12 & 1.61 & 1.535 & 2.18 & 1.62 \\
\hline 4. & 2.68 & 1.61 & 1.624 & 2.34 & 1.60 \\
\hline
\end{tabular}




$\frac{\text { TABLE XIY }}{\text { EXPERIMENTAL SERIES Q }}$
$\frac{\text { Temperature }}{-56^{\circ} \mathrm{C}}$
Total pressure -2.2 to $2.35 \mathrm{~mm} \mathrm{Hg}$
Total flow -63 to $66 \mu$ moles $\mathrm{sec}^{-1}$

\begin{tabular}{|c|c|c|c|c|c|}
\hline $\begin{array}{l}\text { Experi- } \\
\text { mental } \\
\quad \text { No. }\end{array}$ & $\begin{array}{l}\mathrm{CCl}_{4} \\
\text { flow } x 10_{-1}^{6} \\
\text { moles sec }\end{array}$ & $\begin{array}{l}(0)_{0} \times 10^{-15} \text { log } \\
\text { molecules } \mathrm{cc}^{-1}\end{array}$ & $\frac{\left(\mathrm{CCl}_{4}\right)_{0}}{\left(\mathrm{CCl}_{4}\right)_{f}} \times 10^{3}$ & $\begin{array}{l}\int(0) d t \times 10^{-14} \\
\text { molecules } c^{-1} \mathrm{sec}\end{array}$ & $\begin{array}{c}k_{1} \times 10^{17} \\
\text { cc molecules }\end{array}$ \\
\hline$Q-1$ & 3.98 & 1.24 & 6.59 & 4.13 & 3.67 \\
\hline-2 & 1.88 & 1.23 & 8.34 & 4.97 & 3.85 \\
\hline 3 & 4.89 & 1.24 & 5.81 & 3.77 & 3.67 \\
\hline 4 & 4.79 & 1.24 & 5.94 & 3.72 & 3.55 \\
\hline
\end{tabular}




\section{TABLE XV}

EXPERIMENTAL SERIES $R$

Temperature $\quad-100^{\circ} \mathrm{C}$

Total pressure -2.10 to $2.25 \mathrm{~mm} \mathrm{Hg}$

Total flow $\quad-58.5$ to $60.5 \mu$ moles $\mathrm{sec}^{-1}$

\begin{tabular}{|c|c|c|c|c|c|}
\hline $\begin{array}{l}\text { Experi- } \\
\text { mental } \\
\text { No. }\end{array}$ & $\begin{array}{l}\mathrm{CCl}_{4} \\
\text { flow } x 10_{-1}^{6} \\
\text { moles } \mathrm{sec}^{-1}\end{array}$ & $\begin{array}{l}(0)_{0} \times 10^{-15} \\
\text { molecules } \mathrm{cc}^{-1}\end{array}$ & $\log \frac{\left(\mathrm{CCl}_{4}\right)_{\mathrm{o}}}{\left(\mathrm{CCl}_{4}\right)_{\mathrm{f}}} \times 10^{3}$ & $\begin{array}{l}\int(0) d t \times 10^{-14} \\
\text { molecules } c^{-1} \mathrm{sec}\end{array}$ & $\begin{array}{c}k_{1} \times 10^{17} \\
\text { cc molecules }{ }^{-1} \sec ^{-1}\end{array}$ \\
\hline$R-1$ & 3.155 & .254 & 2.49 & .587 & 9.75 \\
\hline 2 & $4 \cdot 925$ & .252 & 1.95 & .497 & 9.03 \\
\hline
\end{tabular}

* Small amounts of nitric oxide were added into the reaction zone to increase the phototube reading by a factor of about 15 . 


\section{TABLE XVI}

\begin{tabular}{ccccc}
\hline $\begin{array}{c}\text { Temperature } \\
{ }_{\mathrm{C}}\end{array}$ & $\frac{1}{\mathrm{~T}} \times 10^{3}$ & $\begin{array}{c}\mathrm{k}_{1} \times 10^{17} \\
\mathrm{cc} \text { molecules }\end{array} \mathrm{sec}^{-1}$ & $\begin{array}{c}\mathrm{k}_{1} \times 10^{-7} \\
\mathrm{cc} \text { moles }\end{array} \mathrm{sec}^{-1}$ & $\log \mathrm{k}_{1}$ \\
\hline 4 & 3.61 & 1.10 & 0.66 & 6.82 \\
10 & 3.51 & 1.63 & 0.98 & 6.99 \\
19 & 3.42 & 1.88 & 1.13 & 7.05 \\
56 & 3.04 & 3.69 & 2.22 & 7.35 \\
100 & 2.68 & 9.35 & 5.63 & 7.75 \\
\hline
\end{tabular}


According to the discussions presented in the previous section, it is reasonable to assume the initial oxygen atom attack on the carbon tetrachloride is rate determining. The other assumptions involved in the method of determining the rate constants of the primary reaction are that carbon tetrachloride is neither reformed nor consumed in the subsequent reactions. Since, in the mechanism proposed, there are no free radicals produced in the primary step, it is extremely unlikely that carbon tetrachloride will be reformed from any secondary process. The active radicals, which are conceivably present in the system, are cl, clo, Cl00 and COCl. However, as noted previously, the reaction of chlorine atoms with carbon tetrachloride is negligibly small under the present experimental conditions. Therefore the consumption of the carbon tetrachloride through this reaction is insiznificant. Although there is no direct evidence regarding the reaction of carbon tetrachloride with 010, 0100 and COCI, it is unlikely that these reactions would be much faster than the reaction of carbon tetrachloride with chlorine atoms. At any rate, bocause of the great speed of reactions (15) and (17), the steady-state concentrations of 010 and Cl00 must be low. Due to the large excess of oxygen available in the system, cocl radicals would be much more likely to react with the oxysen, whose rate has been measured(102) and found to be much faster than the rate of reaction of oxygen atoms with carbon tetrachloride. Therefore, it seems unlikely that the carbon tetrachloride 
will be consumed by the cool radicals. It might be argued that, in adition to atomic oxygen, other products resulting from the electrical discharge of oxygen might react with carbon tetrachloride. In view of the information given in the Introduction, such products might be ozone and excited oxygen. In adition to its low concentration, ozone was found to react exceedingly slowly with carbon tetrachloride. As a matter of fact, the carbon tetrachloride solution has been used as an inert solvent for the study of decomposition of ozone $(105,106)$. Excited molecules found in discharged oxygen by Herron and Schiff(14), whose energy is about $23 \mathrm{Kcal}$ per mole, would have insufficient energy to react with carbon tetrachloride. Recently, in the measurements of the absolute rate constants of reactions of oxygen atoms with ethylene and with butane, Elias and Schiff $(65)_{\text {have }}$ found that the excited oxygen has no significant effect on the rate measurements. The assumptions made in the present detormination of the rate constants therefore seem to be reasonably valid.

As pointed out earlier, the rate measurements can bo affected by the flow conditions. However, evidence obtained from the NO-O reaction in the present system indicated very small axial diffusion, and left little doubt that the present flow conditions are close to those for 'stream-line' flow.

In the determination of the rate of reaction, nitric oxide is likely to be the only noticeable impurity present 
in the systom. Its presence was used in the measurements of the oxygen atom concentrations required for the evaluation of the rate constants. Experiments $0-2$ and $R-4$ were designed with the aim of testing the efiect of the nitric oxide on the rate measurements. However, the rate constants obtained in these experiments were found to be consistent with those obtained in experiments without the addition of nitric oxide. This indicates that nitric oxide has no significant effect on the rate determinations, which is in agreement with the conclusion of Elias and Schiff(65) in their measurements of the rate constants of reactions of oxygen atoms with ethylene and with butane. Of course, the increased amount of nitric oxide in the system would result in a faster rate of consumption of the oxygen atoms through the recombination sequence

$$
\begin{aligned}
& \mathrm{O}+\mathrm{NO}+\mathrm{M} \rightarrow \mathrm{NO}_{2}+\mathrm{M} \\
& \mathrm{NO}_{2}+\mathrm{O} \rightarrow \mathrm{NO}+\mathrm{O}_{2}
\end{aligned}
$$

but this effect has no bearing on the results, since the concentrations of oxygen atoms are measured experimentally. However, all experiments reported here were carried out without the addition of nitric oxide. Small amounts of No, resulting from the discharge on the nitrogen which was present as impurity in oxygen, were too low to affect significantly the reaction.

since experiments in the present investigation were carried out at very low conversions, the heat generated from the reaction is not significant in the rate measurements. 
Inspection of Fig. 6 shows that a maximum rise in temperature due to the reaction is about $1.5^{\circ} \mathrm{C}$. Part of this heat is due to the recombination of the oxygen atoms on the surface of the glass surrounding the thermocouple which measures the temperature. The actual temperature rise caused by the reaction should be even lower. Furthermore, the temperatures were only measured in the centre of the reaction tube, while the temperature near the walls of the reaction vessel would probably be slightly lower, it seems likely that the average temperature in the system is lower than that measured. Therefore, it may be concluded that the heat of reaction has no appreciable effect in the determinations of the rate constants in the present study. Results obtained from Experimental Series $N$ (Table XI) show that there is no trend in the values of the rate constants of the primary reaction with about thirteonfold change in the reactant ratios. This seems to indicate that the reaction obeys the second order kinetics, first order in each of the reactants. It also sugests the validity of the basic assumption of the method, viz. that the carbon tetrachloride is attacked only in the initial step. Otherwise, a trend would be expected in the rate constants obtained over this range of reactant ratios. The effect of pressure on the reaction can be seen in Exporimental Series $N, O$ and $P$. Results obtained seem to indicate that the rate constant of the primary reaction is independent of the total pressure which wa mainly due 
to oxygen. This is consistent with the conclusion reached by Elias and Schiff $(65)$ that rate constants for the reactions of oxygen atoms with ethylone and with butane are pressure independent. In the study of reactions of oxygen atoms with olefins, cretanovic $(54)$ has found that the presence of oxygen does not affect the rate of consumption of the olefins, which is also in accord with the results obtained for the present reaction. The absence of appreciable pressure effect on the primary reaction would seem also to indicate that the reaction has occurred homogeneously in the gas phase, since the rate of diffusion of the reacting species to the walls of the reaction vessel would be different over various pressures. Furthermore, according to the discussion brought forward for the reaction mechanism, the independence of the rate constant on the oxygen pressure might also supplement the conclusion that the primary reaction is indeed the rate-determining step in the overall reaction.

$$
\text { The temperature effect on the rate of reaction can }
$$
be related by the Arrhenius equation

$$
k=A e^{-E / R T}
$$

where $k$ is the rate constant, E the activation energy of the reaction, and $A$ is a constant which is usually referred to as the frequency factor. This equation can also be expressed in an alternative form

$$
\ln k=\ln A-E / R T
$$


The activation energy and the frequency factor are thus obtained from the plot or $\log \mathrm{k}$ against $\frac{1}{\mathrm{~T}}$. The present results treated in this manner are shown in Fig. 19. A reasonably good straight line was obtained. The activation energy calculated from the slope of the plot was found to be $4.5 \pm 0.6 \mathrm{Kcal}$ per mole, and the frequency factor obtained from the intercept of the line is $1.9( \pm 0.8) \times 10^{10} \mathrm{cc}$ mole sec $^{-1}$. Therefore, the rate constant of the primary reaction can be simply represented by the equation

$$
k=1.9( \pm 0.8) \times 10^{10} \exp (-4500 / R T) \operatorname{ccmole} \mathrm{e}^{-1} \mathrm{sec}^{-1} \text {. }
$$

According to the classical or collision theory of bimolecular reaction, if the usual collision number is ascribed to be $10^{14} \mathrm{cc}$ mole $e^{-1} \mathrm{sec}^{-1}$, a 'sterlc' or 'probability' factor of $1.9 \times 10^{-4}$ is obtained for the reaction. This meane that the efficiency of the collision which leads to reaction is vary low. In view of the structure of the carbon tetrachloride molecule and of the modo of the initial reaction proposed, such a low steric factor is not too surprising. However, it is now believed that a large number of elementary reactions have values of the steric factor several powers of 10 less than unity $(41)$. By assuming a steric factor of one, a comon practice in the past, an activation energy for the reaction of oxygen atoms with carbon tetrachloride has been roughly estimated to be 7 to 8 Kcal permole by steacie(4l), based on the results of Harteck and Kopsch(6). It is obvious that should the proper value be used for the steric factor, the activation energy 
Figure 19

$\log k_{1}$ against $\frac{1}{T}$ 


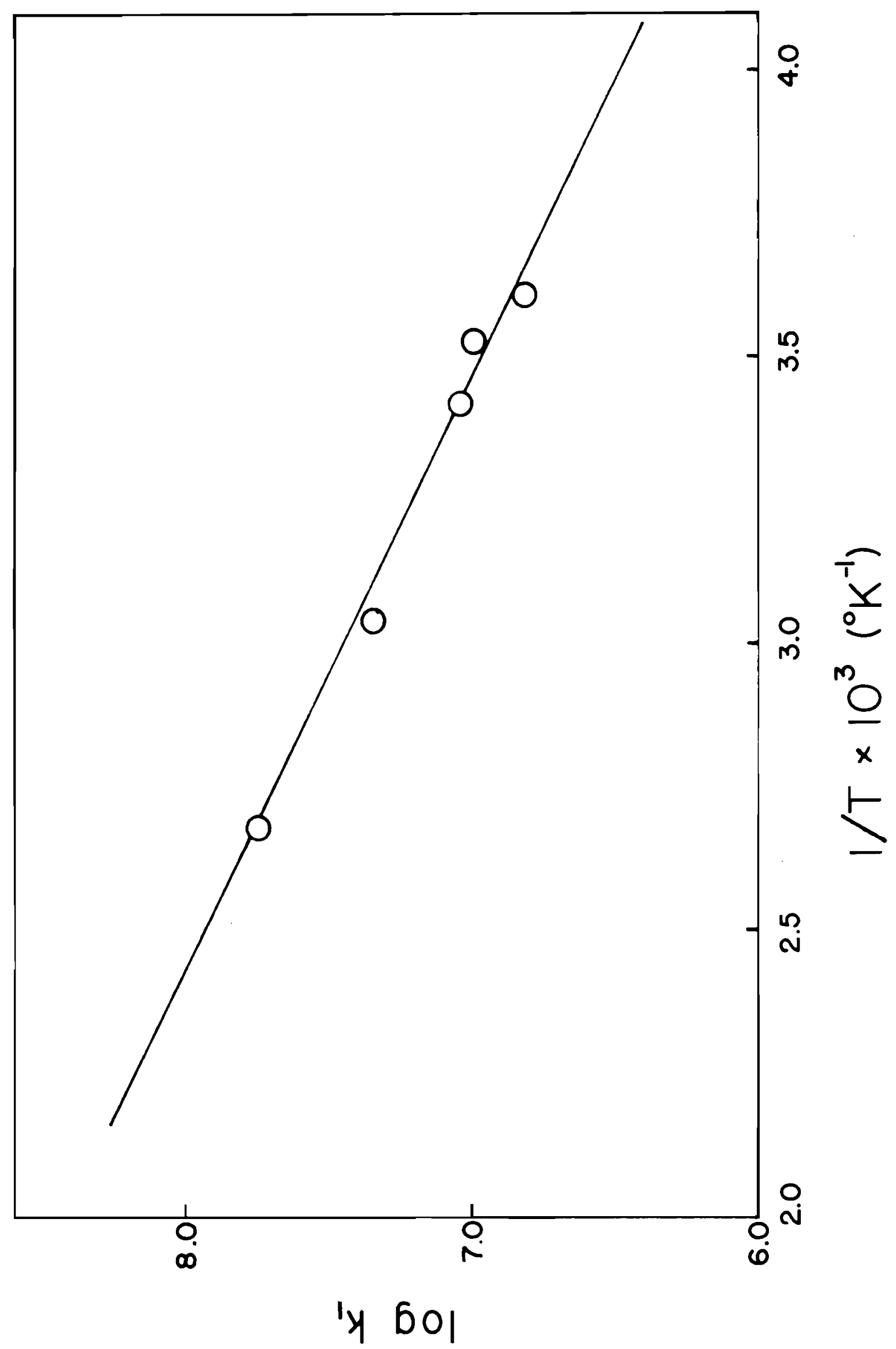


estimated would come closer to the value obtained from the present study. Therefore, it can be seen that the arbitrary assumption of unity for the steric factor could lead to a very erroneous value for the activation energy since they are mutually dependent in the Arrhenius equation, and that the direct determination of these parameters is of prime importance in describing the kinetics of the reaction. 


\section{APPENDIX A}

\section{THE HEAT OF REACTION}

The heats of reaction have been calculated from the standard heats of formation, $Q_{f}^{0}$, of gaseous compounds. The energy values which were obtained from a circular of the National Bureau of standards $(107)$ are shown in Table XVII. For the sake of simplicity, the 'Spectroscopists' convention has been used for all calculations. Accordingly, the heat of reaction is written as

$$
A+B \rightarrow C+D+q K C a l
$$

while the value of $q$ is obtained from the relation

$$
q=Q_{f}^{0}(C)+Q_{f}^{0}(D)-Q_{f}^{0}(A)-Q_{f}^{0}(B)
$$

whereby a positive ' $q$ ' value denotes an exothermic reaction and a negative ' $q$ ' value indicates an endothermic reaction.

\section{TABLE XVII}

\begin{tabular}{lc}
$\frac{\text { HEATS OF FORMATION, } Q_{f}^{\circ}}{\text { Formula }}$ & $\frac{Q_{f}^{\circ} \mathrm{Kcal}}{0}$ \\
\hline $\mathrm{Cl}$ & -59.159 \\
$\mathrm{Cl}_{2}$ & -29.012 \\
$\mathrm{CCl}_{4}$ & 0 \\
$\mathrm{COCl}_{2}$ & 15.3 \\
$\mathrm{CO}$ & 53.30 \\
$\mathrm{CO}_{2}$ & 26.4157 \\
\end{tabular}


APPENDIX B

EXPERIMENTAL DETERMINATION OF THE SEQUENCE OF

ELEMENTARY REACTIONS OF ATOMS AND RADICALS

A method for determining the sequence of elementary reactions of atoms and radicals was developed theoretically and tested experimentally by Avramenko and Kolesnikova $(52,53)$ from their studies of reactions of oxygen atoms with various substances. This method provides information about the successive elementary reactions of atoms and radicals from an examination of the final stable reaction products. A reaction is classified generally into several elementary processes:

(a) Primary reaction: a reaction of an original active centre (oxygen atom) with an original reacting partner;

(b) Quadratic reaction: reactions of primary products (molecules and radicals) with the original active centre;

(c) Cubic reaction: reactions of quadratic products (molecules and radicals) with the original active centre;

(d) Secondary reaction: reactions between primary radicals formed in primary reactions and molecular compounds having no free valencies, and also the decomposition reactions of primary radicals and molecules. Hence, primary and secondary reactions are found by 
a single event of interaction with the original active centre, whereas quadratic reactions require two events, and cubic reactions require three events of interaction with the original active centre.

Denoting the concentration of the original reacting partner by $A$, the original active centre by 0 , primary products by $B$, quadratic products by $D$, cubic products by $F$, secondary products by $C$, radicals by $R$, and the rate constants of the corresponding reactions by $k$ with appropriate indices, a general scheme of the overall reaction can be represented 2.8 follows:

$$
\begin{aligned}
& 0+A \stackrel{k_{1}}{\longrightarrow} \begin{cases}B & k_{1}^{\prime} \\
B_{1}+R & k_{1}^{\prime \prime}\end{cases} \\
& \mathrm{R}+\mathrm{o}_{2} \stackrel{\mathrm{k}_{2}}{\longrightarrow} \mathrm{c}+\mathrm{R}_{1} \quad \mathrm{k}_{2}^{\prime} \\
& 0+B(\text { or C }) \stackrel{k_{4}}{\longrightarrow} \begin{cases}D & k_{4}^{\prime} \\
D_{1}+R_{2} & k_{4}^{\prime \prime}\end{cases} \\
& 0+D \stackrel{k_{3}}{\longrightarrow} \begin{cases}\mathrm{F}_{3}^{\prime} \\
\mathrm{F}_{1}+\mathrm{R}_{3} & \mathrm{k}_{3}^{\prime}\end{cases} \\
& 0+\text { wall } \rightarrow \frac{1}{2} 0_{2}+\text { wall } k_{0} \\
& \mathrm{O}+\mathrm{O}+\mathrm{M} \rightarrow \mathrm{O}_{2}+\mathrm{M} \quad \mathrm{k}_{\mathrm{M}}
\end{aligned}
$$

On the basis of this general scheme the following kinetic equations can be constructed for $A, B, C, D, F$ and 0 . 


$$
\begin{aligned}
\frac{d(A)}{d t} & =-k_{1}(A)(O) \\
\frac{d(B)}{d t} & =k_{1}^{\prime}(A)(O)-k_{4}(B)(O) \\
\frac{d(O)}{d t} & =k_{2}^{\prime}(R)\left(O_{2}\right)-k_{4}(C)(O) \\
\frac{d(D)}{d t} & =k_{4}^{\prime}(B)(O)-k_{3}(D)(O) \\
\frac{d(F)}{d t} & =k_{3}^{\prime}(D)(O) \\
-\frac{d(O)}{d t} & =k_{1}(O)(A)+k_{4}(O)(B)+k_{3}(O)(D)+k_{0}(O)+k_{M}(O)^{2}
\end{aligned}
$$

With application of the following boundary conditions

$$
\text { when } A=A_{0},(0)=(0)_{0} \text { and } B=D=C=F=0 \text {; }
$$

$$
A=A_{f}, B=B_{f}, D=D_{f}, F=F_{f}, C=C_{f} \text { and }(0)_{f}=0
$$

the simultanoous solution of the above equetions gives the expressions for the quantities of $B, C, D$ and $F$ as a function of A.

For the primary product, $B$, the following expression is obtained:

$$
B_{f}=\frac{k_{1}^{\prime}}{k_{1}-k_{4}} A_{0}\left(\alpha^{k_{4} / k_{1}}-\alpha\right)
$$

Where $B_{f}$ denotes the final concentration of the primary product, $A_{0}$ denotes the initial concentration of the original reacting partner, and $\alpha$ denotes the ratio of $A_{f} / A_{0}$.

For the secondary product, $C$, an expression similar to (1) is obtained:

$$
c_{f}=\frac{k_{1}^{\prime} k_{2}^{\prime}}{k_{2}\left(k_{1}-k_{4}\right)} A_{0}\left(\alpha^{k_{4} / k_{1}}-\alpha\right) \ldots \ldots \ldots \ldots
$$


Where $C_{f}$ is the final concentration of the secondary product. For the quadratic product, $D$, an expression of the following form is obtained:

$D_{f}=\frac{k_{4}^{\prime} k_{1}^{\prime}}{k_{1}-\frac{1}{k_{4}} A_{0}}\left[\left(\frac{1}{k_{4}-k_{3}}-\frac{1}{k_{1}-k_{3}}\right) \alpha^{k_{3} / k_{1}}-\frac{1}{k_{4}-k_{3}} \alpha^{k_{4} / k_{1}}+\frac{\alpha}{k_{1}-k_{3}}\right] \ldots$

Where $D_{f}$ is the final concentration of the quadratic product.

For the cubic product, $F$, which does not react further with atomic oxygen, the following expression is obtained:

$$
\begin{aligned}
F_{f}=\frac{k_{4}^{\prime} k_{1}^{\prime}}{k_{4}-k_{1}} A_{0}\left[\left(\frac{1}{k_{4}-k_{3}}-\frac{1}{k_{1}-k_{3}}\right)\right. & \left(\alpha^{k_{3} / k_{1}}-1\right)-\frac{k_{3}}{k_{4}\left(k_{4}-k_{3}\right)}\left(\alpha^{k_{4} / k_{1}}-1\right) \\
& \left.+\frac{k_{3}}{k_{1}\left(k_{1}-k_{3}\right)}(\alpha-1)\right] \ldots
\end{aligned}
$$

Where $F_{f}$ is the final concentration of the cubic product.

For a product formed as a result of both the primary and the quadratic reaction, i.e. a mixed product, $M$, the following expression can be obtained:

$$
\begin{aligned}
M_{f}=\frac{k_{1}^{\prime}}{k_{1}-k_{4}} A_{0}\left(\alpha^{k_{4} / k_{1}}-\alpha+\right. & \frac{k_{4}^{\prime}}{k_{4}-k_{3}} \alpha^{k_{3} / k_{1}}-\frac{k_{4}^{\prime}}{k_{1}-k_{3}} \alpha^{k_{3} / k_{1}} \\
& \left.-\frac{k_{4}^{\prime}}{k_{4}-k_{3}} \alpha^{k_{4} / k_{1}}+\frac{k_{4}^{\prime}}{k_{1}-k_{3}} \alpha\right) \ldots
\end{aligned}
$$

Where $M_{f}$ is the final concentration of the mixed product.

The relation between $\alpha$ and $A_{0}$ is given by the formula:

$$
A_{0}=\left\{-\frac{k_{0}}{k_{M}}+\left[(0)_{0}+\frac{k_{0}}{k_{M}}\right] \alpha^{k_{M} / k_{1}}\right\} /\left[(a+b+c) \alpha^{k_{M} / k_{1}}-a \alpha-(b+c) \alpha^{k_{4} / k_{1}}\right](6)
$$


Where $(0)_{0}=$ initial concentration of atomic oxygen.

$a=\frac{k_{1}}{k_{1}-k_{M}}+\frac{k_{1} k_{4}}{\left(k_{4}-k_{1}\right)\left(k_{1}-k_{M}\right)}-\frac{k_{1} k_{3} k_{4}}{\left(k_{4}-k_{1}\right)\left(k_{1}-k_{3}\right)\left(k_{1}-k_{M}\right)}$

$b=\frac{k_{1} k_{3} k_{4}}{\left(k_{4}-k_{1}\right)\left(k_{4}-k_{3}\right)\left(k_{4}-k_{M}\right)}-\frac{k_{1} k_{4}}{\left(k_{4}-k_{1}\right)\left(k_{4}-k_{M}\right)}$

$c=\frac{k_{1} k_{3} k_{4}}{\left(k_{4}-k_{1}\right)\left(k_{1}-k_{3}\right)\left(k_{3}-k_{M}\right)}-\frac{k_{1} k_{3} k_{4}}{\left(k_{4}-k_{1}\right)\left(k_{4}-k_{3}\right)\left(k_{3}-k_{M}\right)}$

The physical significance of $\alpha$ is such that it can vary from zero to unity. When the rate constants $k_{1}, k_{3}$, $k_{4}, k_{0}$ and $k_{M}$ are given definite values, the values of $\alpha$ can be found for various values of $A_{0}$. However, the relation between $\alpha$ and $A_{0}$ can also be measured experimentally, which was found to be consistent with that calculated from equation (6) for some typical examples.

By the use of the known dependence of $\alpha$ on $A_{0}$ and by a suitable choice of the rate constants, the relation of $B_{f}$, $D_{f}, F_{f}$ and $M_{f}$ to $A_{0}$ can then be represented graphically with the aid of equations (1), (3), (4) and (5). Figure 20 demonstrates the dependence of the rates of formation of products on $A_{0}$ for the reaction products, in which curves $1,2,3$ and 4 represent the dependence of the primary product, the quadratic product, the cubic product and the mixed product respectively. The differences between these curves can be clearly seen: the curve for the cubic product bends over toward the maximum value at a lower value of $A_{0}$ 
Figure 20

THE DEPENDENCE ON A。 OF THE FINAL CONCENTRATIONS OF PRODUCTS OF THE REACTION OF OXYGEN ATOMS WITH ETHANE (THE EXPERIMENTALLY FOUND VALUE OF $\alpha$ WAS USED IN THE CALOULATIOIN).

$$
\begin{aligned}
& \text { Curve } 1 \text { - purely primary product } \\
& \text { " } 2 \text { - purely quadratic product } \\
& \text { " } 3 \text { - purely cubic product } \\
& \text { " } 4 \text { - mixed product }
\end{aligned}
$$




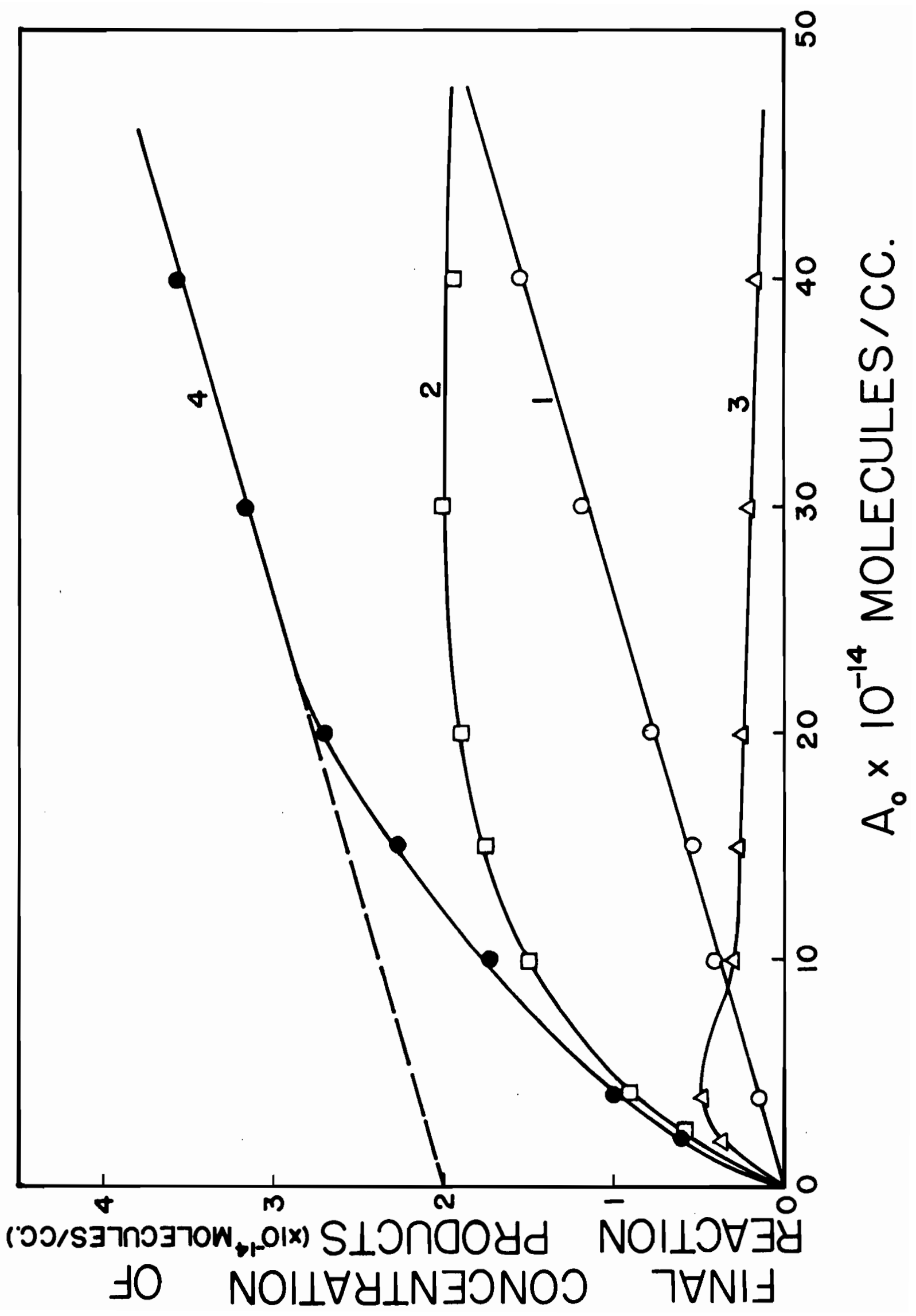


than the curve for the quadratic product, which itself bends over at a lower value of $A_{0}$ than the curve for the primary product. Also, curves 3 and 2 have maxima but curve 1 has only a limiting value. The curve for the mixed product, like that for the quadratic product, bends over at a lower value of $A_{0}$ than the curve for the pure primary product, but with increase in $A_{0}$ curve 4 does not attain a maximum, as the pure quadratic product does, but continues to rise linearly, like the curve for the pure primary product. The physical significance of these curves in a chemical reaction can be readily understood by the following considerations: when $A_{0}$ is low, 0-atoms may react not only with $A$, but also with primary and quadratic products. As $A_{0}$ is increased at a constant concentration of 0-atoms, an increasing proportion of atoms will react with $A$ and a diminishing proportion will react with reaction products. Finally, at sufficiently high concentration of $A$, O-atoms will react only with $A$, which results in a limiting value for the primary product. The mixed product is a combined function of the primary and quadratic products. When the linear part of curve 4 is extrapolated to meet the axis of ordinate (broken line of curve 4), the intercept formed corresponds to the value of the maximum final concentration of the quadratic product. From a mathematical and graphical analysis, it was concluded that whatever ratios of $k_{1}, k_{4}$ and $k_{3}$ may bo assumed, the conclusions concerning the different forms of the functions of $B_{f}, D_{f}, F_{f}$ and $M_{f}$ always hold good. It 
was also reported that the correctness of this theoretical treatment has been very well verified experimentally. 


\section{SUMMARY AND CONTRIBUTIONS TO KNOWLEDGE}

(1) Various methods for oxygen atom measurement have been tested, and the merit of each method was described.

A movable jet technique was developed to measure

the atom decay in the flow system. This technique was found to be consistent with the photometric method for oxygen atom decay measurements.

The recombination of oxygen atoms was studied with

a very low atom concentration in a flow system at $10^{\circ}$ and $100^{\circ} \mathrm{C}$ and at various total pressures of oxygen.

(4) The recombination coefficient ( $Y$ ) on Pyrex was found to be $0.30 \times 10^{-4}$ at $10^{\circ} \mathrm{C}$ and $0.93 \times 10^{-4}$ at $100^{\circ} \mathrm{C}$. This indicates a considerable temperature coefficient for $Y$. The rate constant of the reaction

$$
\mathrm{O}+\mathrm{O}_{2}+\mathrm{O}_{2}-\mathrm{O}_{3}+\mathrm{O}_{2}
$$

was measured by assuming that the overall atom docay is first order in 0 -atom concentration, which is a common practice in the evaluation of this rate constant. A negative activation energy of about $0.5 \mathrm{Kcal}$ per mole was obtained for this reaction.

(5) Results obtained indicate that the direct atom recombination reaction

$$
\mathrm{O}+\mathrm{O}+\mathrm{O}_{2} \rightarrow \mathrm{O}_{2}+\mathrm{O}_{2}
$$

is significant in the overall atom decay. Thus the 
usually measured 'rate constant' for reaction (2), $k_{2}^{\prime}$, is not a constant, but depends on the ratio of $(0) /\left(\mathrm{O}_{2}\right)$ in the system by the following relation

$$
k_{2}^{\prime}=k_{2}+k_{4}(0) /\left(o_{2}\right)
$$

(6) The reaction of oxygen atoms with carbon tetrachloride was investigated in a flow system at temperatures from $4^{\circ}$ to $100^{\circ} \mathrm{C}$ and at total pressures froin about $2 \mathrm{~mm}$ to $4 \mathrm{~mm} \mathrm{Hg}$. Atomic oxygen was produced by microwave discharge of moleculer oxygen and by the titration of 'active nitrogen' with nitric oxide.

(7) The reaction was found to proceed without a reaction flame. The products of the reaction are $\mathrm{Cl}_{2}, \mathrm{CO}$, $\mathrm{COCl}_{2}$ and $\mathrm{CO}_{2}$. No compounds containing more than one carbon atom were detected.

(8) The rate of 0-atom disappearance and the rate of $\mathrm{CCl}_{4}$ disappearance in the reaction were measured. The ratio of these two rates was found to be much higher in an oxygen-containing system than in an oxygen-free system. This difference can be explained by a $\mathrm{Cl}_{2}$-catalyzed recombination of 0 -atoms in the presence of $\mathrm{O}_{2}$.

(9) Tre initial step in the reaction was found to be consistent with the following scheme:

$$
\begin{aligned}
0+\mathrm{CCl}_{4} \rightarrow\left(\mathrm{CCl}_{4} \mathrm{O}\right) & \rightarrow \mathrm{COCl}_{2}+\mathrm{Cl}_{2} \\
& \rightarrow \mathrm{CO}+2 \mathrm{Cl}_{2}
\end{aligned}
$$


where $\left(\mathrm{CCl}_{4}\right.$ o) represents a collision complex. Evidence obtained indicates that the rate of dissociation of the collision complex through reaction (I) is faster than that through reaction (II) by a factor of not more than two.

(10) A mechanism is proposed to explain the dependence of the products on the flow rates of reactents for this reaction.

(11) The rate constant of the primary reaction, $k_{I}$, was measured under various experimental conditions. The reaction was found to obey second order kinetics, first order in each of the reactants. The rate constant, $k_{1}$, can be represented by the equation

$$
k_{1}=1.9 \times 10^{10} \exp (-4500 / \mathrm{RT}) \operatorname{ccmole} \mathrm{mec}^{-1}
$$




\section{BI BL I OGRAPHY}

1. Becquerel, M.E. Ann. Chim. Phys., 2I, 40 (1859).

2. Thomson, J.J. Phil. Mag., 22, 321 (1891).

3. Strutt, R.J. Proc. Phys. Soc., 23, 66 (1910).

4. Strutt, R.J. Proc. Phys. Soc., 23, 147 (1910).

5. Stoddart, E.M. Proc. Roy. Soc. A147, 454 (1934).

6. Harteck, P. and Kopsch, U. Z. Phys. Chem. Bl2, 327 (1931).

7. Bonhoeffer, K.E. Z. Physik Chem., 113, 199, 492 (1924).

8. Cvetanovic, R.J. J. Chem. Phys. 23, 1203 (1955).

9. Ford, H.W. and Endow, N. J. Chem. Phys., 27, 1156 (1957);

10. Benson, W. and Axworthy, A.E. J. Chem. Phys., 26, $1718(1957)$.

11. Avramenko, L.I. Zhur. Fiz. Khim., 23, 790 (1949).

12. Linnett, J.W. and Marsden, D.G.H. Proc.Roy.Soc.,A234,489(1956).

13. Kaufman, F. J. Chem. Phys., 28, 352 (1958).

Proc. Roy. Soc., A247, 123 (1958).

14. Herron, J.T. and Schiff, H.I. Can. J. Chem., 36, 1159 (1958).

15. Elias, L., Ogryzlo, E.A. and Schiff, H.I. Can. J. Chem., 37, 1680 (1959).

16. Morgan, J.E., Elias, L. and Schiff, H.I. J. Chem. Phys., 33 , $930(1960)$.

17. Kistiakowski, G.B. and Volpi, G.G. J.Chem.Phys.,27,1141(1957).

18. Kaufman, F. and Kelso, J.R. Seventh symposium on Combustion. P. 9 (1958).

19. Kaufman, F. and Decker, L.J. Seventh Symposium on Combustion. P. 57 (1958).

20. MeCarthy, R.L. J. Chem. Phys., 22, 1360 (1954).

21. Tanaka, Y. and Shimazu, M. J. Sci. Res. Inst. (Tokyo) 43, 241 (1949).

22. Harteck, P. Trans. Faraday Soc., 30, 134 (1934). 
23. Schumacher, H.J. 2. Physik. Chem., BIO, 7 (1930).

24. Kurt, O.E. and Phipps, I.E. Phys. Rev.,34, 1357 (1929).

25. Rawson, E.B. and Beringer, R. Phys. Rev.,88, 677 (1952).

26. Kaplan, J. Nature, 159, 673 (1947).

27. Branscomb, L.M. Phys, Rev., 86, 258 (1954).

28. Broida, H.P. and Gaydon, A.G. Proc.Roy.Soc., A222, 18 (1954).

29. Foner, S.N. and Hudson, R.L. J. Chem. Phys., 25, 601 (1956).

30. Herzberg, G. Spectra of Diatomic Molecules, P. 446,

(D. Tan Nostrand Co., New York, 1950).

31. Lipscomb, F.J., Norrish, R.G.W. and Thrush, B.A. Proc. Roy. Soc., A233, 455 (1956).

32. McGrath, W.D. and Norrish, R.G.W. Proc. Roy. Soc.; A.242, 265 (1957).

33. Greaves, J.C. and Linnett, J.W. Trans. Faraday Soc; 52, 1338 (1959).

34. Kaufman, F. Private communication.

35. Geib, K.H. and Harteck, P. Ber., 66B, 1815 (1933).

36. Geib, K.F. and Harteck, P. Trans. Faraday Soc.30,131(1934).

37. Geib, K.H. and Voidya, W.M. Proc. Roy. Soc.,Al78,351(1941).

38. Geib, K.H. Ergeb. exakt. Naturwiss., 15, 44 (1936).

39. Geib, K.H. Z. Elecktrochem., 47, 761 (1941).

40. Rice, F.O. and Teller, E. J. Chem. Phys., 6, 489 (1938).

41. Steacie, E.W.R. Atomic and Free Radicals Reactions, 2nd Ed., (Reinhold Pub. Co., New York, 1954).

42. Harteck, P. and Kopsch, U. Z. Elecktrochem.,36, 714(1930).

43. Stercie, E.W.R. and Parlee, N.A.D. Can.J.Research, B16, $203(1938)$.

44. Kuschnerev, M. and Schechter, A. Compt. Rend. Acad. Sci., U.R.S.S., 32, 560 (1941).

45. Norrish, R.G.W. Proc. Roy. Soc., Al50, 36 (1935). 
46. Avramenko, I.I. and Lorentso, P.V. Zhur. Fiz. Khim., 26, 1084 (1952).

47. Avramenko, L.I. and Lorentso, P.V. Chem. Tech. (Berlin) 2. $193(1953)$.

48. Avramenko, L.I. and Kolesnikova, R.V. Daklady Akad. Nauk., S.S.S.R., 89, 1037 (1953).

49. Avramenko, L.I. and Kolesnikova, R.V. Daklady Akad. Nauk., S.S.S.R., 91, 107 (1953).

50. Avramenko, L.I. and Kolesnikova, R.V., Zhur. Fiz. Khim. $30,581(1956)$.

51. Avramenko, L.I. and Kolesnikova, R.V. Voprosy Khim. Kimetiki Kataliza i Reaktsionnoi Sposofnosti, Moscow, Akad. Nauk, S.S.S.R., P. I (1955).

52. Avramenko, L.I. and Kolesnikova, R.V. Daklady Akad. Nauk., S.S.S.R., 92, 349 (1953).

53. Avramenko, L.I. and Kolesnikova, R.V. Izv. Akad. Nauk., S.S.S.R., Otdel. Khim. Nauk.,(3) 386 (1955).

54. Cretanovic, R.J. J. Chem. Phys., 25, 376 (1956).

55. Cretanovic, R.J. J. Chem. Phys., 25, 376 (1956).

56. Cretanovic, R.J. Can. J. Chem., 34, 775 (1956).

57. Cretanovic, R.J. Can. J. Chem., 36, 623 (1958).

58. Sato, S. and Cretanovic, R.J. Can. J. Chem., 37, 953 (1959).

59. Sato, S. and Cretanovic, R.J. Can. J. Chem., 36, 970 (1958).

60. Sato, S. and Cretanovic, R.J. Can. J. Chem., 36,1668 (1958). 61. Jarvis, J.M.S. and Ovetanovic, R.J. Can.J.Chem.,37,529(1959). 62. Cretanovic, R.J. and Doyle, L.C. Can.J.Chem., 38, 2187 (1960). 63. Cretanovic, R.J. J. Chem. Phys., 30, 19 (1959). 64. Cretanovic, R.J. Can. J. Chem., 38, 1678 (1960). 65. Elias, L. and Schiff, H.I. Can. J. Chem., 38, 1657 (1960). 66. Sobering, S.E. and Winkler, C.A. Can.J.Chem.,36,1223(1958). 67. Copeland, P.D. Phys. Rev., 36, 1221 (1930). 
68. Greaves, J.C. and Linnett, J.W. Trans. Faraday Soc. $52,1346(1959)$.

69. Kaufman, R. and Kelso, J.R. J.Chem.Phys., 32, 301 (1960).

70. Ogryzlo, E.A. Ph.D. Thesis, McGill University (1958).

71. Langmuir, I. J. Am. Chem. Soc., 36, 1708 (1914).

72. Tollefson, E.E. and LeRoy, D.J. J.Chem.Phys.,16,1057(1948).

73. Avramenko, L.I. and Kolesnikova, R.V. Zhur. Fiz. Khim. $\underline{29}, 539(1955)$.

74. Spealman, M.I. and Rodebush, W.H. J. Am. Chem. Soc. 27, $1474(1935)$.

75. Norrish, R.G.W. and Porter, G. Proc.Roy.Soc., A210,439(1952).

76. Kistiakowski, G.B. and Kydd, P.H. J. Am. Chem. Soc., 19, $4825(1957)$.

77. Hertz, G. Z. Physik, 19, 35 (1923).

78. 0lsen, J.C., Ferguson, G.E., Sobetta, V.J. and Scheflan, L. Ind. Eng. Chem. (Analytical) 3, 189 (1931).

79. LeRoy, D.J. Can. J.Research, B28, 492 (1952).

80. Mullen, P.W. Modern Gas Analysis, P. 120. (Interscience Pub. Inc., New York, 1955).

81. Lunge, G. and Ambler, H.R. Technical Gas Analysis, P. 300 . (Gurney and Jackson Co., London, 1934).

82. Dickens, P.G., Gould, R.D., Linnett, J.W. and Richmond, A. Nature, 187, 686 (1960).

83. Harteck, P. and Dondes, S. J.Chem.Phys., 21, 2240 (1953).

84. Greaves, J.C. and Linnett, J.W. Trans. Faraday Soc., 55, 1355 (1959).

85. Lavrovskaya, G.K. and Voevodskii, V.V. Zhur. Fiz. Khim., 25, 1050 (1951).

86. Andrussov, L. Z. Electrochem., 24, 566 (1950).

87. Golden, J.A. and Myerson, A.L. J.Chem.Phys.,28,978(1958).

88. Kretschmer, O.B. and Petersen, H.L. J. Chem. Phys. $33,948(1960)$.

89. Reeves, R.R., Mannella, G. and Harteck, P. J. Chem. Phys. $32,623(1960)$. 
90. Bodenstein, M. and Wolgast, K. Z.Phys.Chem.,61,422 (1908).

91. Melville, H.W., Robb, J.C. and Tutton, R.C. Discussion Faraday soc., 10, 154 (1951).

92. Franke, W.K. and Schumacher, H.J. Z.Phys.Chem., B42, 297 (1939).

93. Dunford, B., Evans, H.G.V. and Winkler, C.A. Can.J.Chem., $34,1074(1956)$.

94. Porter, G. Proc. Roy. Soc., A200, 284 (1950).

95. Porter, G. and Wright, F.J. Discussion Faraday Soc.,

$$
14,23(1953) \text {. }
$$

96. Schwab, G.M. Z. Physik. Chem. B178, 123 (1936).

97. Schumacher, H.J. and Wolff, K. Z. Physik. Chem., B25, $161(19 \overline{34})$.

98. Schwab, G.M. and Heyde, U. 2.Physik.Chem. B8,157 (1930).

99. Bodenstein, M., Lenher, S. and Wagner, C. Z. Physik. Chem., B3, 459 (1929).

100. Bodenstein, M., Brenschede, W. and Schumacher, H.J.

Z. Physik. Chem., B40, 121 (1938).

101. Burns, W.G. and Dainton, F.S. Trans. Faraday Soc., $48,39(1952)$.

102. Rollefson, G.K. J. Am. Chem. Soc., 52, 148 (1933).

103. Schumacher, H.J. Z. Physik. Chem., 129, 241 (1927).

104. Bodenstein, M. and Onoda, T. Z. Physik. Chem.,

$$
131,153(1927) \text {. }
$$

105. Moelwyn-Hughes, E.A. and Hinshelwood, C.N. Proc. Roy. Soc., A131, 177 (1931).

106. Bowen, E.J., Moelwyn-Hughes, E.A. and Hinshelwood, C.N. Proc. Roy. Soc. Al34, 211 (1931).

107. National Bureau of Standards, Circ. No. 500, Selected Values of Chem. Thermodynamic Properties,

(washington, 1952). 